\title{
WestVirginiaUniversity
}

THE RESEARCH REPOSITORY @ WVU

$1-1-2006$

\section{A Floristic quality index for West Virginian wetland and riparian plant communities}

James S. Rentch

James Thomas Anderson

Follow this and additional works at: https://researchrepository.wvu.edu/

wv_agricultural_and_forestry_experiment_station_bulletins

\section{Digital Commons Citation}

Rentch, James S. and Anderson, James Thomas, "A Floristic quality index for West Virginian wetland and riparian plant communities" (2006). West Virginia Agricultural and Forestry Experiment Station Bulletins. 730.

https://researchrepository.wvu.edu/wv_agricultural_and_forestry_experiment_station_bulletins/621

This Bulletin is brought to you for free and open access by the Davis College of Agriculture, Natural Resources And Design at The Research Repository @ WVU. It has been accepted for inclusion in West Virginia Agricultural and Forestry Experiment Station Bulletins by an authorized administrator of The Research Repository @ WVU. For more information, please contact ian.harmon@mail.wvu.edu. 


\title{
A Floristic Quality Index for West Virginia Wetland and Riparian Plant Communities
}

\author{
By James S. Rentch and James T. Anderson \\ Division of Forestry and Natural Resources
}

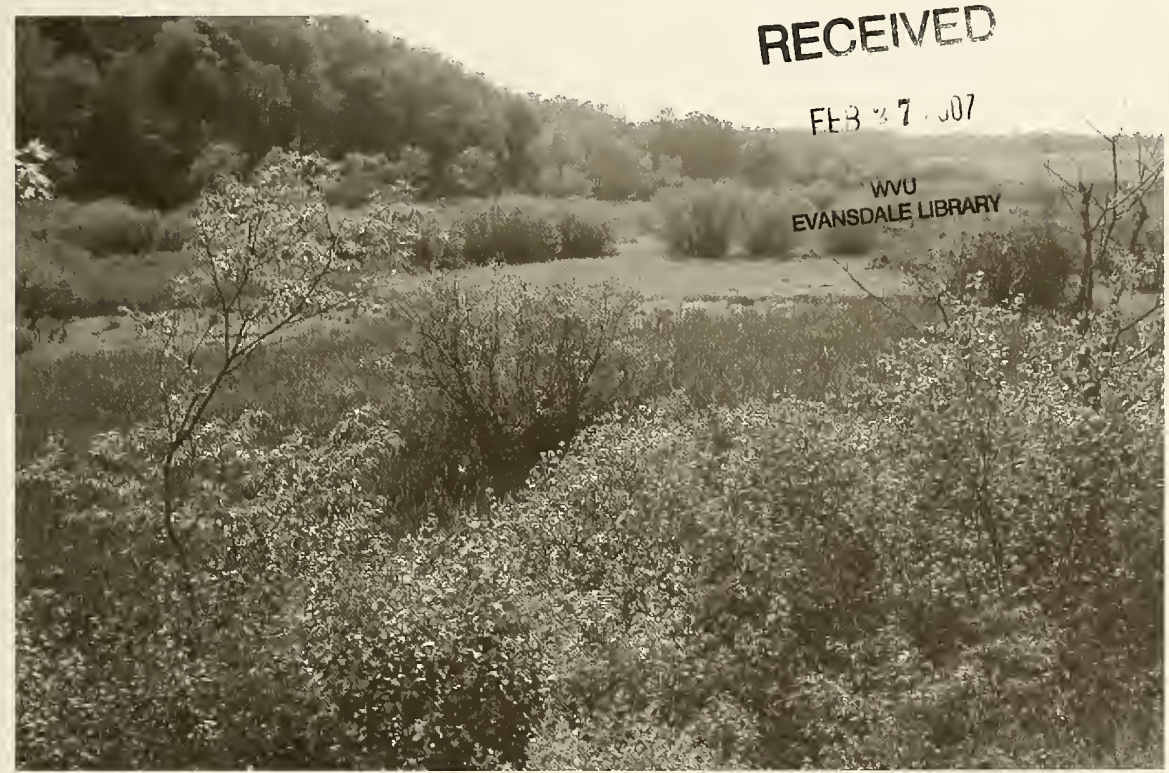

Bulletin 730

West Virginia Agricultural \& Forestry Experiment Station Davis College of Agriculture, Forestry, and Consumer Sciences 2006

$\$ 127$ 


\section{Contributors}

Harold Adams, Elizabeth Byers, David Dick, Donna Ford-Werntz, William Grafton, P. J. Harmon, Cynthia Huebner, James Rentch, Steven Stephenson, Brian Streets, and James Vanderhorst.

Funding:

Provided by the Canaan Valley Institute, Thomas, West Virginia, by the US Department of Agriculture CREES, Award No. 2004-38874-02133. 


\section{A Floristic Quality Index for West Virginia Wetland and Riparian Plant Communities}

By James S. Rentch and James T. Anderson Division of Forestry and Natural Resources

\section{Table of Contents}

Executive Summary

Introduction: Why Apply a Floristic Quality Index to West Virginia? ............................... 3

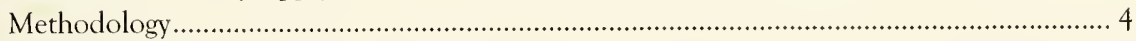

A. Wetland and Riparian Flora ….................................................................. 4

B. Origin of Wetland and Riparian Flora ....................................................... 5

C. The Coefficient of Conservatism ..................................................................... 5

D. Calculation of Floristic Quality Index ….................................................... 9

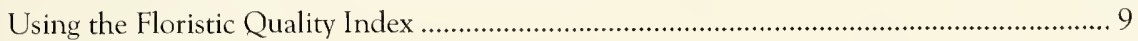

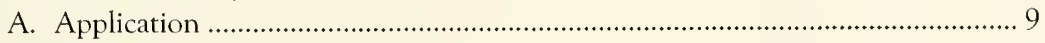

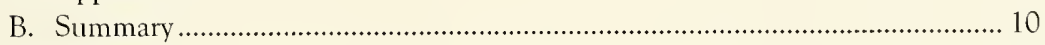

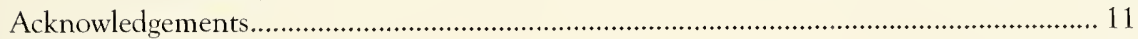

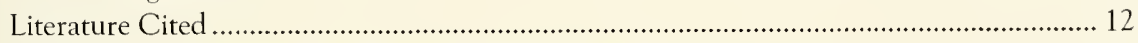

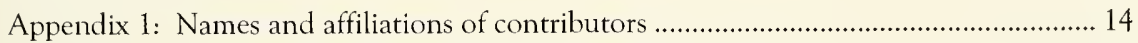

Appendix 2: C-values for wetland/riparian flora of West Virginia................................ 15 


\section{Digitized by the Internet Archive in 2010 with funding from \\ Lyrasis Members and Sloan Foundation}




\section{EXECUTIVE SUMMARY}

In order to ensure long-term conservation of the state's natural biodiversity and to set conservation priorities, land managers often require a practical method for identifying, comparing, and ranking the value of natural areas. One technique of assessing the conservation value of a site is the Floristic Quality Index (FQI). First developed in the Chicago region, this method relies on the assignment of a Coefficient of Conservatism (C value) ranging from 0 to 10 to each plant taxa based on its tolerance to disturbance and habitat degradation, as well as its fidelity to specific habitats. Taxa with low $\mathrm{C}$ values are very tolerant of site degradation and show little fidelity to any specific community or habitat. In contrast, species with high $\mathrm{C}$ values are much less tolerant of degradation and generally found only in a small number of high quality habitats. The aggregate conservatism of all plant species found on a site is then used to calculate a Floristic Quality Index.

This document reports efforts to extend the FQI methodology to West Virginia. From existing sources, we compiled a list of wetland and riparian plant taxa in the state, along with their origin. We then enlisted the cooperation and contribution of eleven botanists around the state to assign Coefficients of Conservatism to 1,745 plant taxa, using guidelines modeled after efforts in other states. Altogether, contributors offered over 24,000 values. C scores for each taxa were averaged and reconsidered until three conditions were met: a) each taxa had at least two $\mathrm{C}$ values submitted, b) the range of values submitted for a taxon was 3 or less, and c) for taxa with more than two values, the standard deviation was less than the mean. Only 38 taxa failed to satisfy these conditions, and were deleted from the final list. Of the 1,707 taxa we recognized in this effort, $286(16.7 \%)$ were determined to be nonnative to the region. The entire native flora had a mean $\mathrm{C}$ value of 6.1. A floristic quality index (FQI) can be calculated to rank sites in order of their floristic quality. The final list is attached as an appendix.

Proper application of the FQI method requires a thorough inventory of the target plant community and identification of all plant species present. Then, the appropriate $\mathrm{C}$ value can be applied to each species, and the FQI is then calculated as the average of all $\mathrm{C}$ values (native species only) multiplied by the square root of the number of native species $(\mathrm{N})$ present. Mean $\mathrm{C}, \mathrm{N}$, and $\mathrm{FQI}$ values can all be affected by the botanical skills of the investigator and the time of year of sampling. FQI is primarily intended to be used to compare similar community types; comparisons of two or more different community types, or pooling of results from communities within a single larger complex may give misleading results for reasons that have little to do with inherent floristic quality.

We recommend application of this technique where the objective is to 1 ) identify natural areas with high conservation value, 2) compare the floristic quality among similar community types at different locations, 3) monitor trends in floristic quality over time, and 4) assess restoration efforts. FQl is one tool of many; it complements, but does not directly assess wildlife habitat, wetland function, or human use value. 
In addition to the publication of this list and use description, additional work needs to be done:

1. Provide a user-friendly computer program so FQI values can be easily calculated.

2. Test its usefulness and limitations on existing data, including both known high quality sites, restoration sites, and degraded sites.

3. Extend the assignment of $\mathrm{C}$ values to upland plant species and bryophytes.

4. Our primary goal was to develop statewide rankings for the flora. However, we realize that some taxa are specific to certain physiographic provinces of the state, and exhibit varying degrees of conservatism over their range. Initial steps were attempted to recognize these facts, and as a future task, identification of $\mathrm{C}$ values by physiographic province is needed. 


\section{INTRODUCTION: WHY APPLY A FLORISTIC QUALITY INDEX TO WEST VIRGINIA?}

Since the arrival of European settlers, a large portion of the natural environment of West Virginia has been extensively modified. Forest clearing for agriculture, logging, mining, along with industrial, and urban and residential development have profoundly changed the landscape and altered its floristic composition. With habitat change, some native plant species have been reduced in frequency or replaced by other, non-native species that are better suited to the new ecological conditions. Changes in the makeup of wildlife communities have paralleled floristic changes, and, the natural hydrology of many streams and wetlands, natural fire regimes, and other important abiotic processes also have been modified. Changes have been particularly intense in wetland and riparian areas. According to Dahl (1990), West Virginia lost nearly $50 \%$ of its wetlands between 1780 and 1980. As a result, landscape modifications have restricted portions of the native biota and natural plant communities to small and often fragmented locations actoss the state.

To ensure long-term conservation of natural biodiversity, land managers need a practical method for identifying, comparing, and ranking the value of natural areas, and to set conservation priorities. The Floristic Quality Index (FQI) is one method of assessing the conservation value of sites that is based on floristic composition. It is based on the concept that plant species display varying degrees of tolerance to habitat degradation and disturbance along with varying degrees of fidelity to specific habitats and habitat quality. Swink and Wilhelm $(1979,1994)$, developers of the index, termed this tolerance and fidelity "species conservatism." They assigned each native plant species in the Chicago region a coefficient of 0 to 10 based on its conservatism relative to other native species in the region's flora, and from that, calculated a Floristic Quality Index. The method has subsequently been adapted for use by several states, including lllinois (Taft et al. 1997), Michigan (Herman et al. 2001), northern Ohio (Andreas and Lichvar 1995, Andreas et al. 2004), South Dakota (Northern Great Plains Floristic Quality Index Panel 2001), Pennsylvania (Laughlin 2001), Virginia (Virginia Floristic Quality Assessment Index Advisory Council, 2004), and Wisconsin (Bernthal 2003, Kreider et al. 2003).

Proposed applications of the FQI technique include 1) identifying natural areas with high floristic significance, 2) comparing the floristic quality among similar community types at different locations, 3) monitoring trends in floristic quality over time, and 4) assessing habitat restoration efforts (Herman et al. 2001). The FQI has also been used to determine wetland replaceability and set wetland mitigation criteria (Andreas and Lichvar 1995). This document reports efforts to develop a FQI for riparian and wetland plant species in West Virginia. 


\section{METHODOLOGY}

In the following three sections, we outline the steps that were taken in the West Virginia effort.

\section{A. Wetland and Riparian Flora}

The first step involved in developing a Floristic Quality Index for West Virginia required identifying all of the flora that are found in wetland and riparian habitats in the state. For this, we used the Checklist and Atlas of Vascular Flora of West Virginia (Harmon et al. 2004) and the National List of Plant Species That Occur in Wetlands (Reed 1988) along with its 1996 revisions (Reed 1996). These lists classify plant species using a Wetland Indicator Status (WIS), a rating that is based on the probability that a species will occur in wetlands versus non-wetlands across the state-wide distribution of the species. Taxa with the following WIS categories were considered:

Obligate Wetland (OBL) Species that almost always occur under natural conditions in wetlands (estimated probability $>99 \%$ ).

Facultative Wetland (FACW) Species that usually occur in wetlands, but occasionally are found in non-wetlands (estimated probability $67 \%$ - 99\%).

Facultative (FAC) Species that are equally likely to occur in wetlands or nonwetlands (estimated probability $34 \%$. $66 \%)$.

Facultative Upland (FACU) Species that usually occur in non-wetlands, but are occasionally found in wetlands (estimated probability $1-33 \%$ ).

No indicator (NI) Species for which insufficient information was available to determine an indicator status.

Known (Kn.) Species with no assigned WIS, but that are known to occur in palustrine plots of the WV Natural Heritage Program. This could be equivalent to $\mathrm{FACU}$ or wetter.

Figure 1. Wetland Indicator Status (WIS) of wetland and riparian plant taxa in West Virginia, based on Harmon et al. (2004). (Category "Known" is included in FACU).

\section{Wetland Indicator Status}

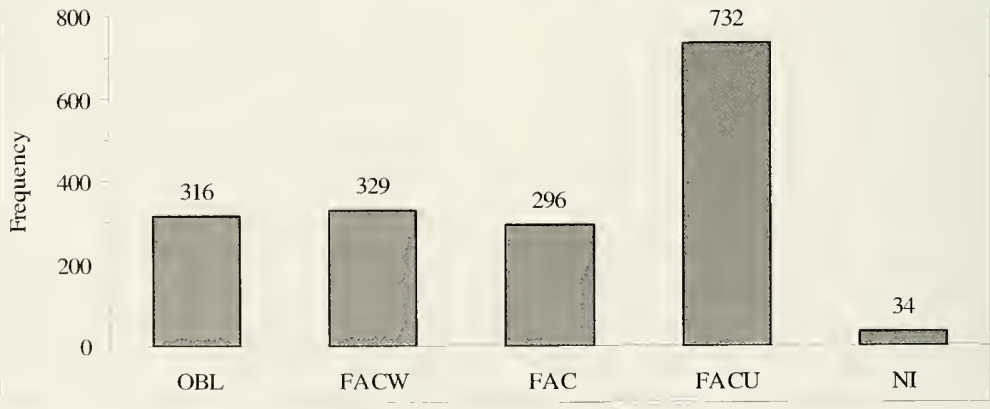




\section{B. Origin of Wetland and Riparian Flora}

The second step involved identifying the origin of each of the 1,707 taxa from the list above. For this, we again used the checklist categories of Harmon et al. (2004).

Native $(\mathrm{N})$ species are considered to have occurred in West Virginia prior to European settlement, and still occur naturally within the state.

Adventive (A) species are native elsewhere in North America north of Mexico prior to European settlement, not native to West Virginia, but are now growing in the state, arriving without known intentional introduction.

Introduced (I) species are native elsewhere in North America north of Mexico prior to European settlement, and have been intentionally planted in West Virginia and are now escaped and surviving without cultivation.

Exotic (E) species are not native to North America north of Mexico, but occur without cultivation in West Virginia.

Figure 2. Origin of wetland and riparian plant taxa in West Virginia, based on Harmon et al. (2004). "Other" category includes A/N, E/N, and I/N.

1600

Origin
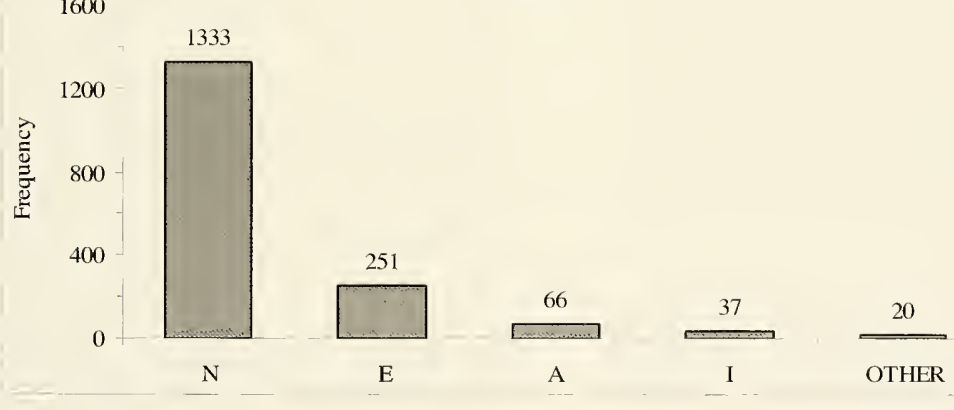

\section{The Coefficient of Conservatism}

A central concept of floristic quality assessment is that of species conservatism (Swink and Wilhelm 1994). All plant species exhibit varying degrees of tolerance to disturbance-both natural and anthropogenic-as well as varying degrees of fidelity to specific habitats.

The expression of this tolerance and fidelity is termed "species conservatism," and is quantitatively expressed as the coefficient of conservatism (C). C values range from $\mathrm{O}$ (taxa well-adapted to high 
levels of disturbance and site degradation, and not limited to any particular plant community) to 10 (taxa restricted to a narrow range of habitat conditions and relatively intolerant of habitat degradation). Bernthal (2003) described the coefficient as an estimated probability that a species is likely to occur in a landscape that resembles what we commonly consider as representative of pre-settlement conditions.

To solicit $C$ values, we sent letters to botanists in West Virginia and surrounding states outlining the justification for developing a FQI for the state, and requesting their participation. Over 30 individuals were initially contacted. Individuals were requested to review the list of 1,707 eligible taxa, and provide $C$ values based on their previous field experience and existing knowledge of the each plant's autecology. We did not ask participants to conduct exhaustive research or literature review; instead, we requested that they supply $\mathrm{C}$ values for those species that they were familiar with and relatively confident about.

As a guide to contributors, we developed descriptions of ranges of $\mathrm{C}$ values based on previous work by Taft et al. (1997), Bernthal (2003), and Andreas et al. (2004). Species examples come from the completed West Virginia list.

- 0-1 Taxa are adapted to severe habitat degradation. Disturbance occurs so frequently, or with such intensity that often only brief periods are available for growth and reproduction. These are primarily weedy species that can flourish in the most highly degraded habitats. Introduced or exotic species automatically receive a rank of 0 , while native "weedy" species such as ragweed (Ambrosia artemisiifolia var. ellatior and barnyard grass (Echinochloa crus-galli) are ranked 1.

- 2-3 Taxa associated with more stable though degraded habitat, but may be found in a variety of habitats. They are generally widespread and not an indicator of a particular community type. Examples included hay-scented fern (Dennstaedtia punctilobula) 2, and common rush (Juncus effusus) and red maple (Acer rubrum) 3.

- 4-6 Taxa have a high consistency of occurrence with a given community type and include many common dominant species. Species can persist under moderate degradation. Examples of this range include the sedge Carex lurida, and New York ironweed (Vernonia noveborancensis) 4; sensitive fern (Onoclea sensibilis) and pipestem (Spiraea alba) 5; and Glade St. Johnswort (Hypericum densiflorum) and smooth arrowwood (Viburnum recognitum) 6.

- 7-8 Taxa associated mostly with natural areas but can persist where the habitat has been somewhat degraded. Increases in the intensity or frequency of disturbance may result in reduction of population size. Examples include Carex atlantica and swamp lousewort (Pedicularis lanceolata) 7, and Oceanorus (Zigadenus leimanthoides) and sundew (Drosera rotundifolia var. rotundifolia) 8 .

- 9-10 Taxa in this category exhibit a high degree of fidelity to a narrow range 
of ecological parameters. They are generally restricted to high-quality natural areas. For example, bog fern (Thelypteris simulata) 9, and bog rosemary (Andromeda polifolia var. glaucophylla) 10 .

Among the contributors, there was some concern over application of the terms "disturbance" and "stability" when identifying highly ranked species. Several contributors noted that there are a number of species with high $\mathrm{C}$ values that might also be considered disturbancedependent. For example, Virginia spiraea (Spiraea virginiana) is a relatively rare shrub that is restricted to areas of deposition along banks of high gradient, highly scoured streams (WVDNR 2006). For this species, flood events are a necessary part of its life history strategy. To accommodate species such as this, we decided to distinguish between disturbance as components of a natural disturbance regime, and degradation, which refers to habitat-altering events of a largely anthropogenic origin, and that occur with a frequency and/or intensity that is beyond the long-term variability of the natural disturbance regime.

Of the 30 botanists contacted, 11 participated fully (see Appendix 1), contributing nearly 24,000 values. For each taxon, we calculated a mean $C$ value, along with a standard deviation, range, and the number of contributors. Revised lists were sent back to contributors for reconsideration until the following conditions were met:

- At least two C values were submitted for a taxon;

- The range of values submitted for a taxon was 3 or less;

- For taxa with more than two values, the standard deviation was less than the mean.

Below are graphs showing the distribution of $\mathrm{C}$ values, frequency of ranges, and the numbers of contributors for each taxa. We identified 286 taxa as invasive or introduced and these were assigned a C value of zero by default. The distribution of $\mathrm{C}$ values that were greater than zero was normal with a mean of $6.1 \pm 1.9$. This is somewhat lower than results from Michigan $($ mean $=6.5$, Herman et al. 2001), and higher than Virginia $C$ values $($ mean $=5.5$, VFQALAC 2004). On the other hand, West Virginia reviewers were less likely to award a C value of $10(3.7 \%$ of the taxa) than in Michigan (23\%). In contrast, only $0.2 \%$ of the taxa in Virginia were ranked 10. After several reconsiderations, the number of taxa which did not meet the three criteria listed above was reduced to 38 . Final state ranks for the 1,707 taxa are provided in Appendix 2. 
Figure 3. Descriptive statistics for coefficient of conservatism [C] values for 1,707 taxa in WV. Graph A shows distribution of C values, Graph B shows the range of $C$ values, and Graph $C$ shows the number of contributors per taxon.

\section{A. Distribution of $\mathrm{C}$ values}

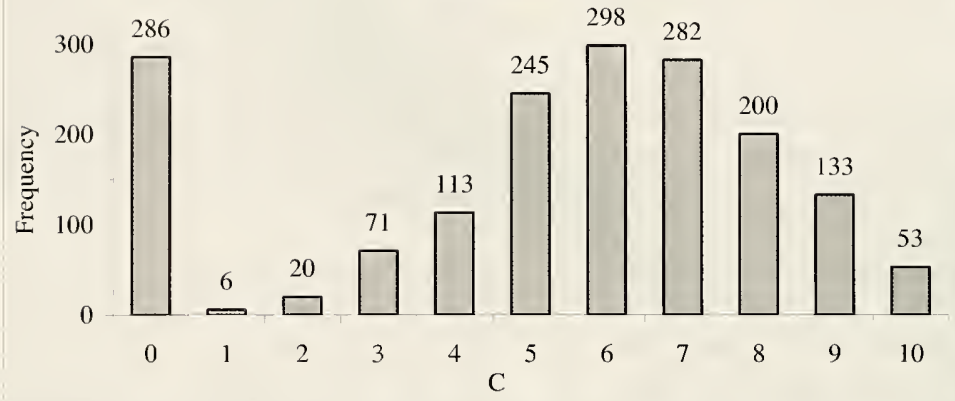

B. Range of $\mathrm{C}$ values

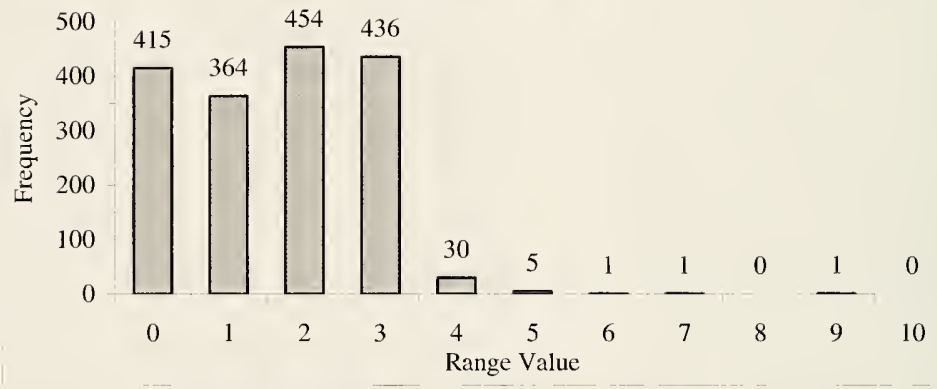

\section{Number of Contributors/Taxon}

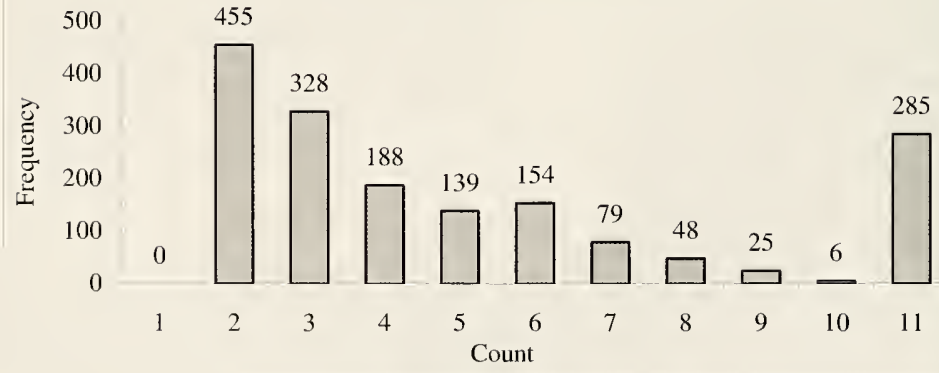




\section{Calculation of Floristic Quality Index}

Using the coefficients of conservatism, a floristic quality assessment of a site can be calculated using two separate measures: I) the average coefficient of conservatism, or Mean C, and 2) the Floristic Quality Index. The Mean $\mathrm{C}$ is calculated:

Mean $\mathrm{C}=\boldsymbol{\Sigma}\left(\mathrm{c}_{1}+\mathrm{c}_{2}+\mathrm{c}_{3}+\ldots . . \mathrm{c}_{\mathrm{n}}\right) / \mathrm{N}$

where $c_{1-n}$ is the coefficient of conservatism for each native and adventive taxon and $\mathrm{N}$ is the total number of native species inventoried in the assessment area. The Floristic Quality Index (FQI) is then calculated:

\section{$\mathrm{FQI}=$ Mean $\mathrm{C} \times \sqrt{\mathrm{N}}$}

While the FQI technique has been widely applied, the body of knowledge is still developing. For example, although the FQI equation uses a square root transformation of $\mathrm{N}$ to limit the influence of area or sample size on species richness, several investigators have found a significant positive relationship between FQI and sample area size (Matthews 2003, Francis et al. 2000). Because of this, Rooney and Rogers (2002) advocated using Mean $\mathrm{C}$ because it is less sensitive to sample size and provides a more unbiased estimate of floristic quality than FQI. Bernthal (2003) recommended computing and interpreting both Mean C and FQI. Selection of which equation to use depends on the purposes and preferences of the investigator, and should be clearly stated.

\section{USING THE FLORISTIC QUALITY INDEX}

\section{Application}

The main requirements for using FQI are skills in plant identification, and sampling and/or inventorying techniques. The better the botanist, the more likely it is that rare or unusual species with relatively high conservatism ratings will be identified, and a true estimate of the FQI obtained. Good botanical skills are particularly needed when identifying species that are in vegetative state only (i.e., not in fruit or flower, Rooney and Rogers 2002).

All other things being equal, the more thorough the sample, the more accurate the assessment. A common technique is a complete inventory-"walkaround"-of a plant community, where each plant species present is identified without any estimate of relative abundance. Often, however, data are collected from fixed-area plot-based inventories, in order to both identify species and assign a relative abundance value. Both are consistent with FQl requirements, however several issues should be considered when considering sampling methodologies, and FQI calculation and comparison.

1. Time of year affects species presence, ease of identification, and thus FQI values. Matthews (2003) examined data from over 600 Illinois wetlands sampled between May and October, and found that mean FQI and N (but not Mean C) were significantly lower in May than in any month between July and October, and lower in June than either July or August. 
Francis et al. (2000) found similar results in Ontario. Lopez and Fennessy (2002) found that combined summer and autumn samples increased FQI by an average of three points over a summer sample only, but that the repeated effort did not affect the way sites ranked relative to each other. Obviously, several samples during the growing season will yield the most comprehensive list of plants present, but this is often not practical. Bernthal (2003) proposed that a single site-visit between mid-June and late August usually yielded reasonable results.

2. Ranges of FQI scores for some communities are greater or lesser than others for reasons that may have little to do with floristic integrity or quality. For example, Sphagnum-Eriophorum bogs are rare wetland plant communities in West Virginia wetlands (Fortney et al. 2006), and provide habitat to a number of species with high $\mathrm{C}$ values such as sundew (Drosera rotundifolia), small and large cranberry (Vaccinium oxycoccus and V. macrocarpon), and snowberry (Gaultheria hispidis). Yet these communities are also very acidic and nutrient poor; plants present tend to be specialized for these harsh conditions, and total species richness tends to be relatively low. For example, we looked at sample results from seven 0.05 ha plots in Canaan Valley and Elder Swamp. Mean C for these sites was relatively high $(6.9 \pm 0.7)$, however average $\mathrm{N}_{\text {nat }}$ was only $8.1+4.5$, and mean FQI was only $19.1 \pm 3.6$.

3. When FQI scores from different investigators or studies are compared, some information on sampling methods is necessary in order to determine if the results are indeed comparable. Sampling techniques do not have to be exact replicates of each other, either by method or intensity. The square root transformation of $\mathrm{N}$ was intended to reduce the effect of sample size and sample area. Nevertheless, efforts should be made to utilize similar sampling techniques. Above all, an investigator should clearly state the methods used.

4. Pooling species lists from several different community types almost always results in higher FQI scores, because as results from more than one community type are summed, sample area increases and the result is invariably a larger $\mathrm{N}$ value. Andreas et al. (2004) recommends that this practice should generally be avoided, but if done, that scores from component communities should also be reported.

\section{SUMMARY}

The Floristic Quality Index for West Virginia was developed as a tool to evaluate the floristic and conservation value of any wetland site based on the abundance of conservative plant species. Although the initial assignment of $\mathrm{C}$ values was somewhat subjective, subjectivity was minimized by averaging the best estimates of botanists familiar with the flora of the state. Finally, the methodology itself is not subjective (Herman et al. 2001). It is standardized, unbiased, and repeatable, and can be applied to any wetland and/or data set. The method is relatively simple and requires only botanical skills and familiarity with plant sampling techniques. 


\section{ACKNOWLEDGEMENTS}

The authors thank all the contributors of coefficients of conservatism for their generosity of time and expertise. These include Harold S. Adams, Elizabeth Byers, David Dick, Donna Ford-Werntz, William Grafton, P. J. Harmon, Cynthia Huebner, James Rentch, Steven Stephenson, Brian Streets, and James Vanderhorst. Dave McGill, Susan Studlar, and George Longenecker provided helpful reviews of this manuscript.

The starting source document for this project was the Checklist and Atlas of the Vascular Flora of West Virginia, version of June 29, 2004, coauthored by Harmon, Ford-Werntz, and Grafton. This checklist and atlas is part of an ongoing revision of Strausbaugh and Core's (1979) classic Flora of West Virginia. Funding was provided by the Canaan Valley Institute through a grant from the US Department of Agriculture CREES, Award No. 2004-3887402133. Support was also provided by the Division of Forestry and Natural Resources at West Virginia University. Finally, we appreciate the knowledge and experience gained from individuals and organizations in other states as they crafted their FQI efforts. This work made ours considerably easier. This is Scientific Bulletin No. 730 of the West Virginia University Agricultural and Forestry Experiment Station, Morgantown, West Virginia. 


\section{LITERATURE CITED}

Andreas, B. K. and R.W. Lichvar. 1995. Floristic Index for Establishing Assessment Standards: A Case Study for Northern Ohio. Technical Report WRP-DE-8, U.S. Army Corps of Engineers, Waterways Experiment Station, Vicksburg, MS. 16 p. +1 appendix.

Andreas, B. K., J. J. Mack, and J. S. McCormac. 2004. Floristic Quality Assessment Index (FQAI) for Vascular Plants and Mosses for the State of Ohio. Ohio Environmental Protection Agency, Division of Surface Water, Wetland Ecology Group, Columbus, Ohio. $219 \mathrm{p}$.

Bernthal, T. W. 2003. Development of a Floristic Quality Assessment Methodology for Wisconsin. Final Report to the USEPA, Region V.

Dahl, T. E. 1990. Wetland losses in the United States, 1780s to 1980s. US Department of the Interior, US Fish and Wildlife Service, Washington, DC.

R. H. Fortney, S. L. Stephenson, and J. Rentch. 2006. Rare plant communities in Canaan Valley, West Virginia, USA. Proceedings, Canaan Valley and its Environs. October 16-19, 2002, Davis, West Virginia.

Francis, C. M., M. J. W. Austen, J. M. Bowles, and W. B. Draper. 2000. Assessing floristic quality in southern Ontario woodlands. Natural Areas Journal 20: 66-77.

Harmon, P. J., D. Ford-Werntz, and W. Grafton. 2004. Checklist and Atlas of the Vascular Flora of West Virginia, version of June 29, 2004. West Virginia Division of Natural Resources, Wildlife Resources Section, P.O. Box 67, Elkins, WV 26241. USA.

Herman, K.D., L.A. Masters, M. R. Penskar, A. A. Reznicek, G. S. Wilhelm, W. M. Brodowicz, and K.P. Gardiner. 2001. Floristic Assessment with Wetland Categories and Examples of Computer Applications for the State of Michigan (FQA), Revised $2^{\text {nd }}$ Edition. Natural Heritage Program, Michigan Department of Natural Resources, Lansing, Michigan. $19 \mathrm{p}$.

Kreider, J., T. Bernthal, and M. Cottingham. 2003. Wisconsin Floristic Quality Assessment User's Manual. Wisconsin Department of Natural Resources, Water Division, Madison, WI. 54 p.

Laughlin, D. 2001. Floristic inventory of the arboretum at Penn State. The Arboretum at Penn State, Special Publication 1.

http://www.arboretum.psu.edu/publications/report.html

Lopez, R. D. and M. S. Fennessy. 2002. Testing the floristic quality assessment index as an indicator of wetland condition. Ecological Applications 12:487-497. 
Matthews, J.W. 2003. Assessment of the floristic quality index for use in Illinois, USA, wetlands. Natural Areas Journal 23:53-60.

Northern Great Plains Floristic Quality Assessment Panel. 2001. Floristic Quality Assessment for Plant Communities of North Dakota, South Dakota (excluding the Black Hills), and Adjacent Grasslands. Northern Prairie Wildlife Research, Jamestown, ND. http://www.npwrc.usgs.gov/resource/2001/fqa/

Reed, P.B., Jr. 1988. National List of Plant Species That Occur in Wetlands: Region I, Northeast. U.S. Fish \& Wildlife Service. Biological Report 88. 244 p.

Reed, P.B., Jr. 1996. Revision of the National List of Plant Species That Occur in Wetlands. Department of the Interior, U.S. Fish and Wildlife Service, Washington, DC. 209 p. Available from: http://www.nwi.fws.gov/bha/download/1996/national.txt

Rooney, T.P. and D.A. Rogers. 2002. The modified floristic quality index. Natural Areas Journal 22: 340-344.

Strausbaugh, P. D., and E. L. Core. 1979. Flora of West Virginia. $2^{\text {nd }}$ ed. Seneca Books, Morgantown, WV. 1079 p.

Swink, F. and G. Wilhelm. 1979. Plants of the Chicago Region. $3^{\text {rd }}$ ed. Morton Arboretum, Lisle. 922 p.

Swink, F. and G. Wilhelm. 1994. Plants of the Chicago Region. $4^{\text {th }}$ ed. Indiana Academy of Science, Indianapolis. $921 \mathrm{p}$.

Taft, J.B., G.S. Wilhelm, D.M. Ladd, and L.A. Masters. 1997. Floristic quality assessment in Illinois: a method for assessing vegetation integrity. Erigenia 15:3-95.

Virginia Floristic Quality Assessment Index Advisory Committee (VFQAIAC). 2004. Virginia Wetland Plants C-Value List. Commonwealth of Virginia, Department of Environmental Quality, Office of Wetlands, Water Protection Compliance. Available at: http://www.deq.state.va.us/wetlands/pdf/virginiacvaluescompleterev1.pdf 31 p.

West Virginia Department of Natural Resources (WVNR). 2006. Rare, Threatened And Endangered Species Fact Sheets In West Virginia: Virginia spiraea (Spiraea virginiana). Available from: http://www.wvdnr.gov/wildlife/RETSpecies.asp 


\section{APPENDIX 1.}

Names, affiliations, and addresses of coefficient of conservatism contributors.

Harold S. Adams (retired)

Department of Biology

Dabney Lancanster Community College

1000 Dabney Dr.

Clifton Forge, VA 24422

Elizabeth Byers, P. J. Harmon, Brian Streets, and James Vanderhorst

WV Natural Heritage Program

Division of Natural Resources, Wildlife Section

PO Box 67, Elkins

WV 26241

David Dick

WV Department of Agriculture

Plant Industries Division

1900 Kanawha Blvd., E.

Charleston, WV 25305-0191

Donna Ford-Werntz

Department of Biology

West Virginia University

PO Box 6057

Morgantown, WV 26506-6057

William Grafton and James Rentch

Division of Forestry and Natural Resources

West Virginia University

PO Box 6125

Morgantown, WV 26506-6125

Cynthia Huebner

USDA Forest Service, NE Research Station

180 Canfield St.

Morgantown, WV 26505-3180

Stephen Stevenson

Department of Biological Sciences

University of Arkansas

Fayetteville, AR 72701 


\section{APPENDIX 2.}

Mean coefficient of conservatism values for wetland and riparian plant taxa in West Virginia. Information shown includes a) scientific name, b) Taxonomic authority, c) common name(s), d) origin (see text for explanation of codes), e) Wetland Indicator Status (WIS-see text for explanation of codes), and f) $\mathrm{C}$ values. 


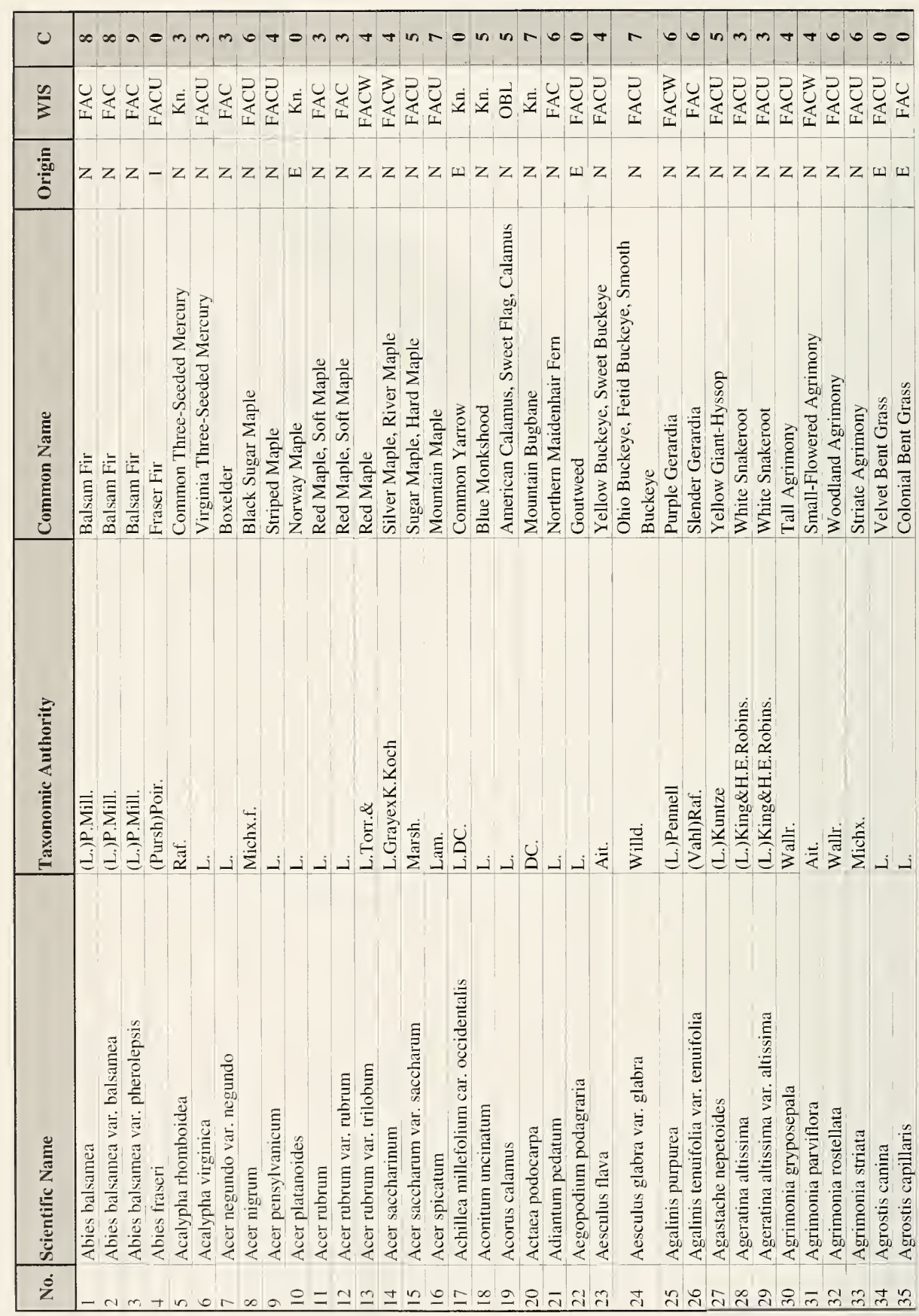




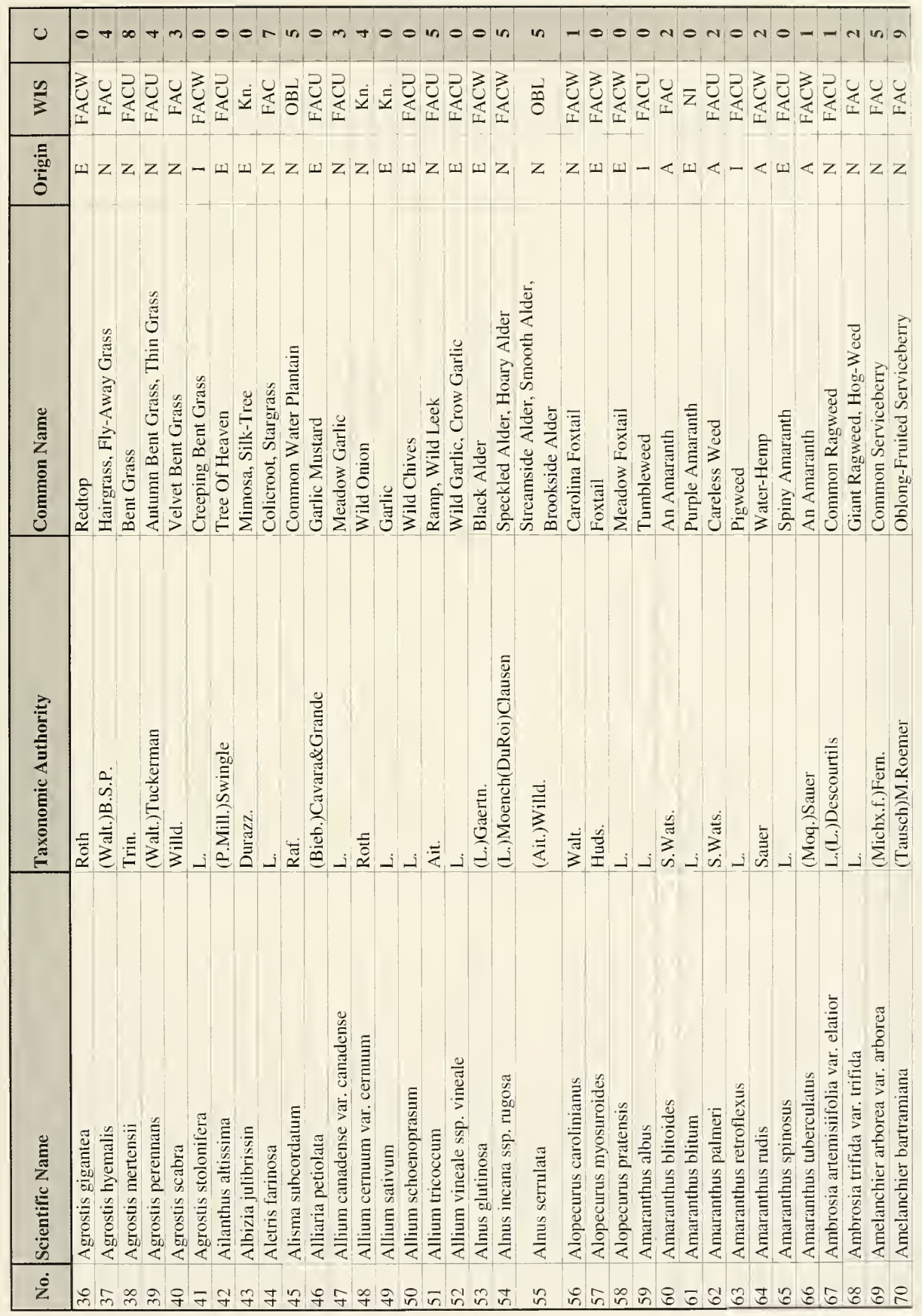




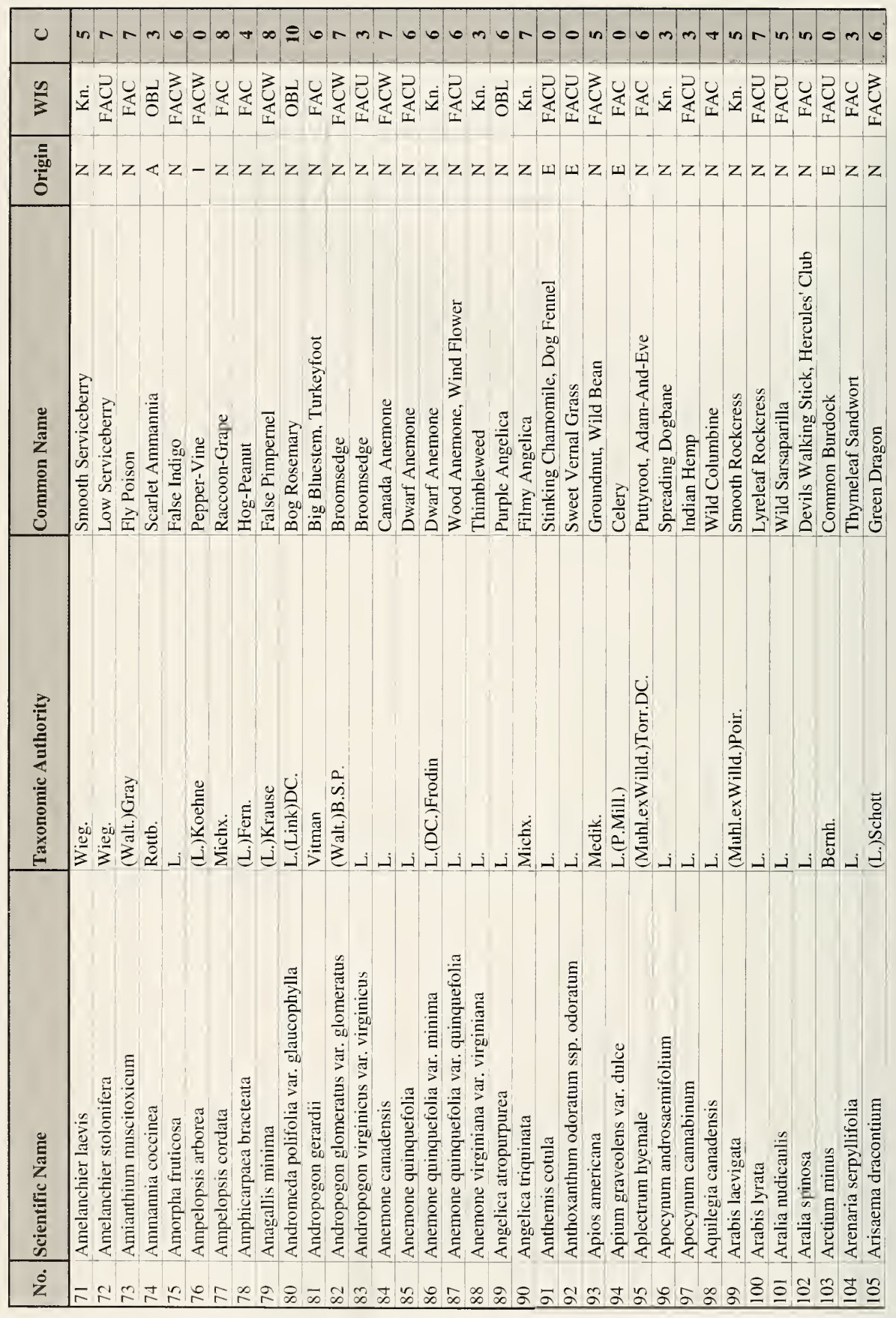




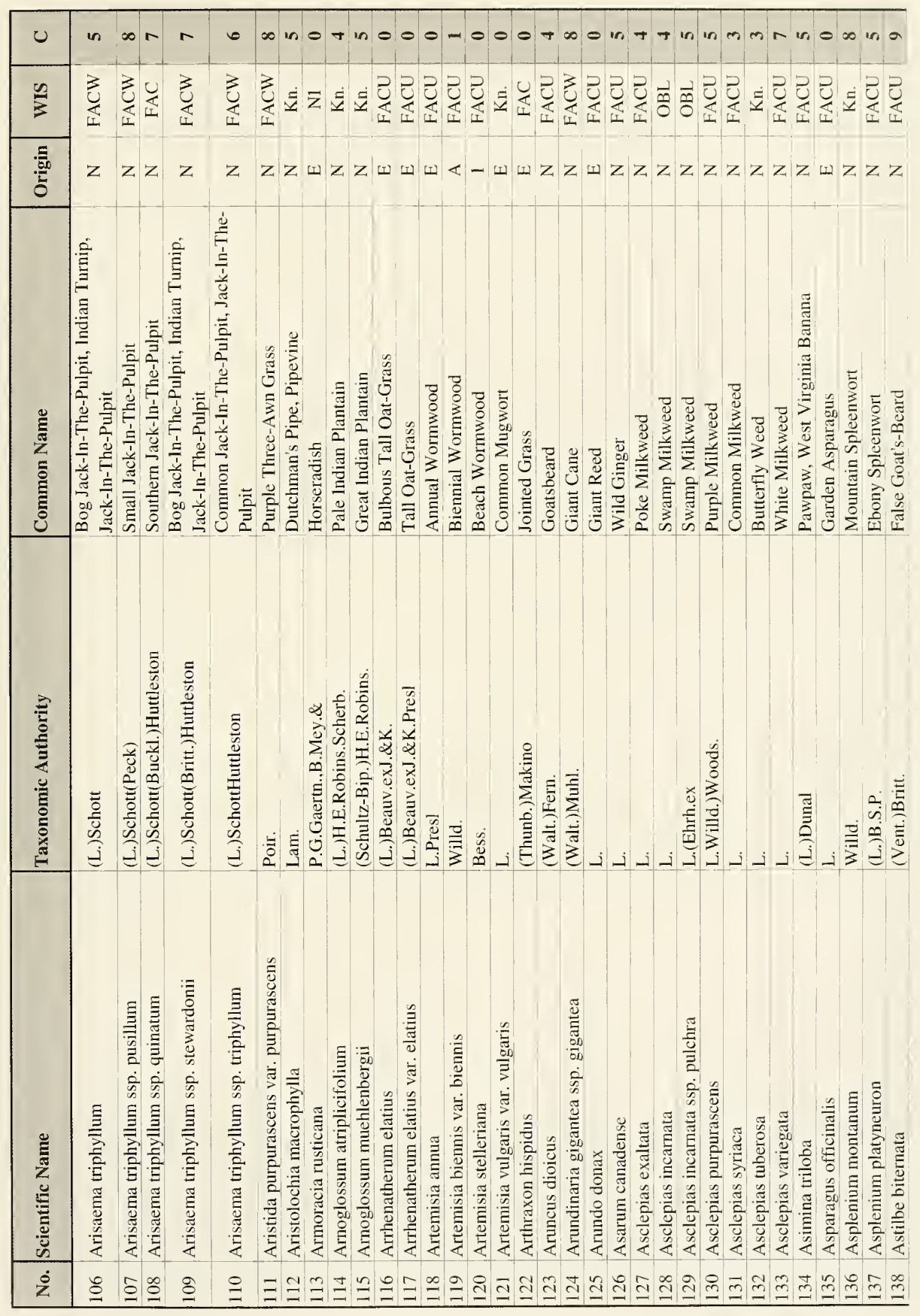




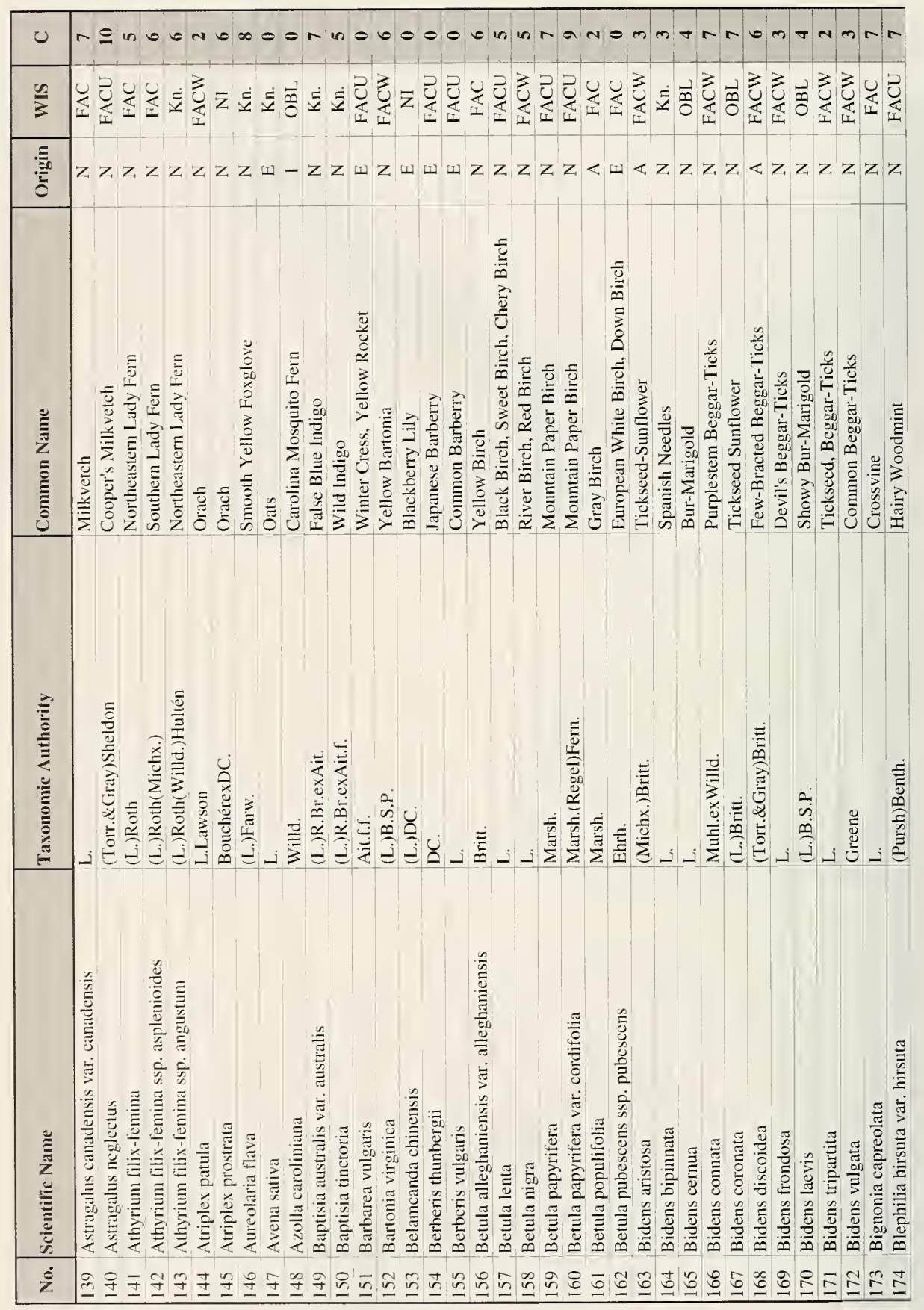




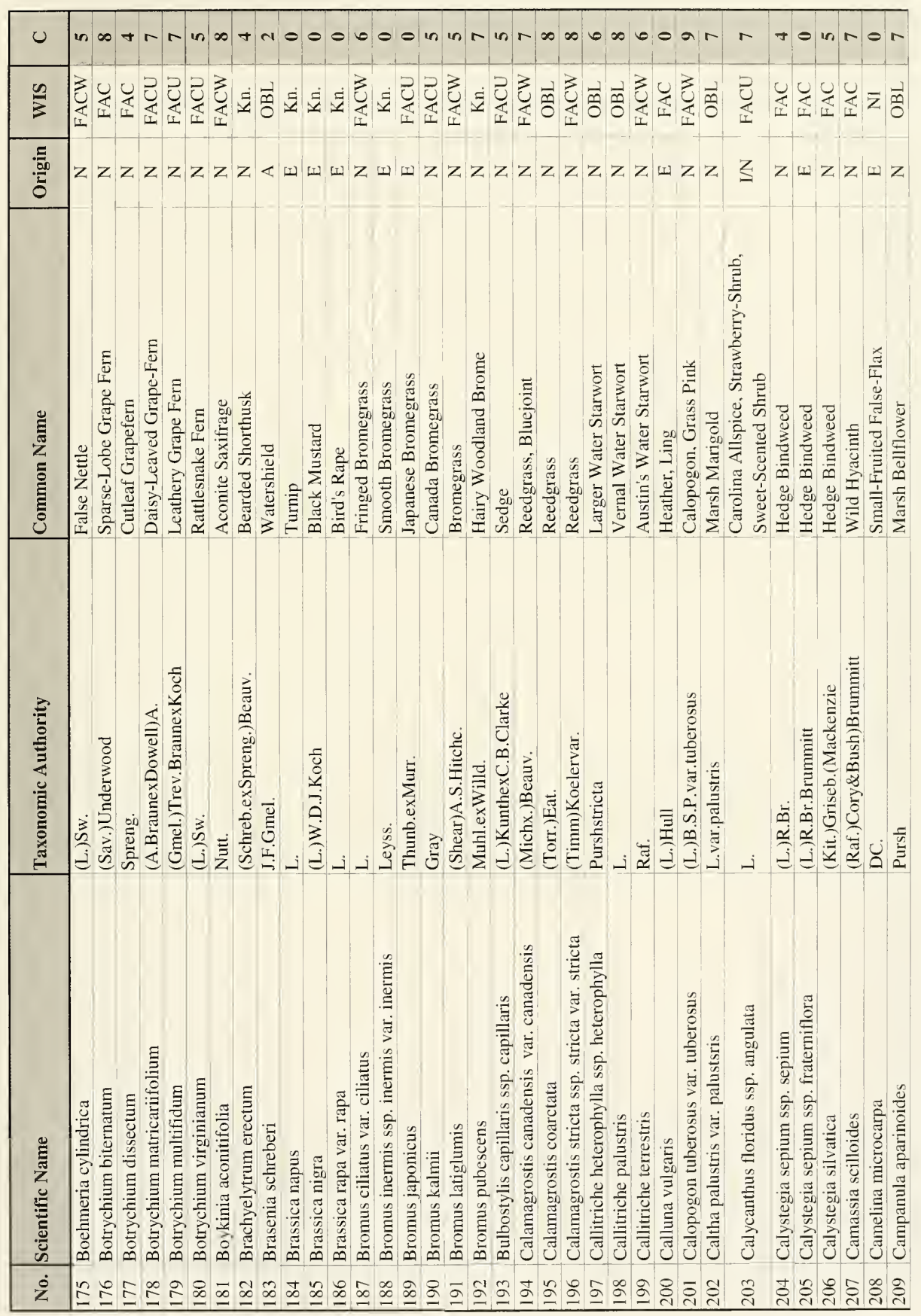




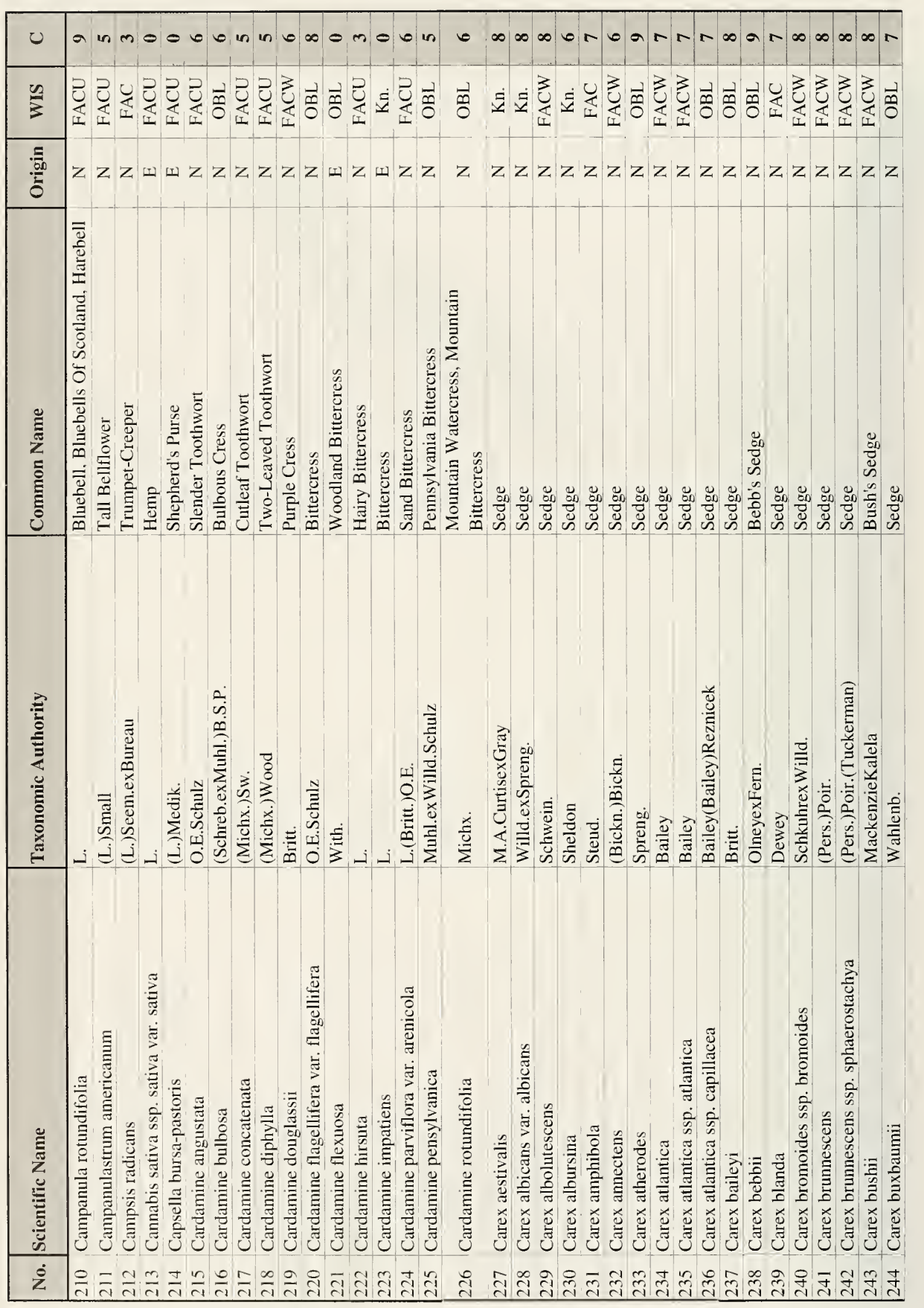




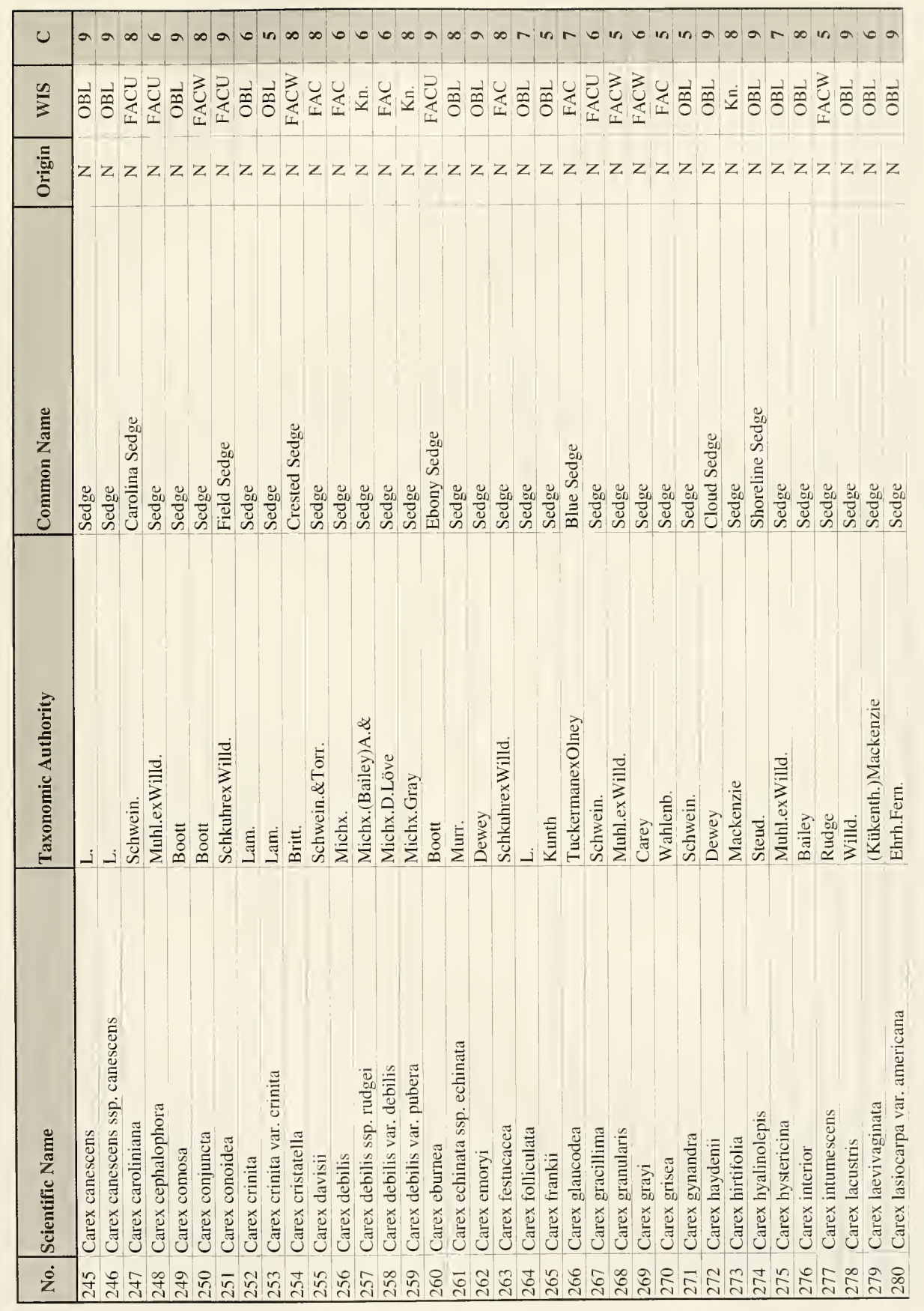




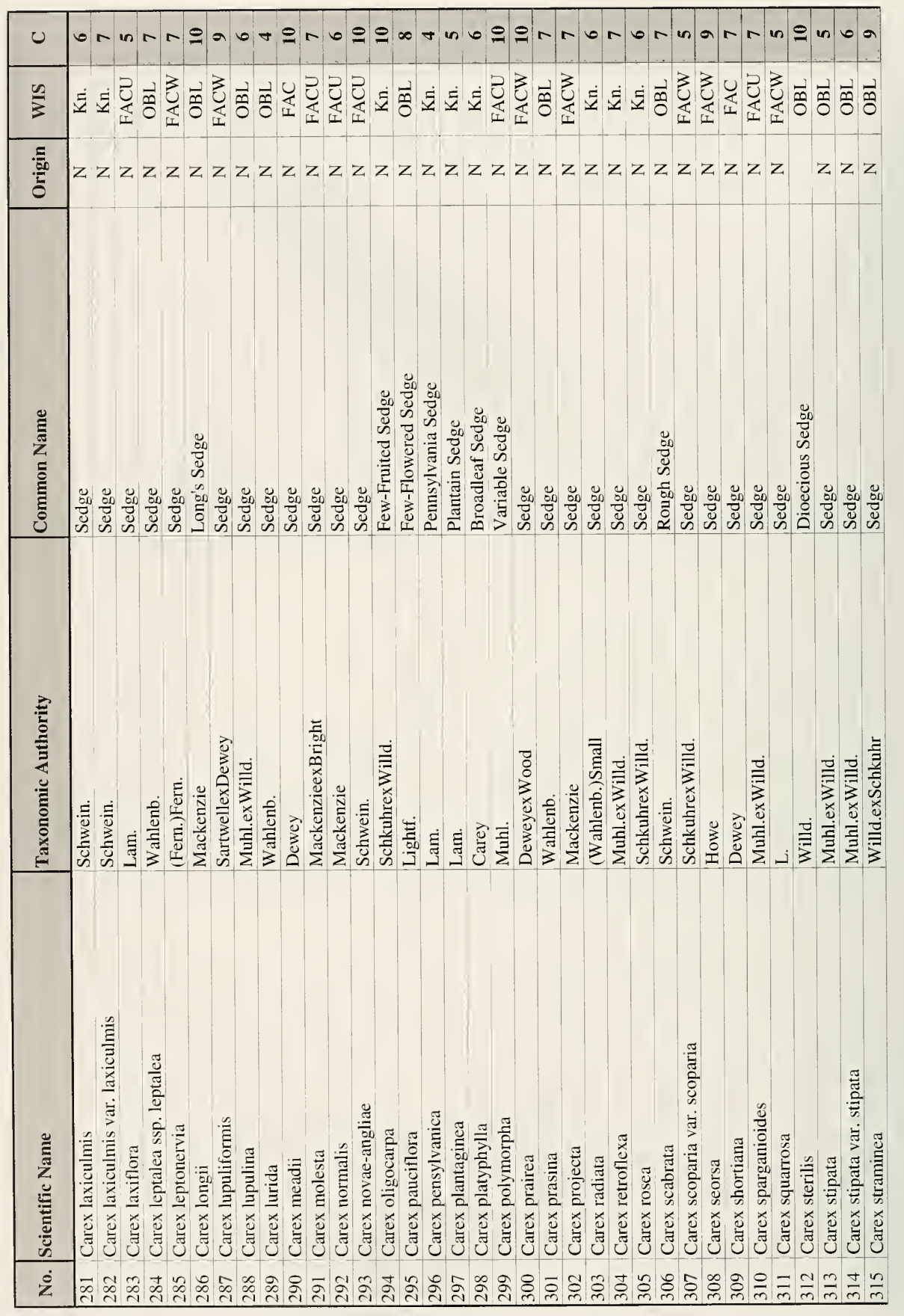




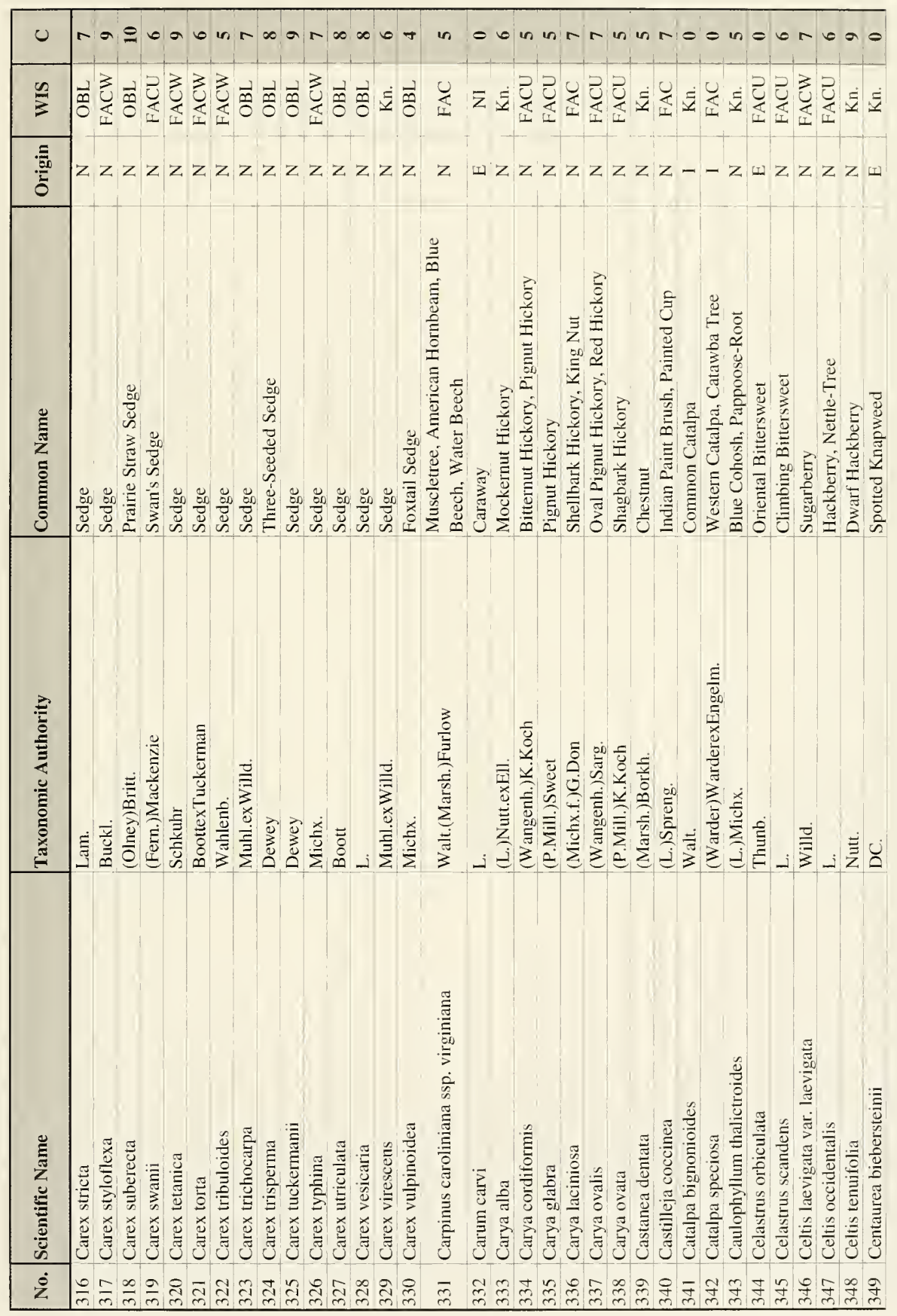




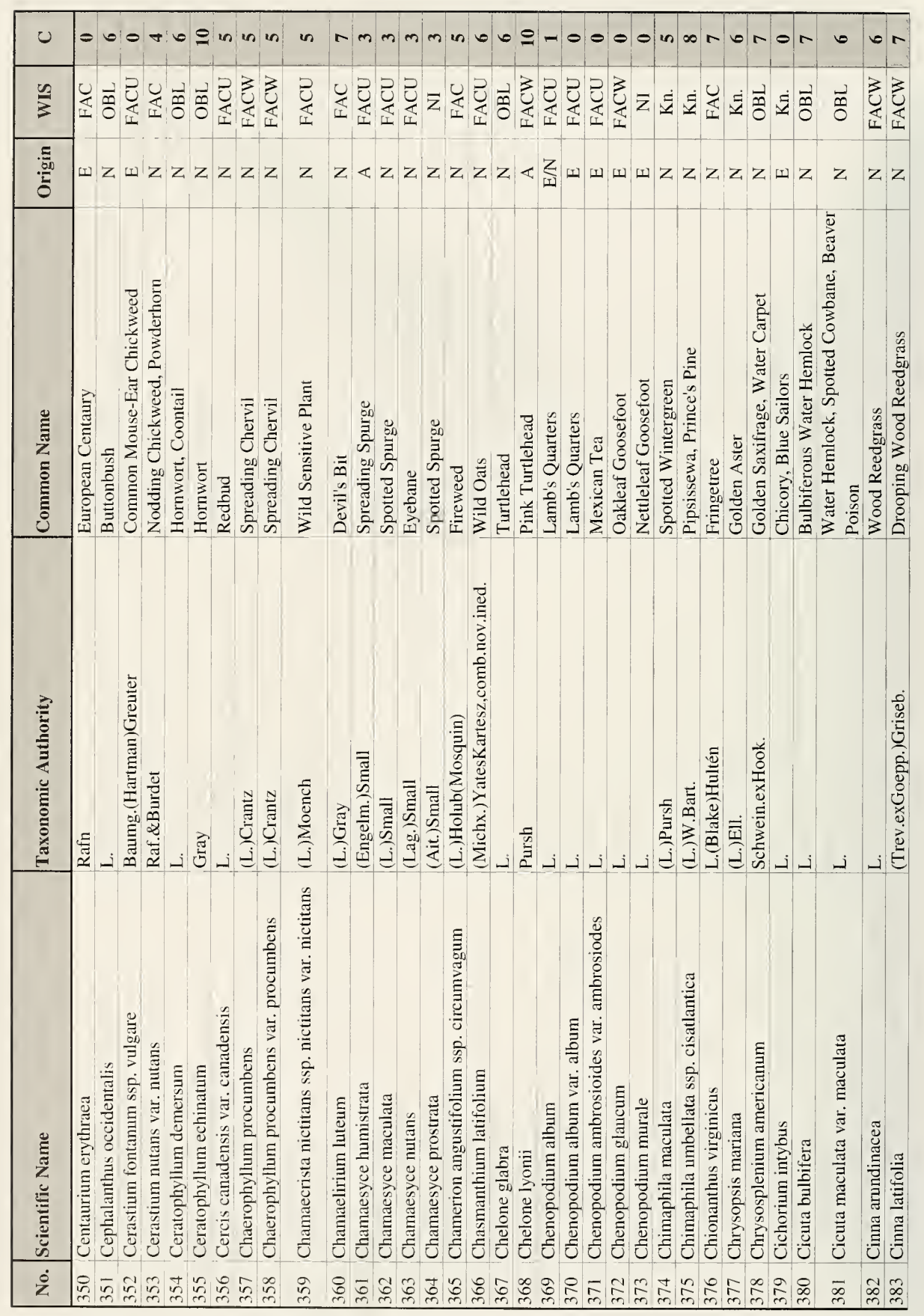




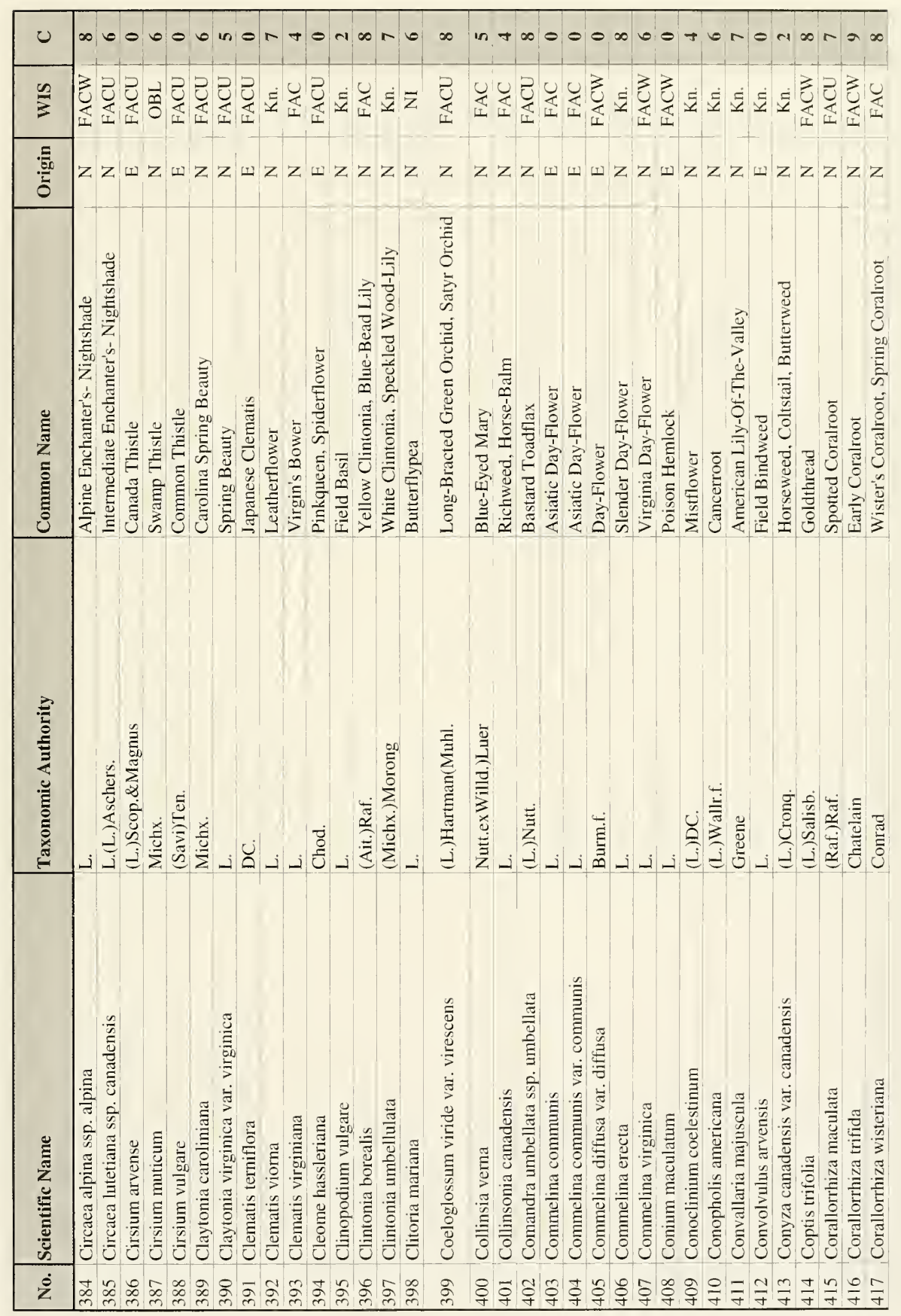




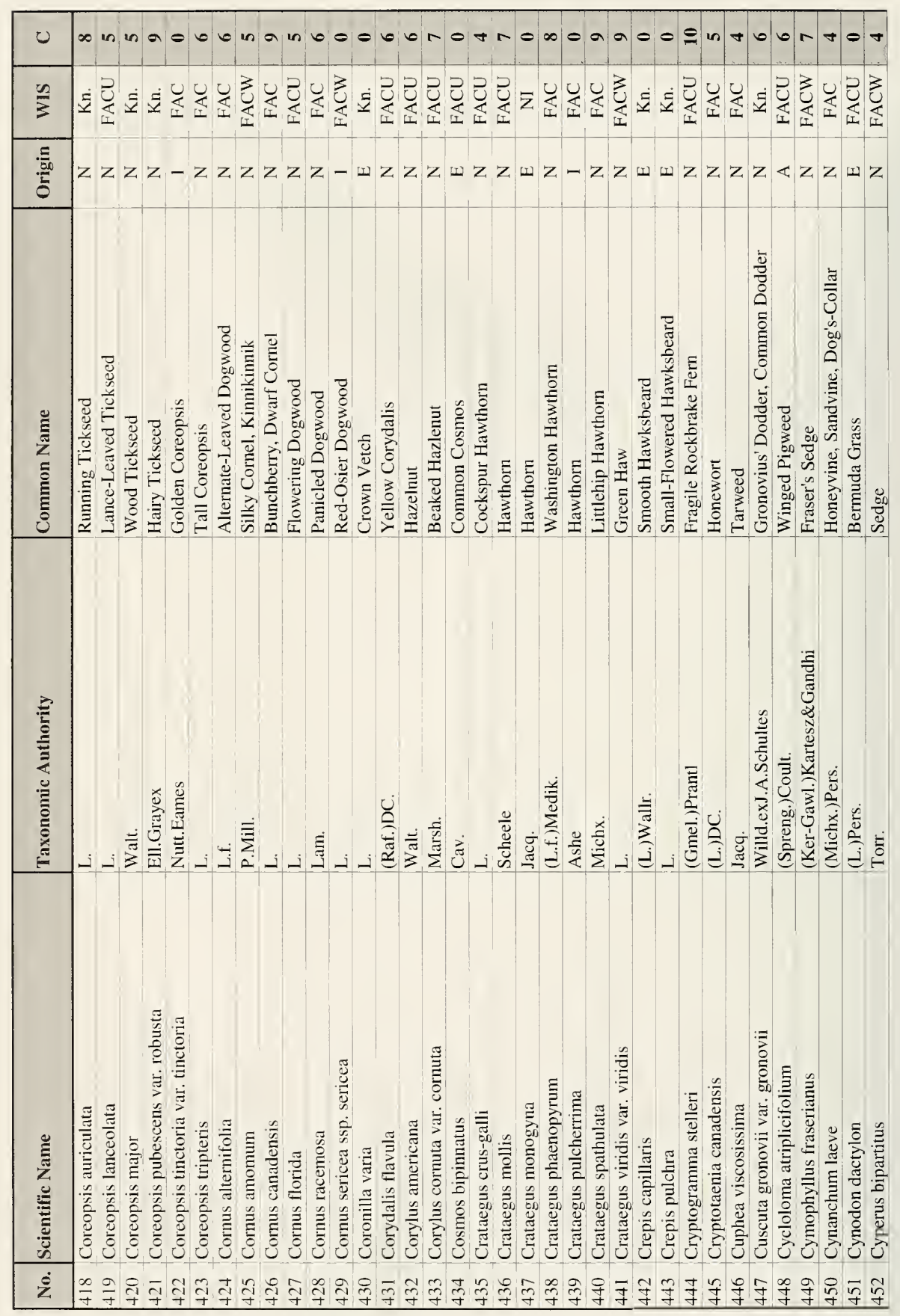




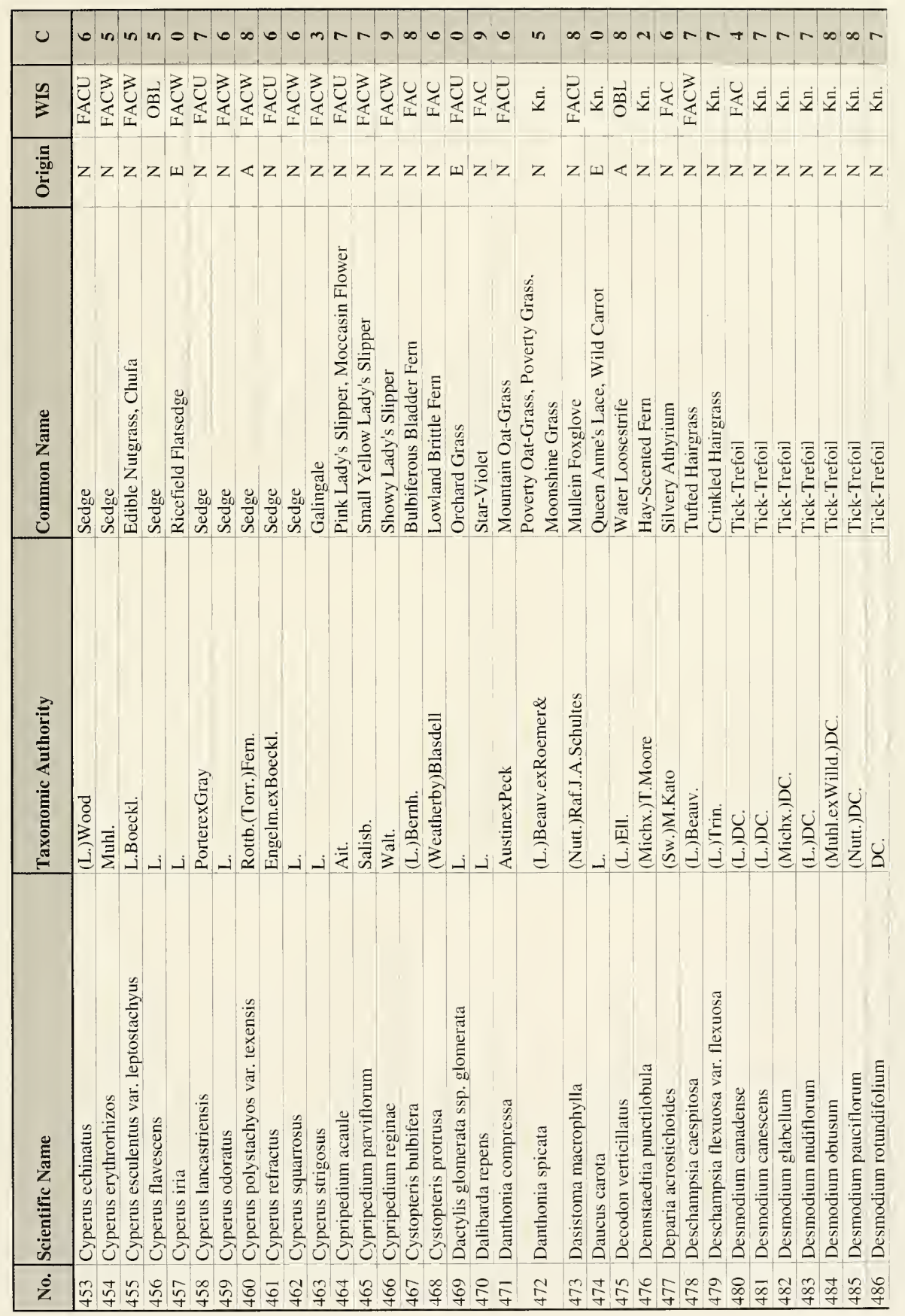




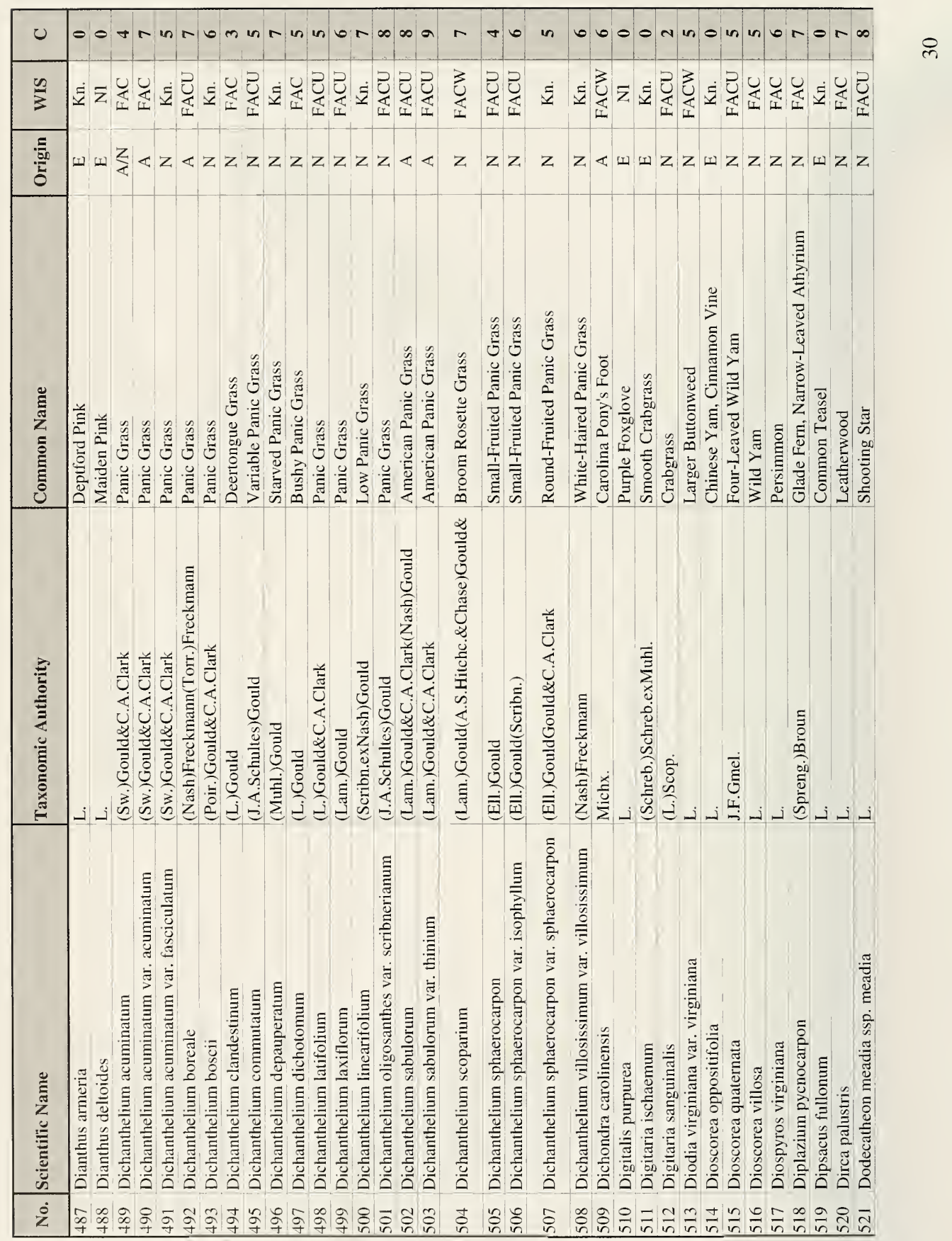




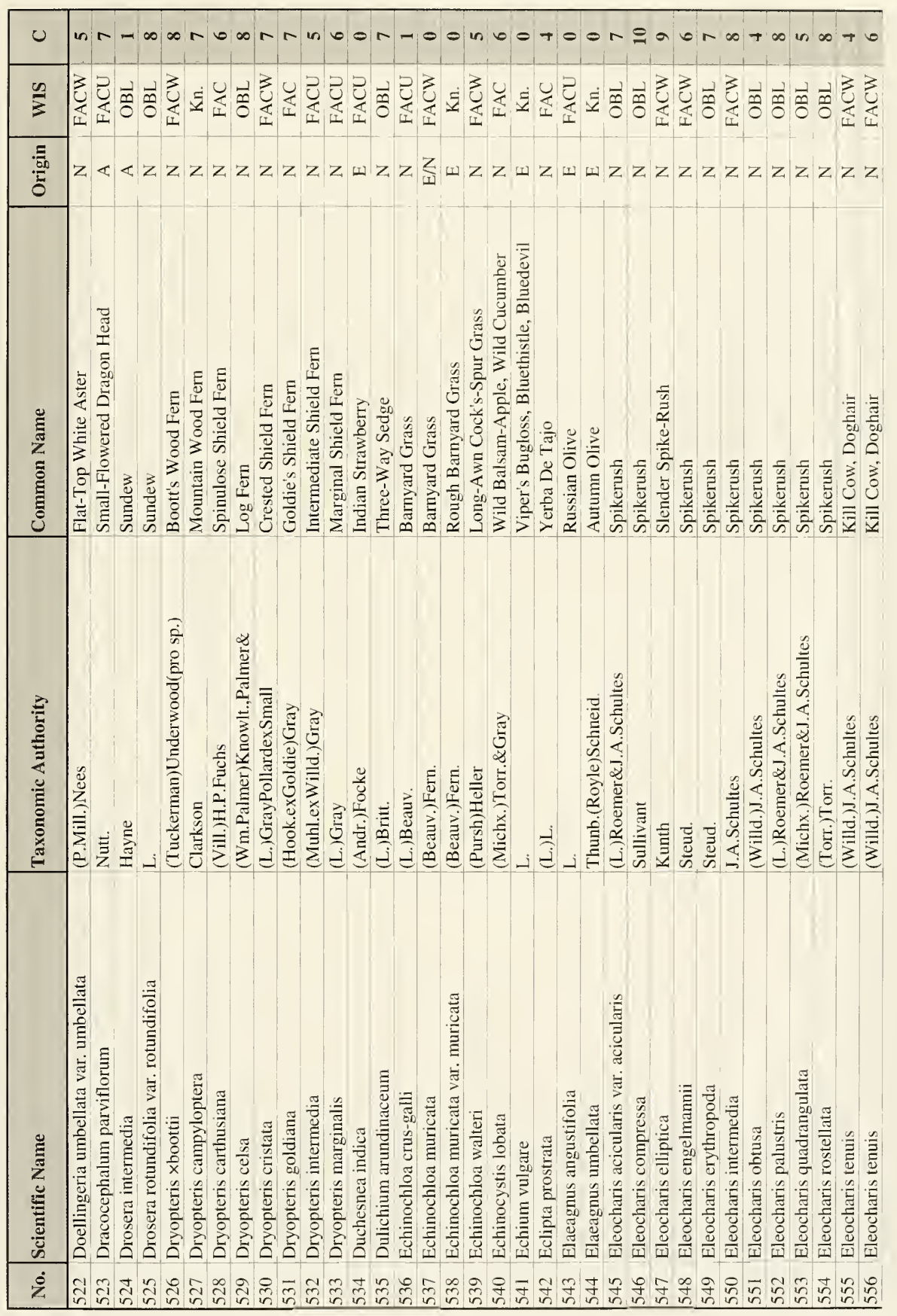




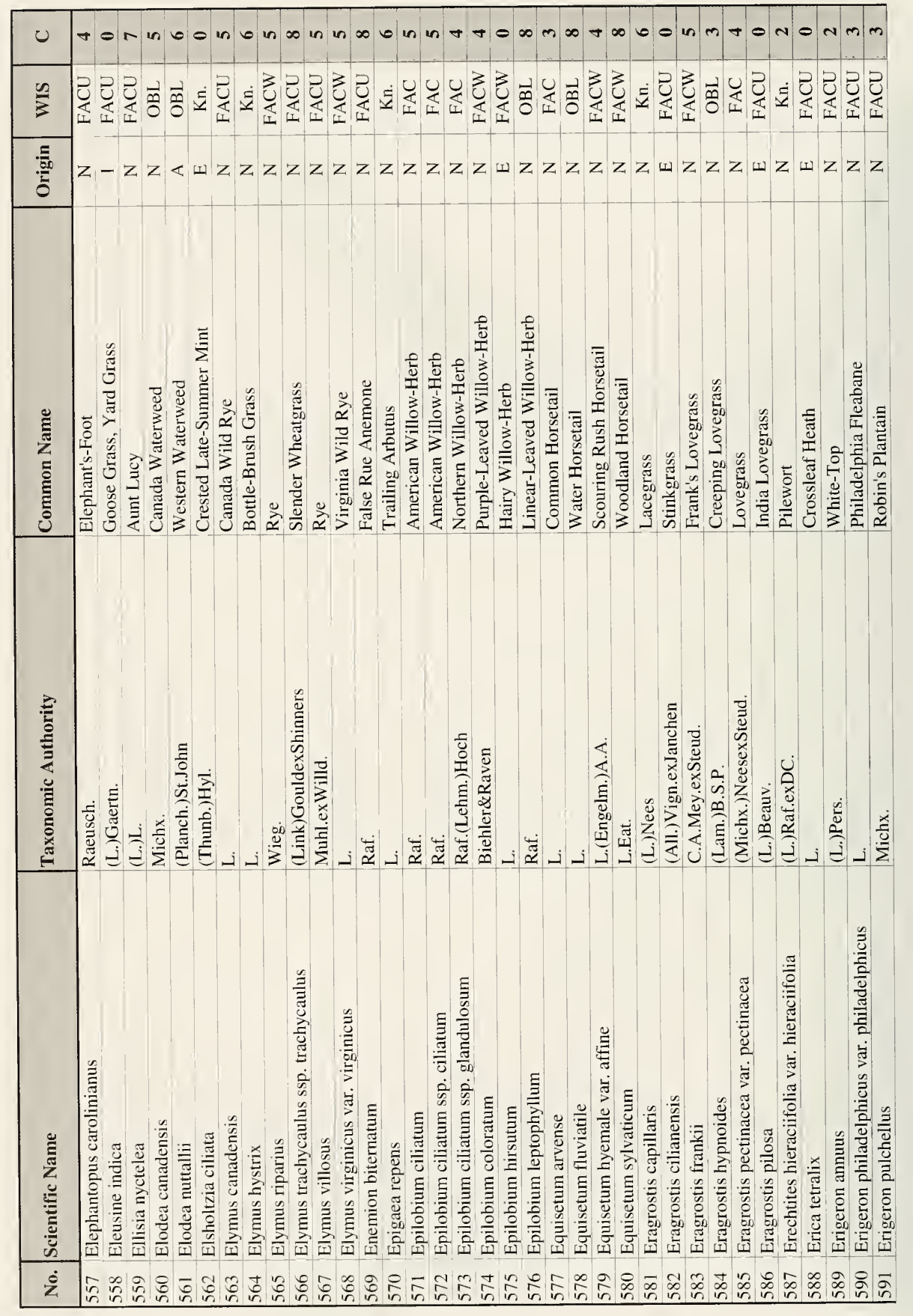




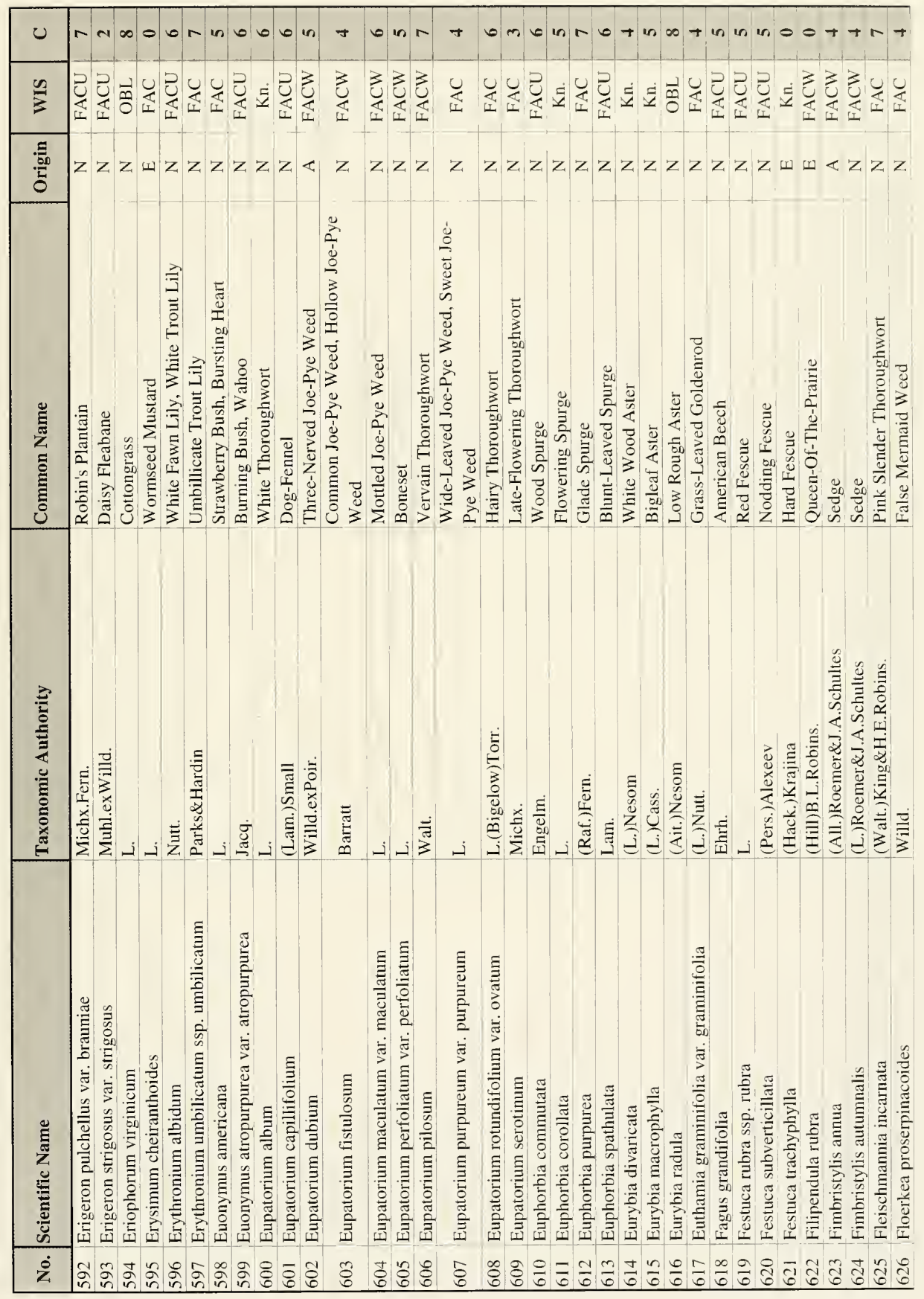




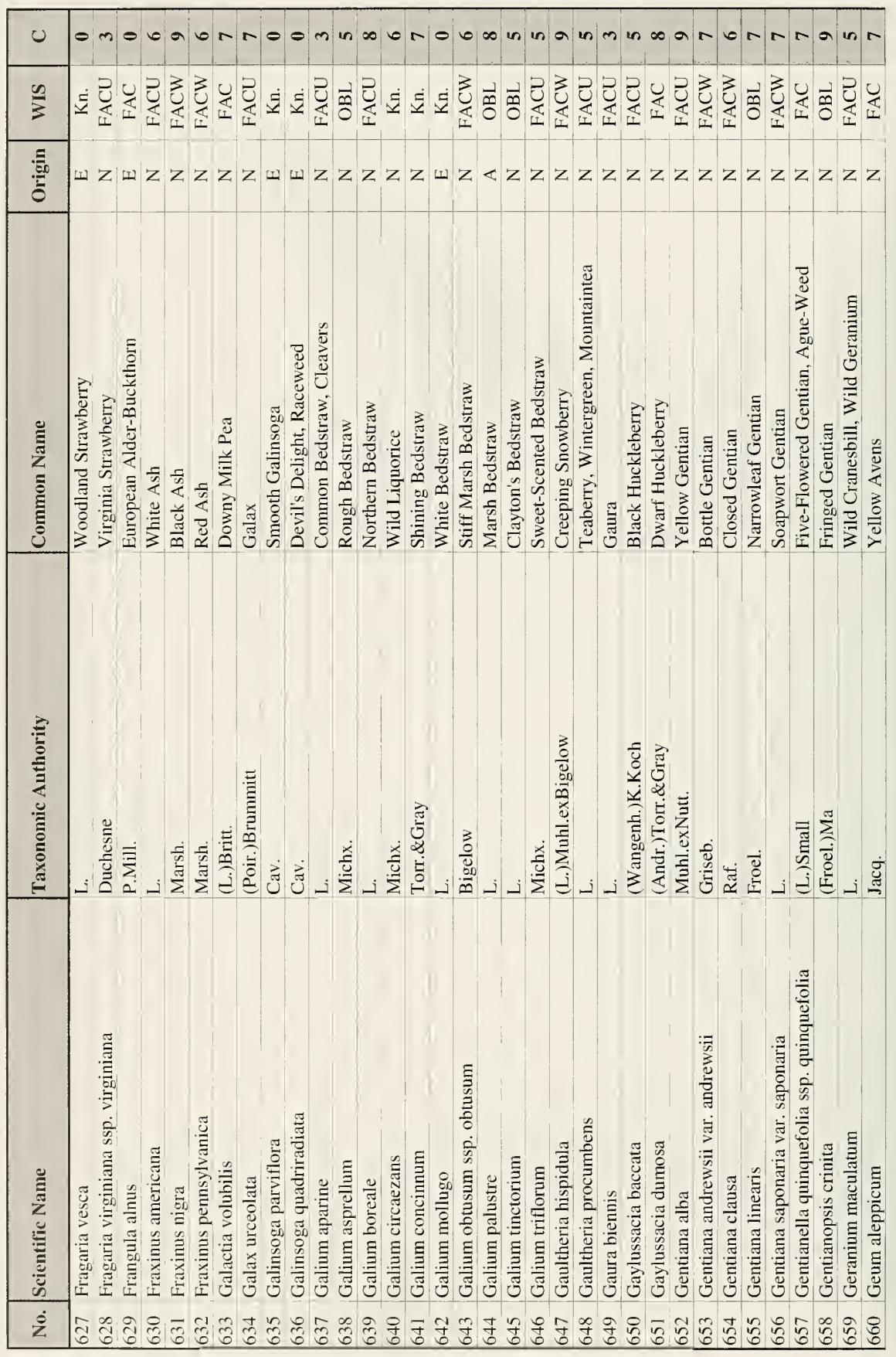




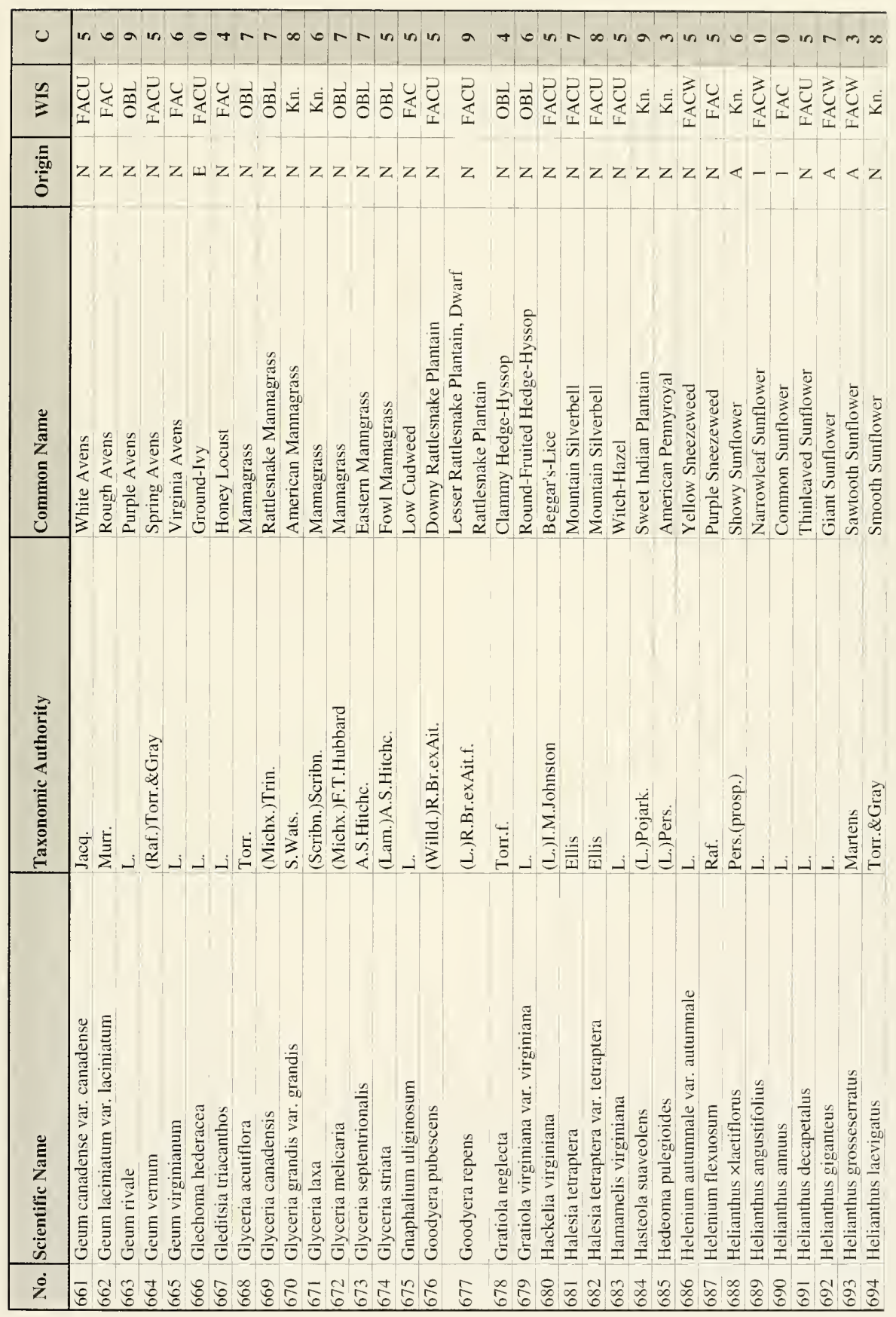




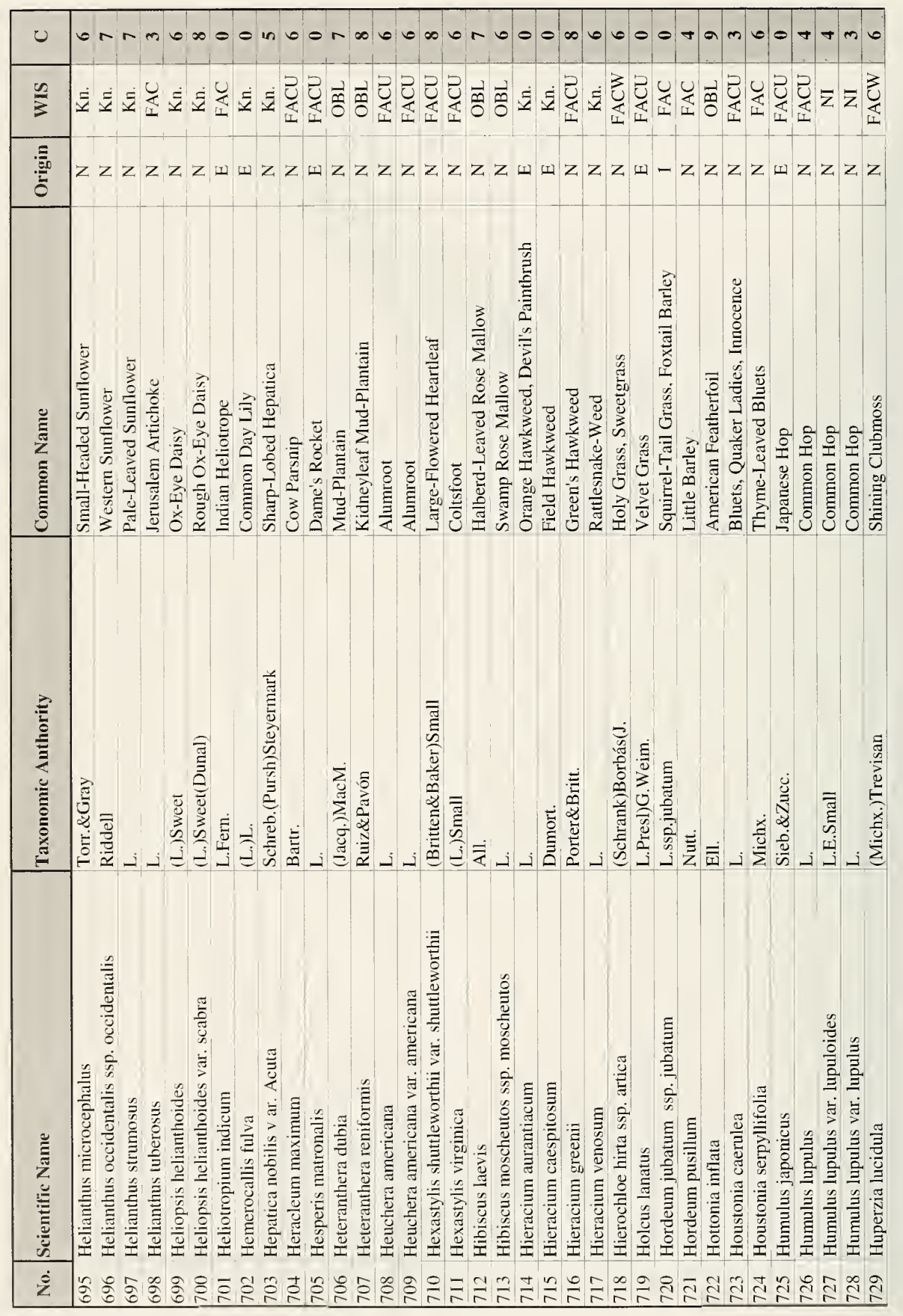




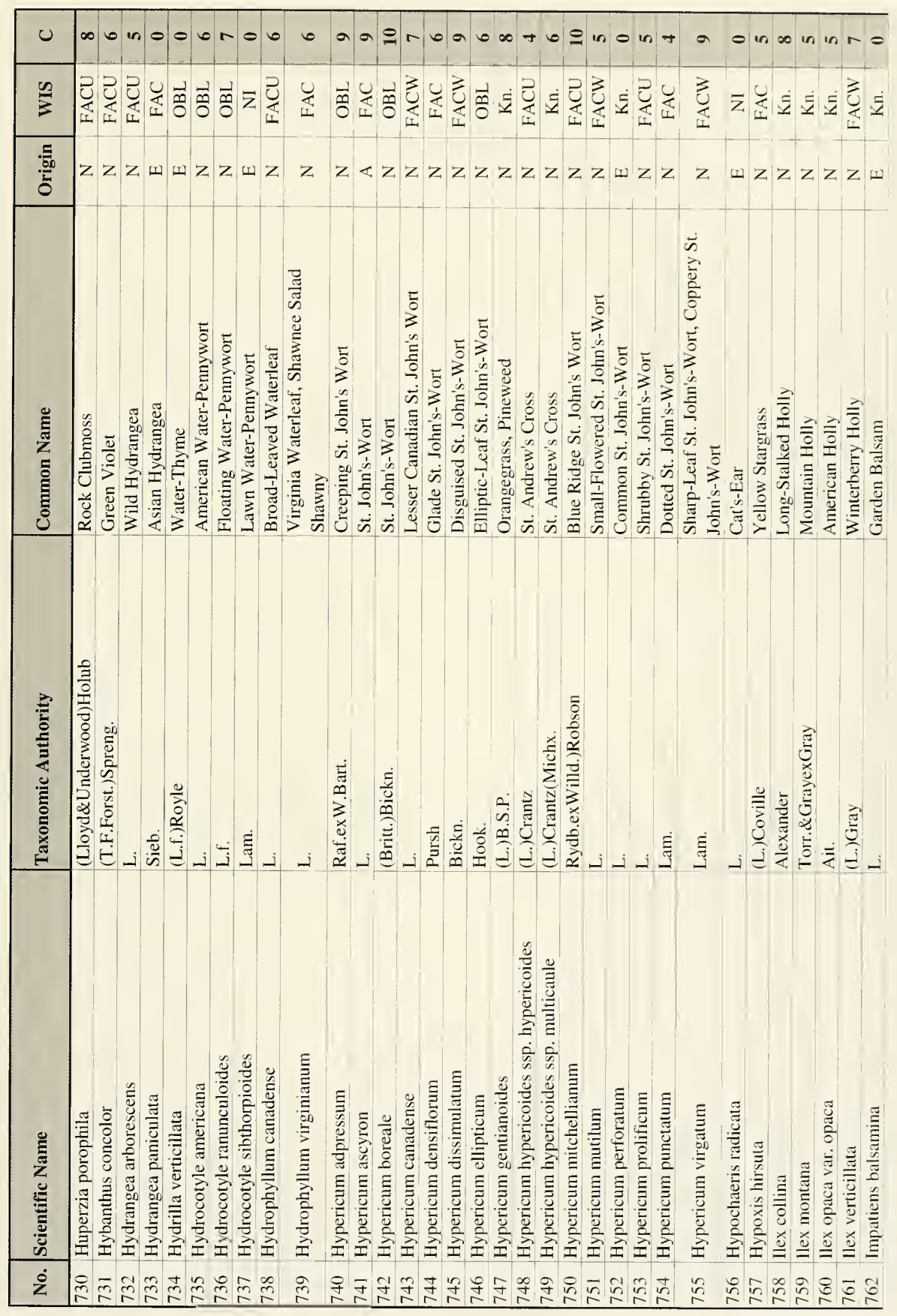




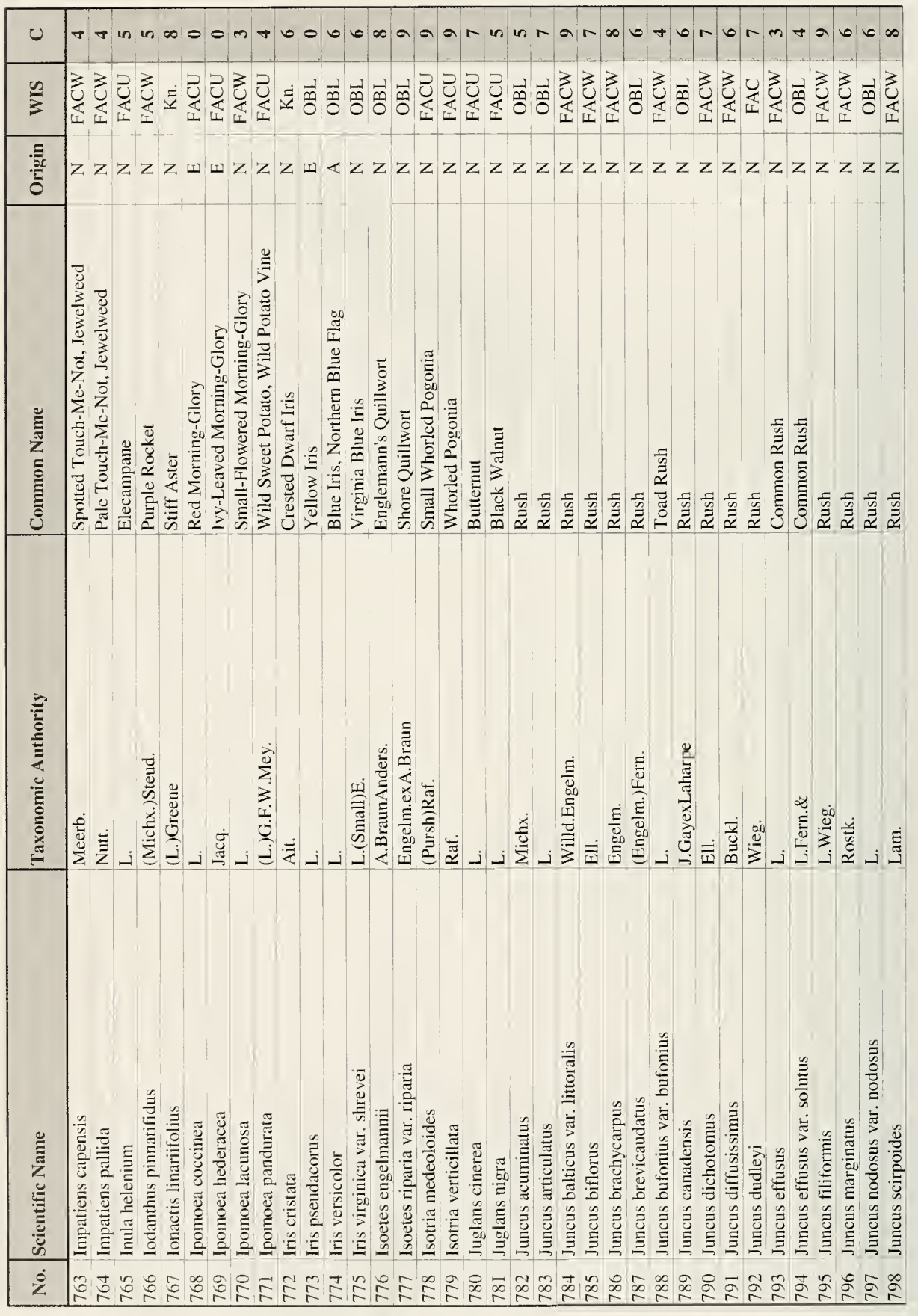




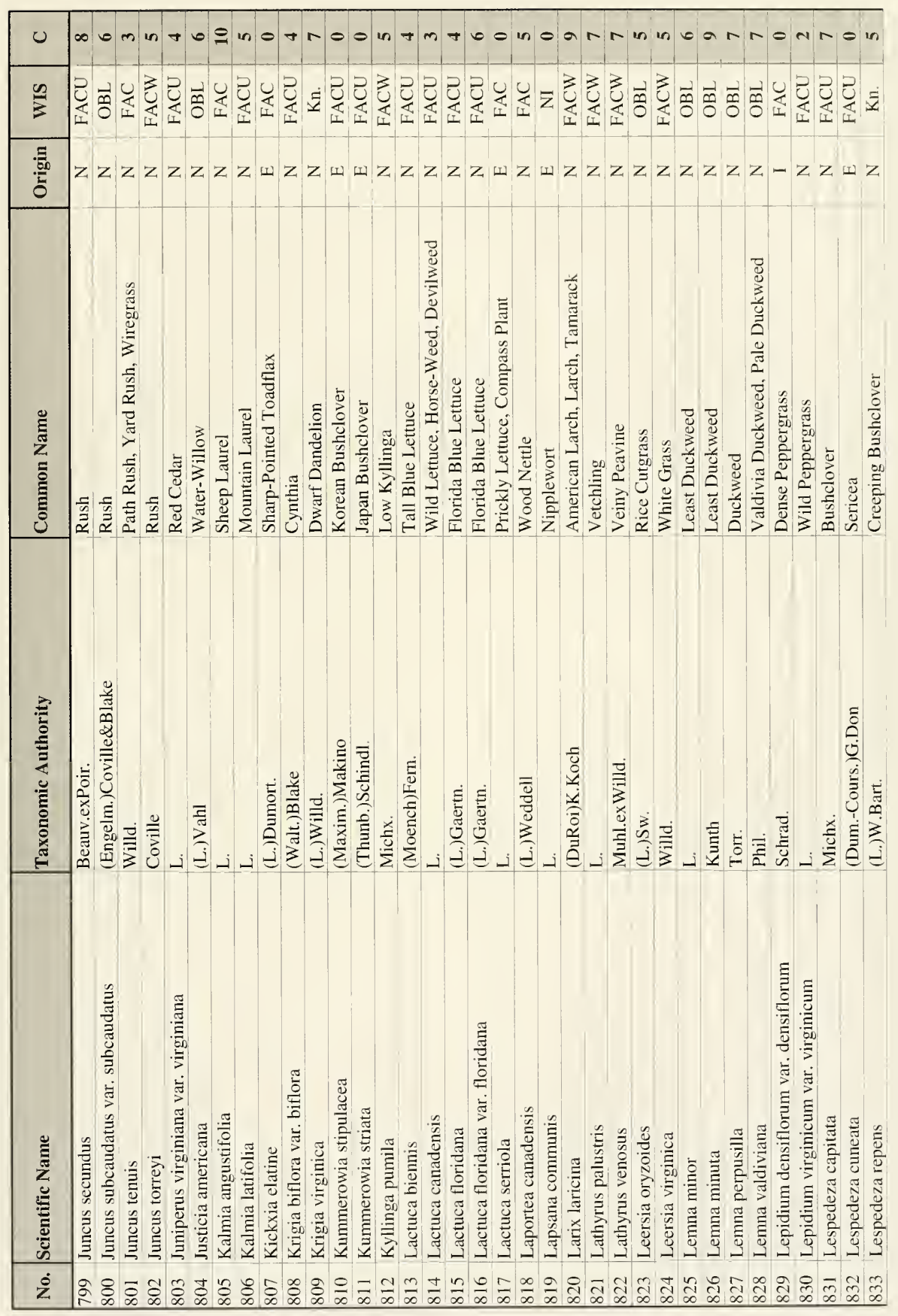




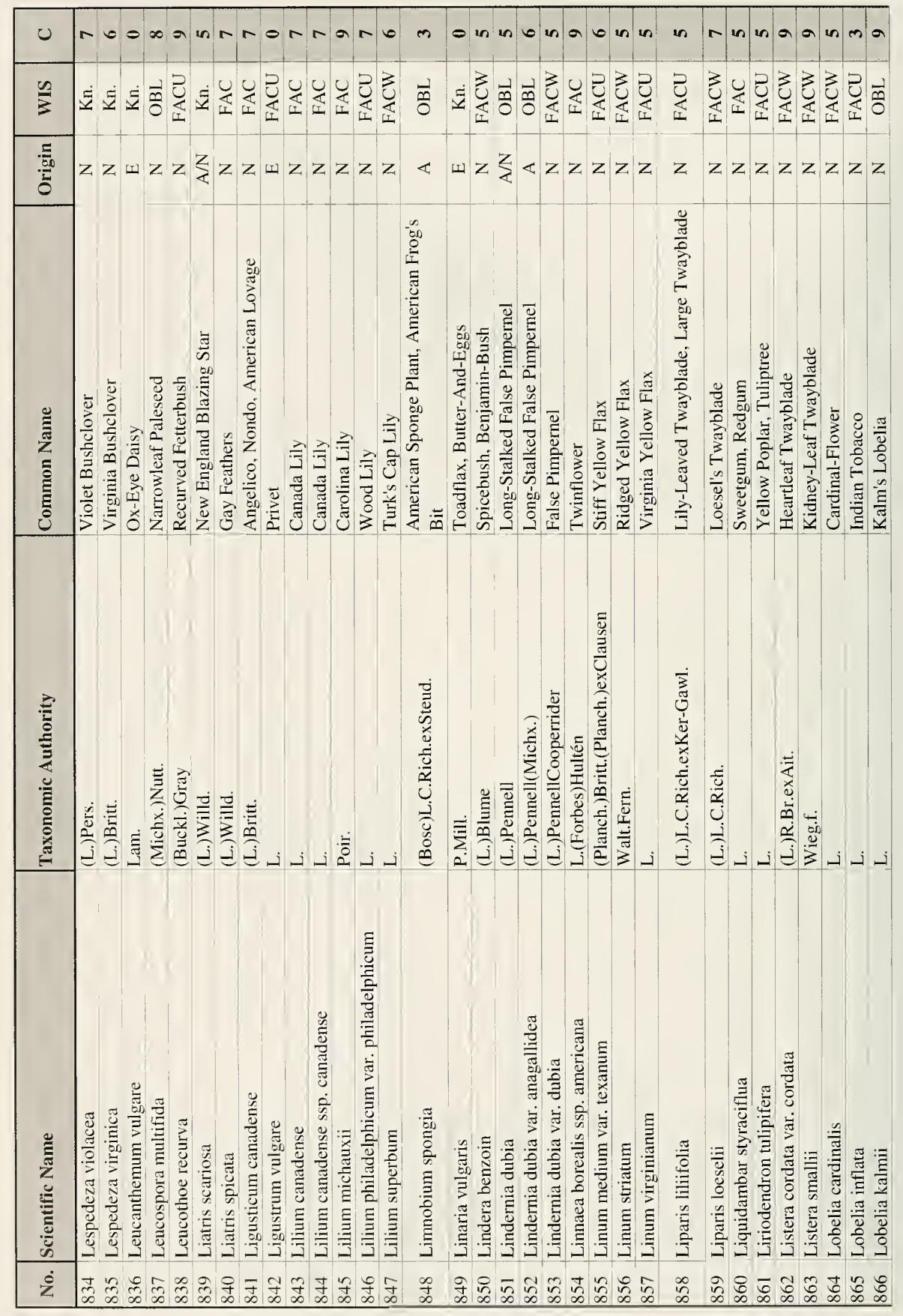




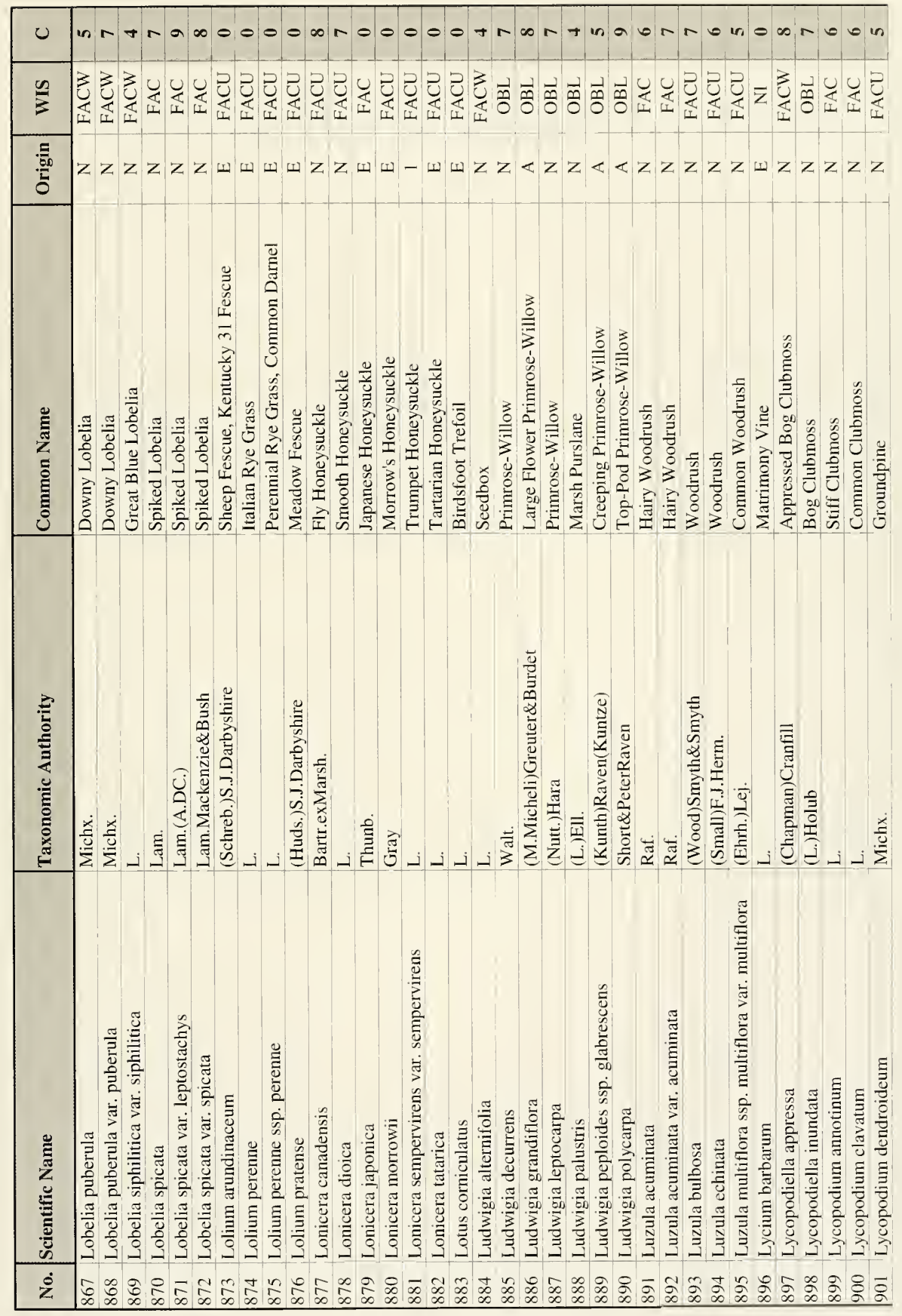




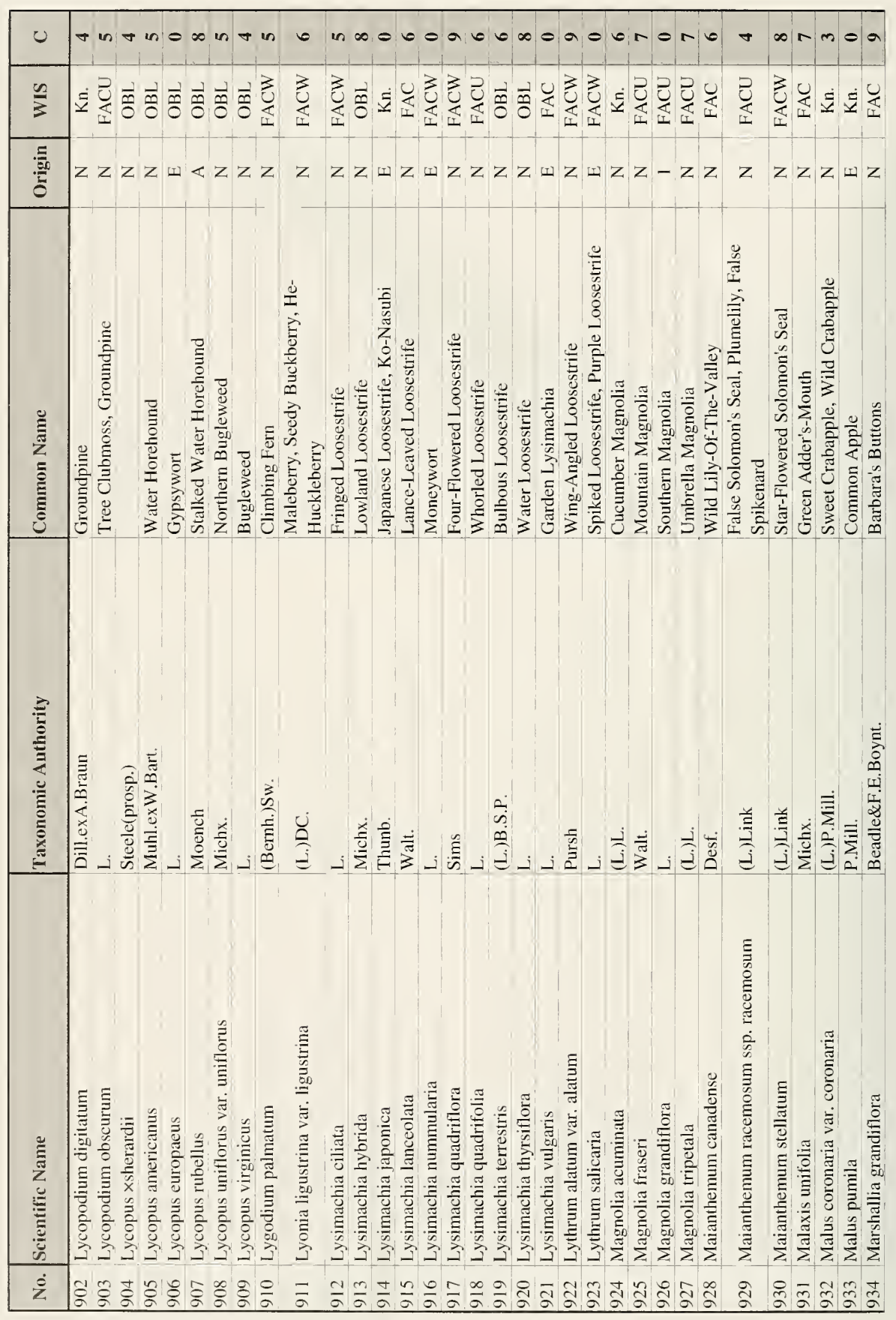




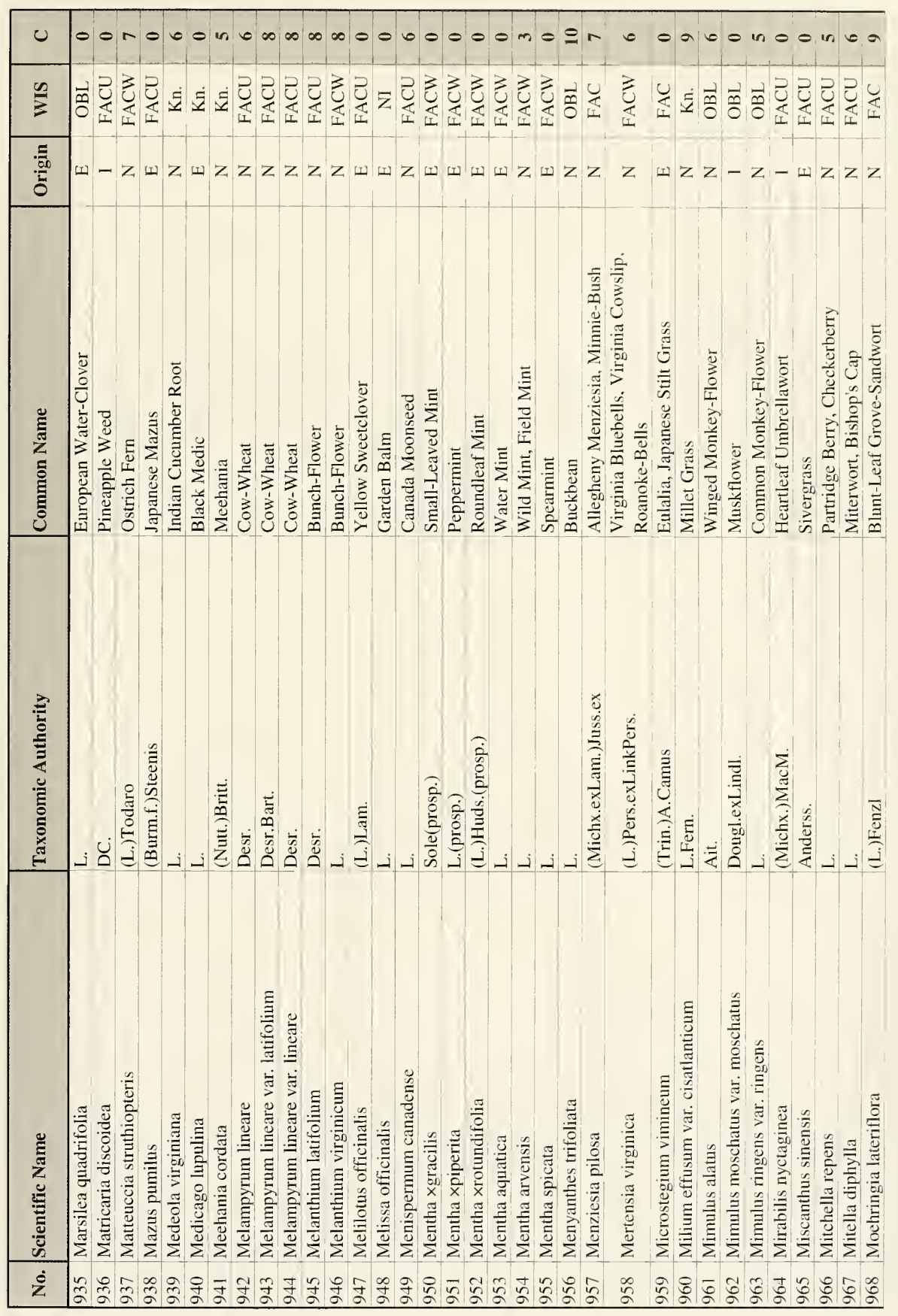




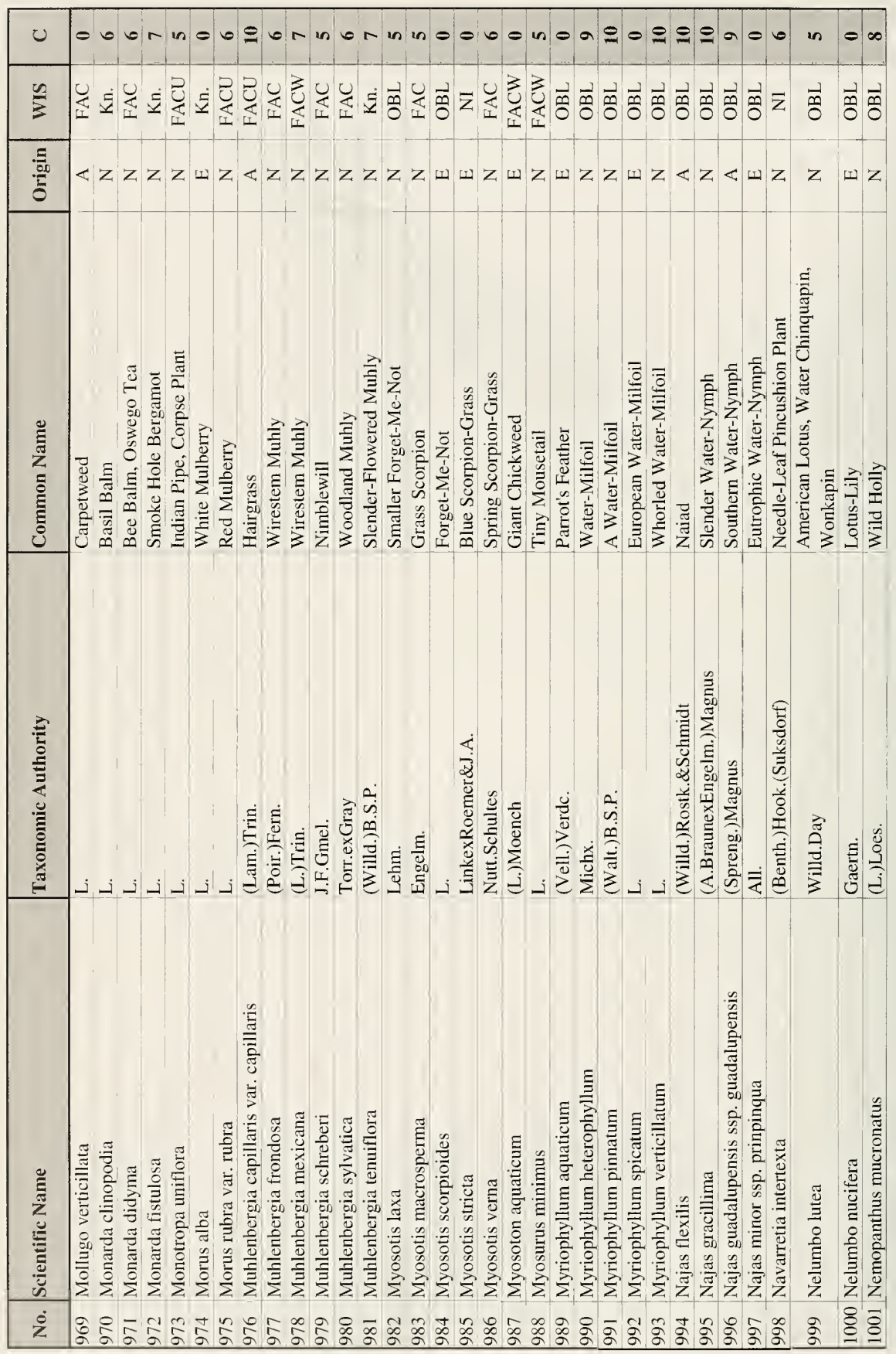




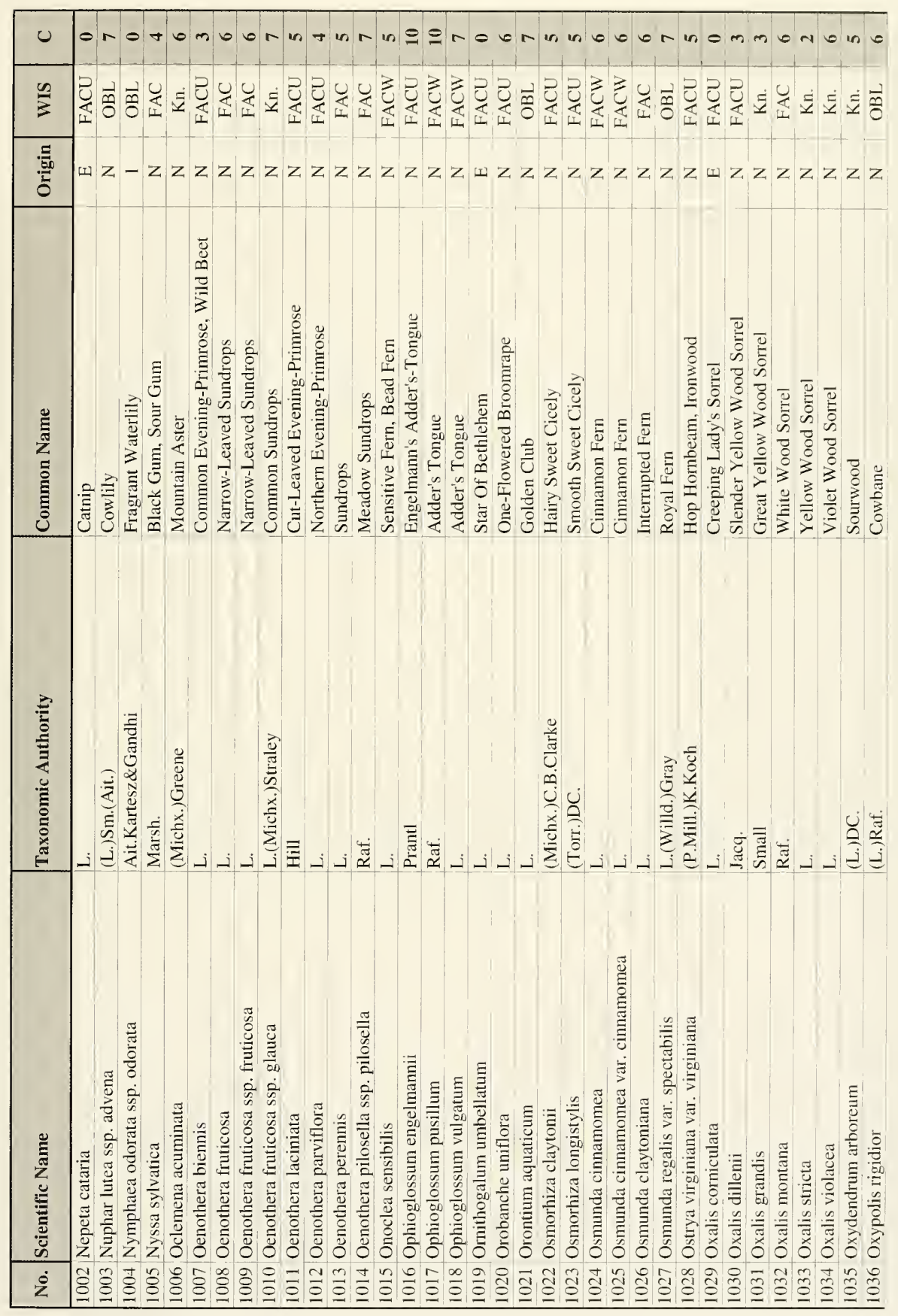




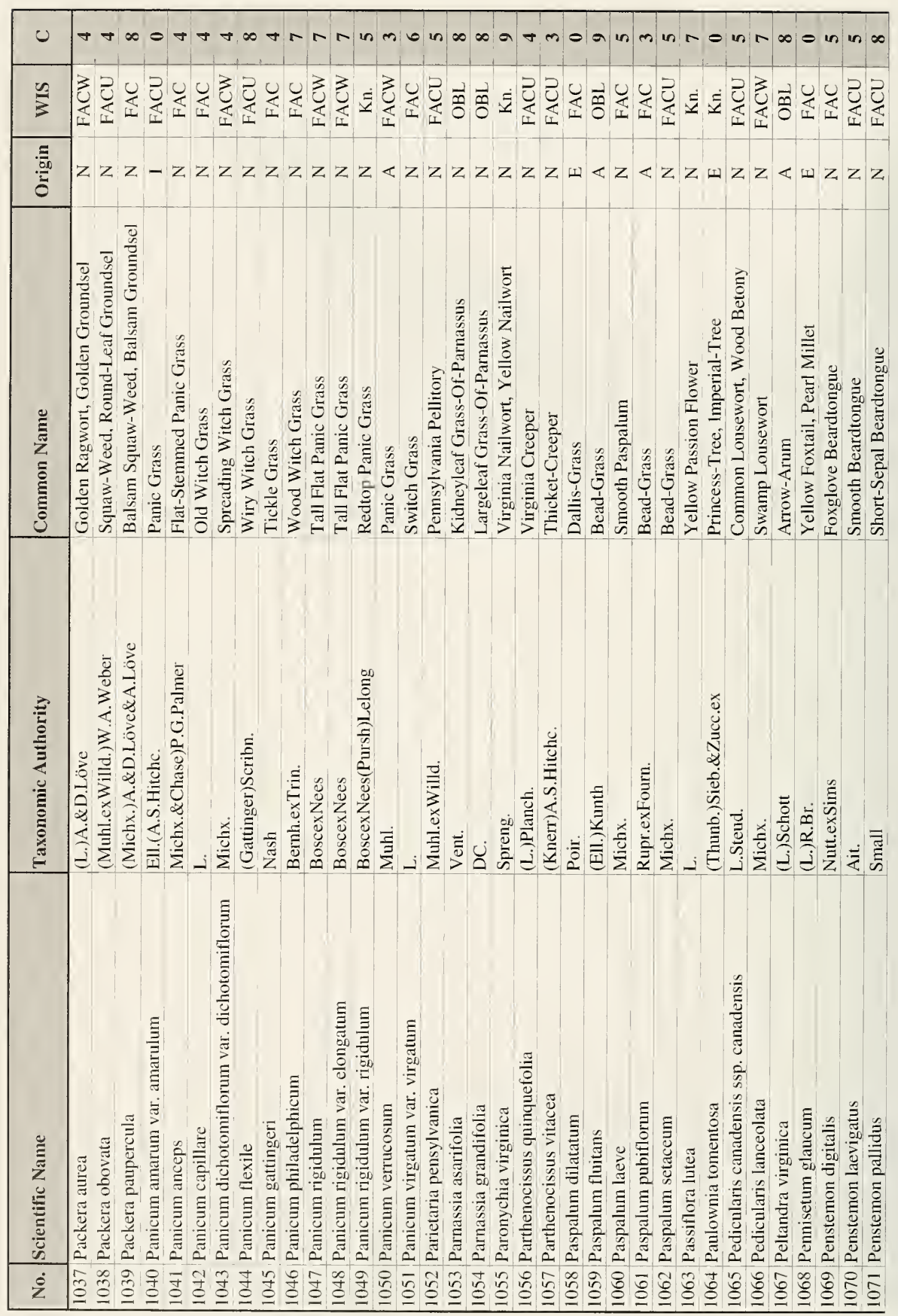




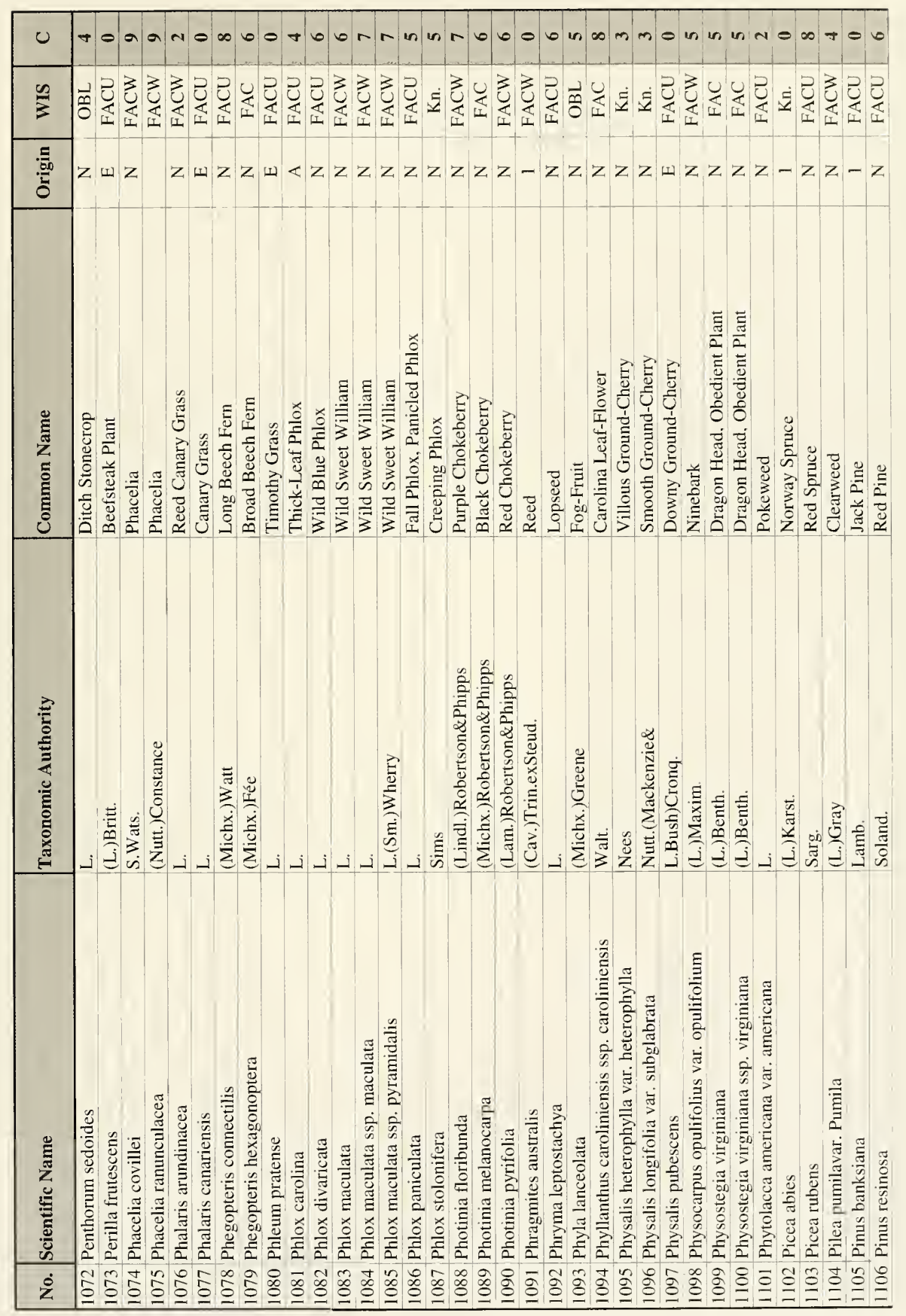




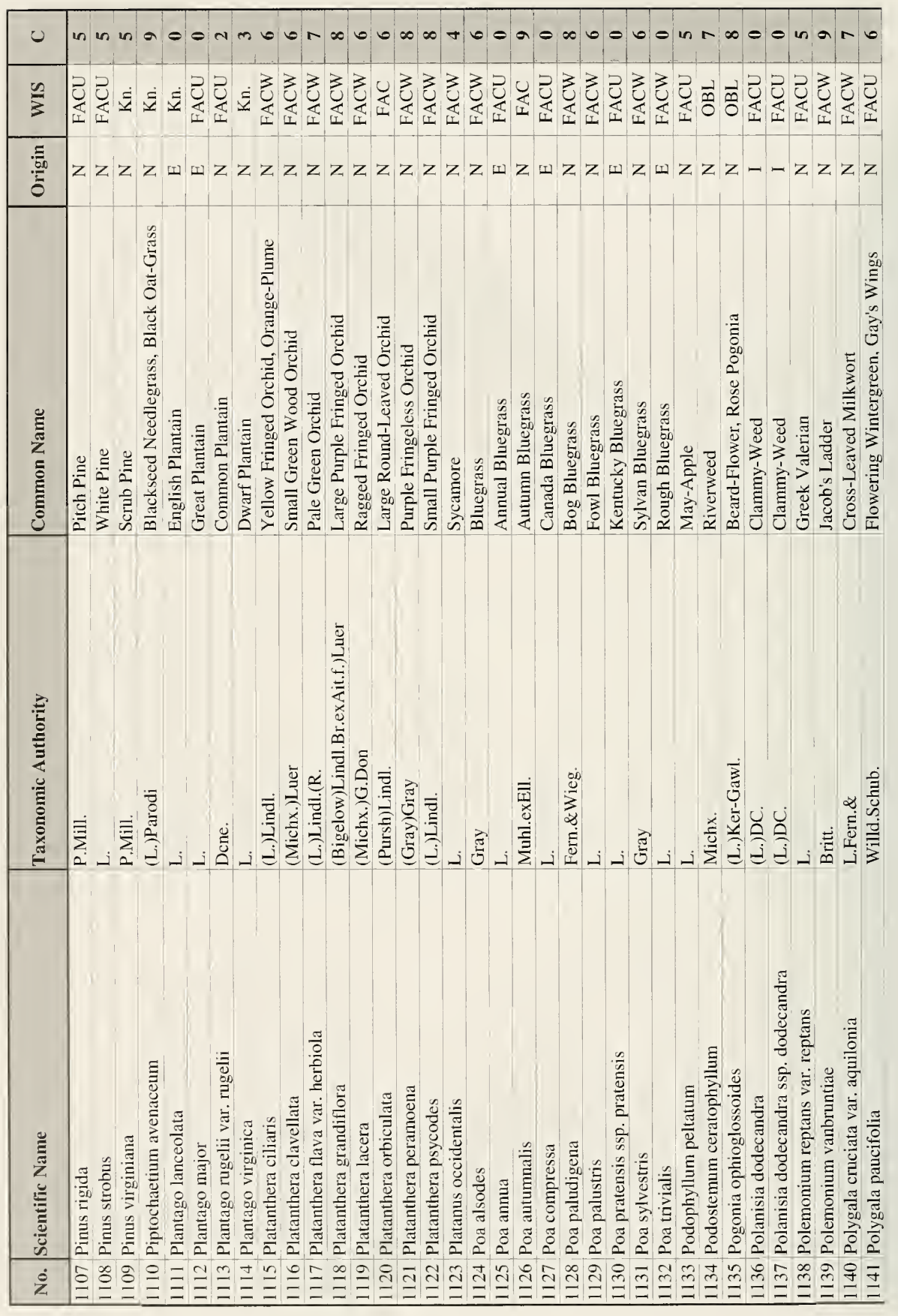




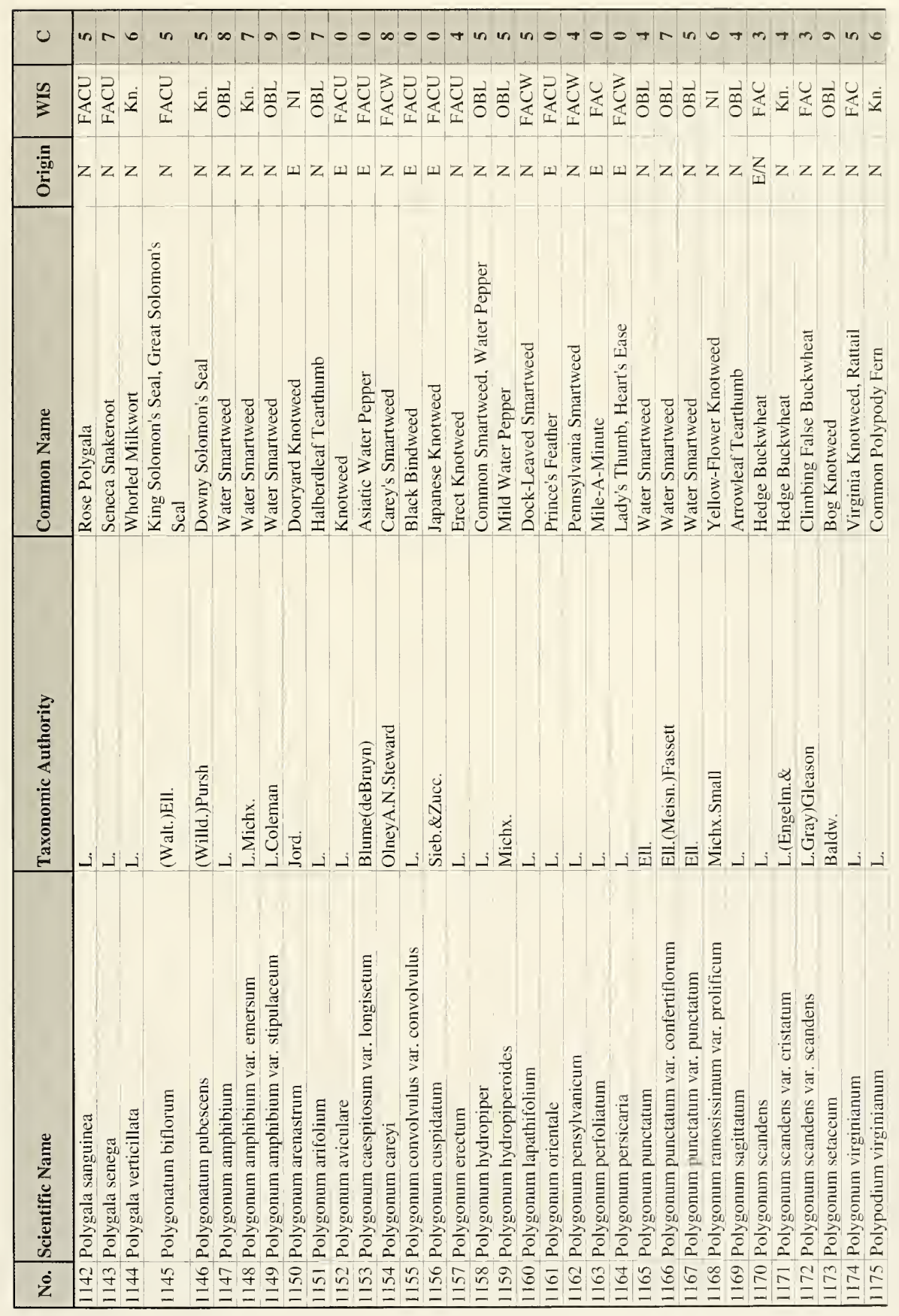




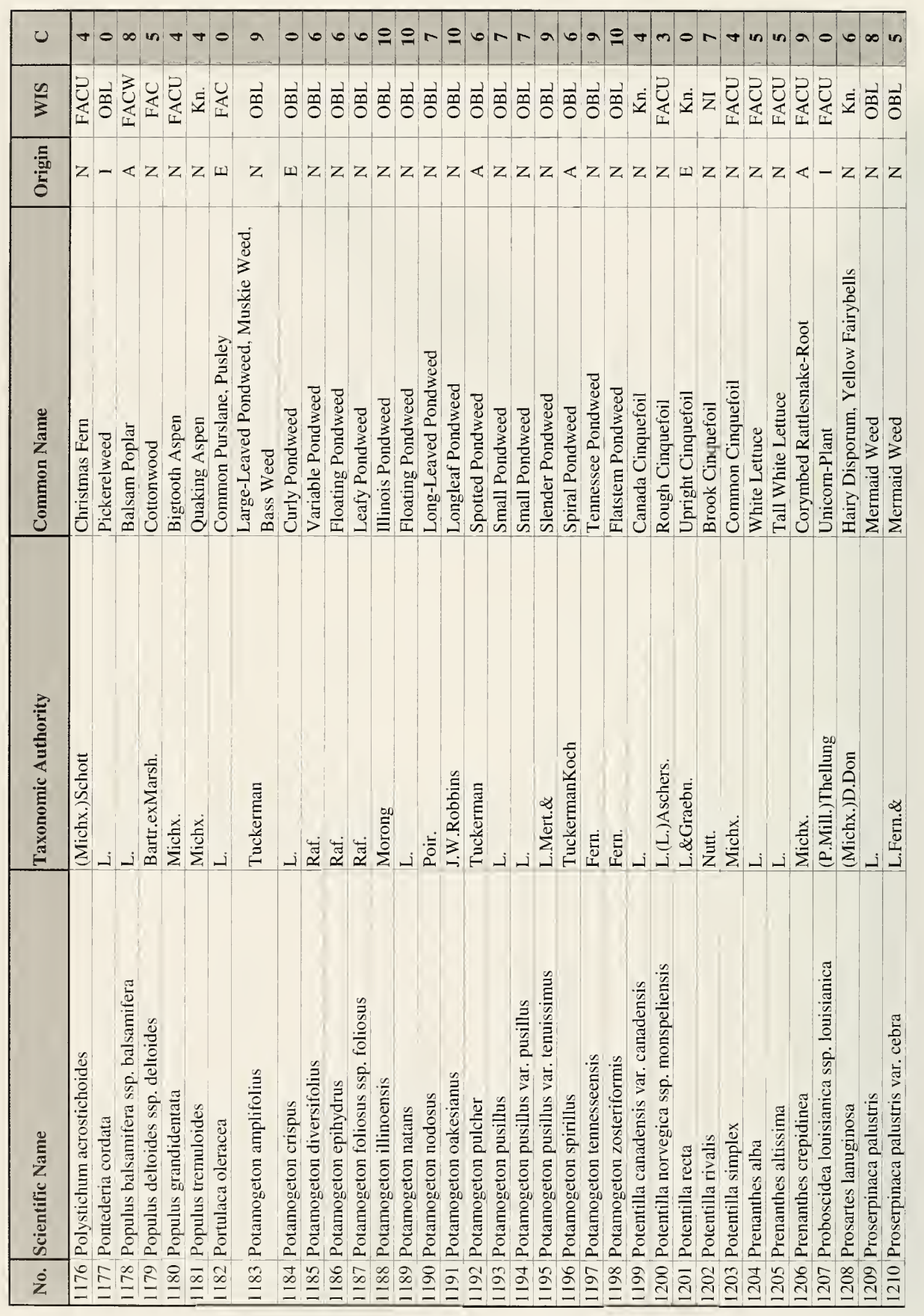




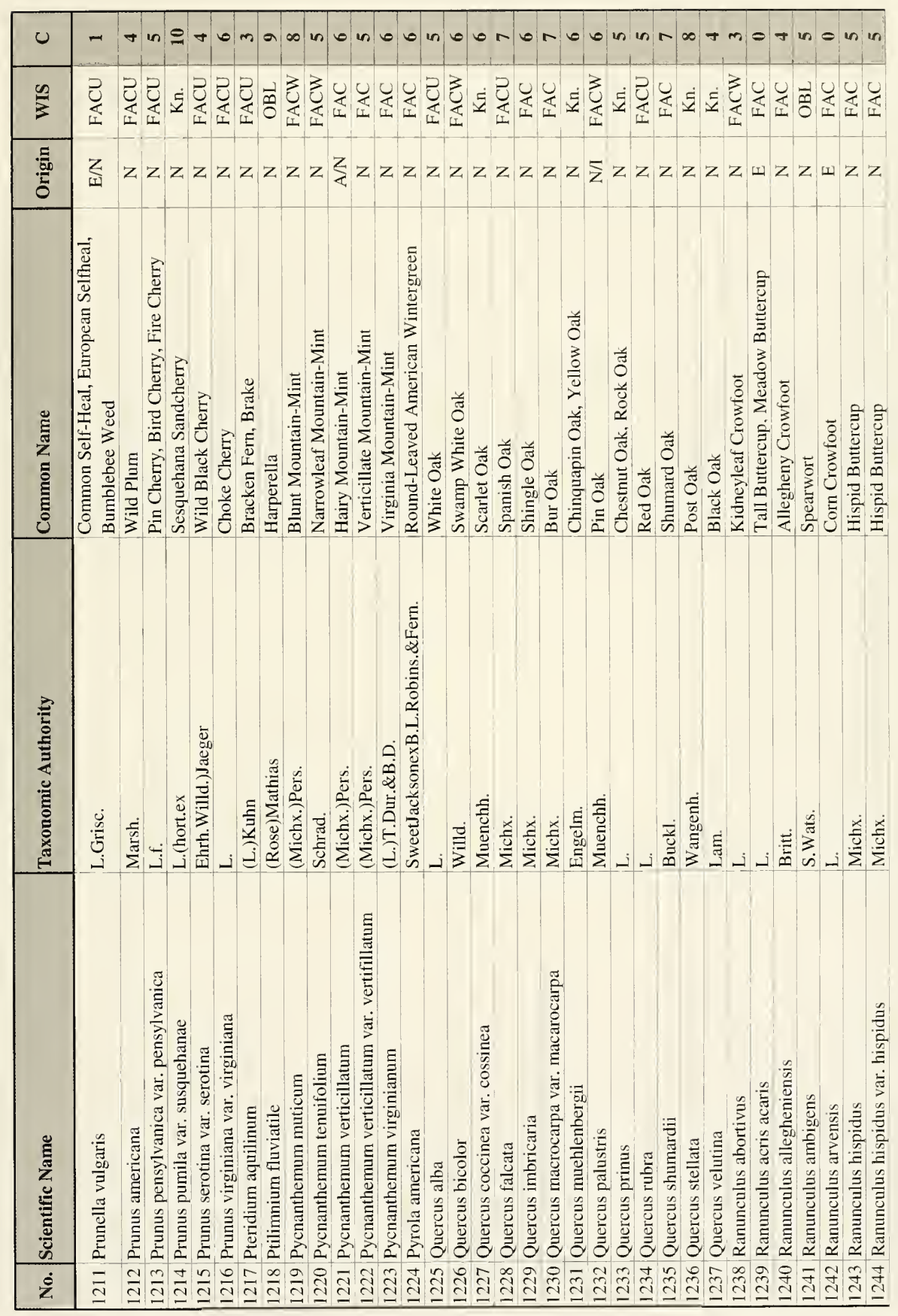




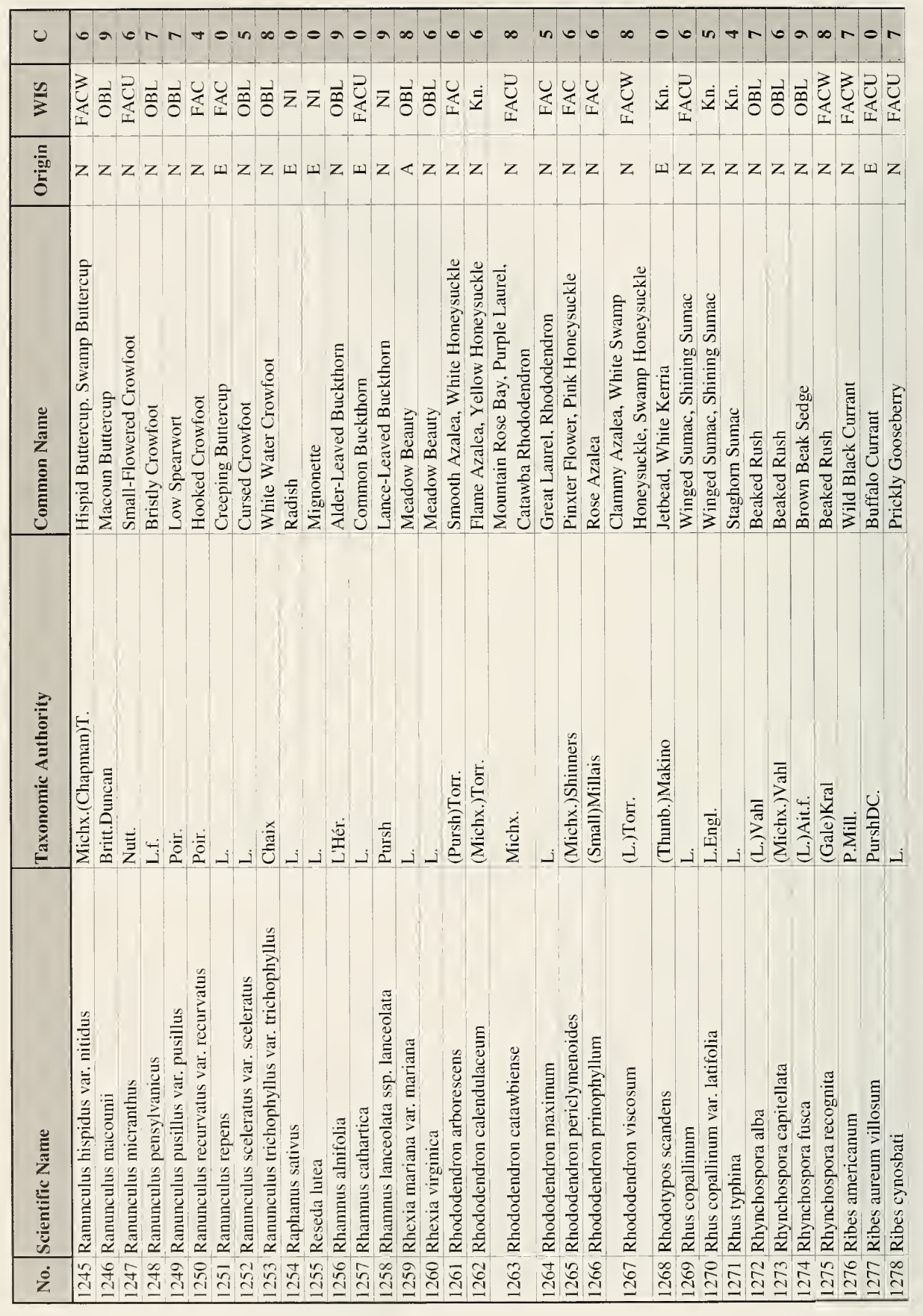




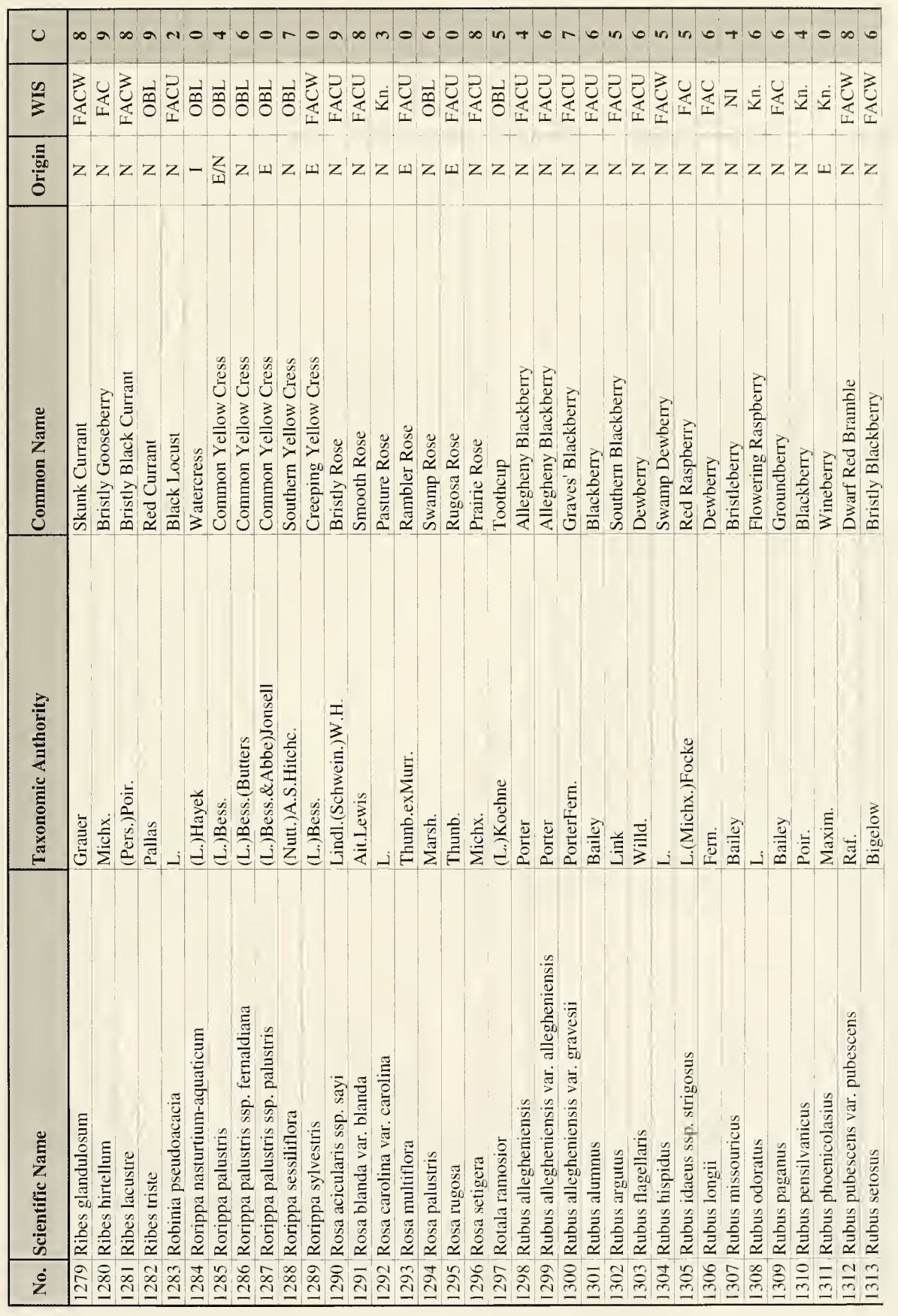




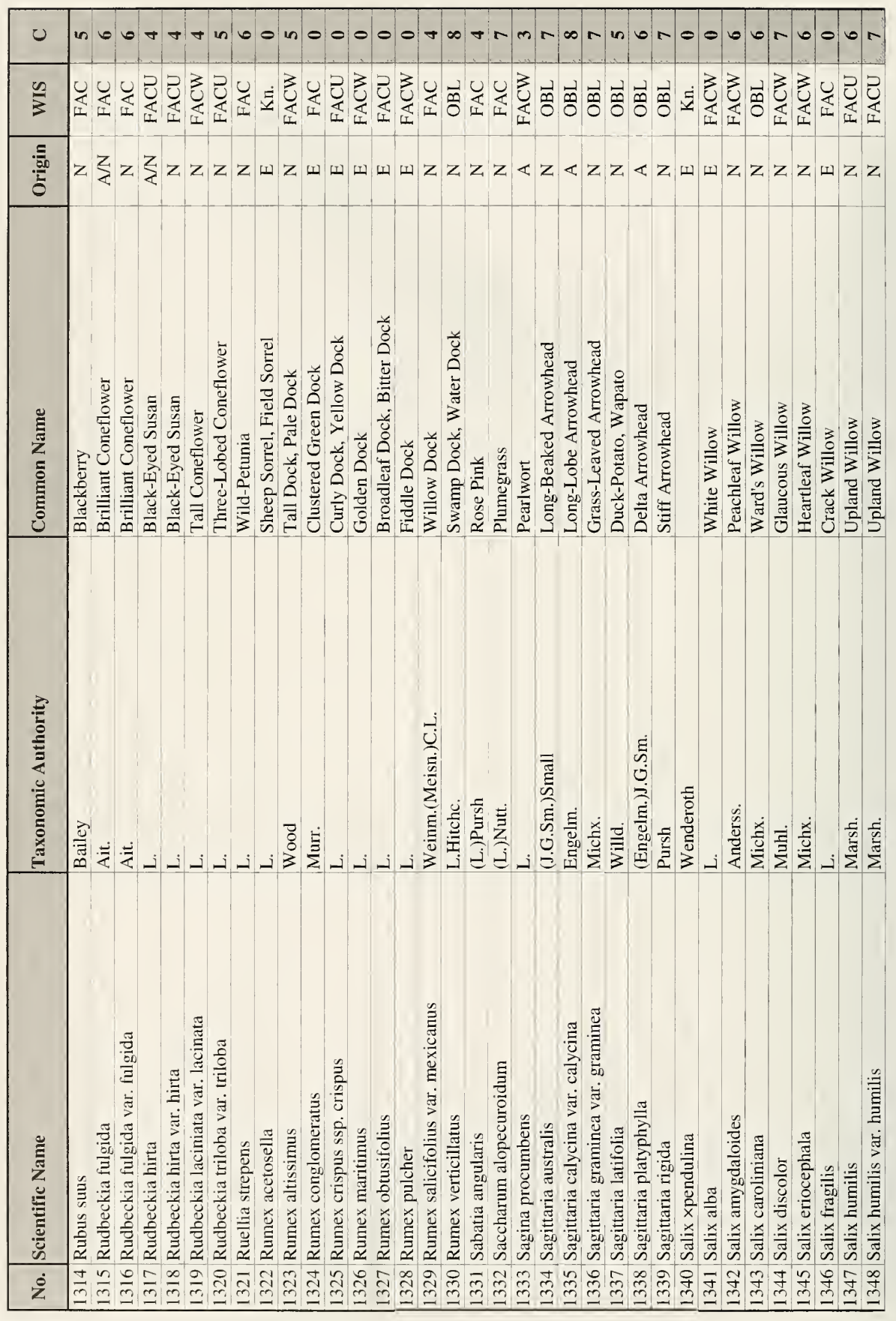




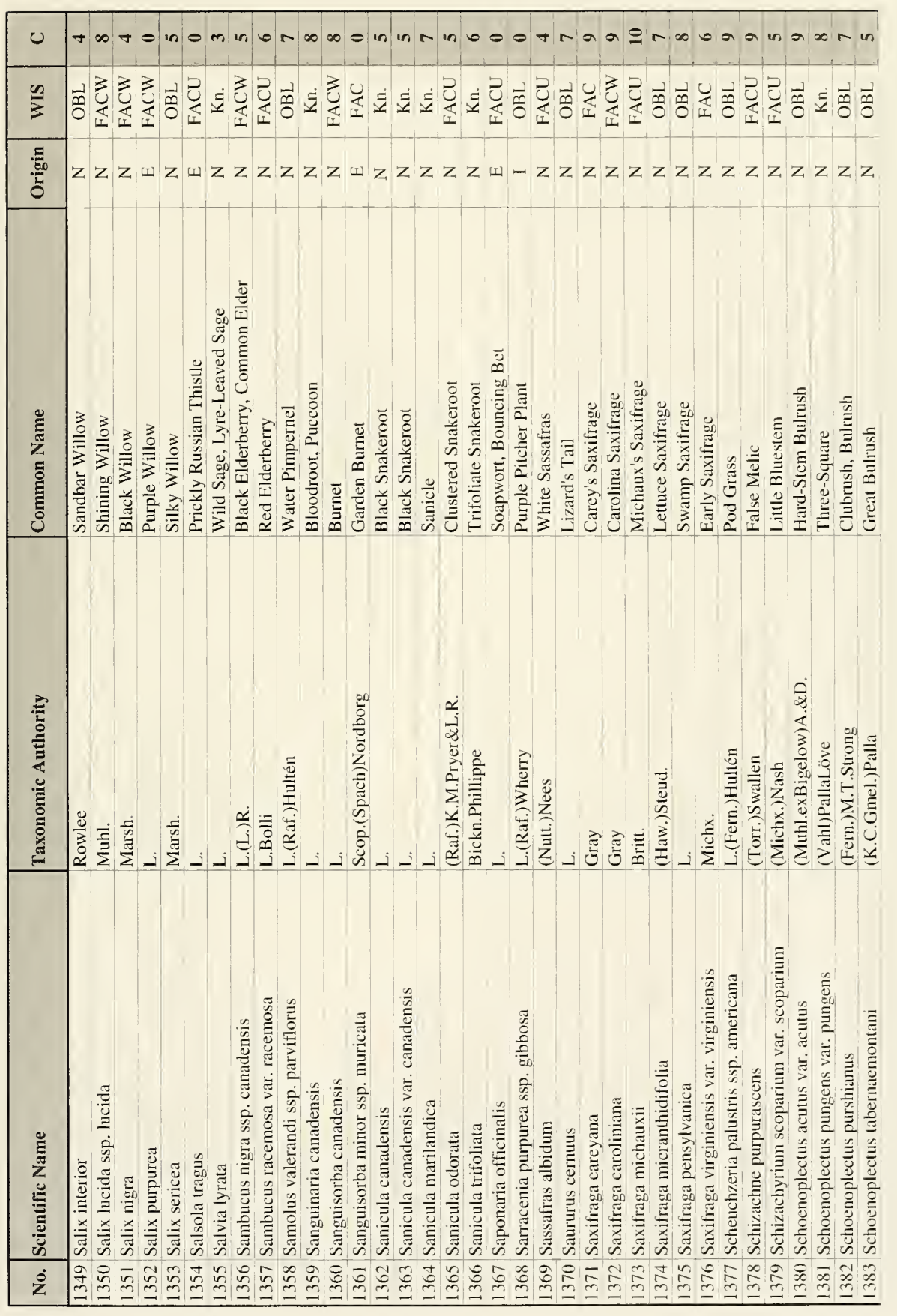




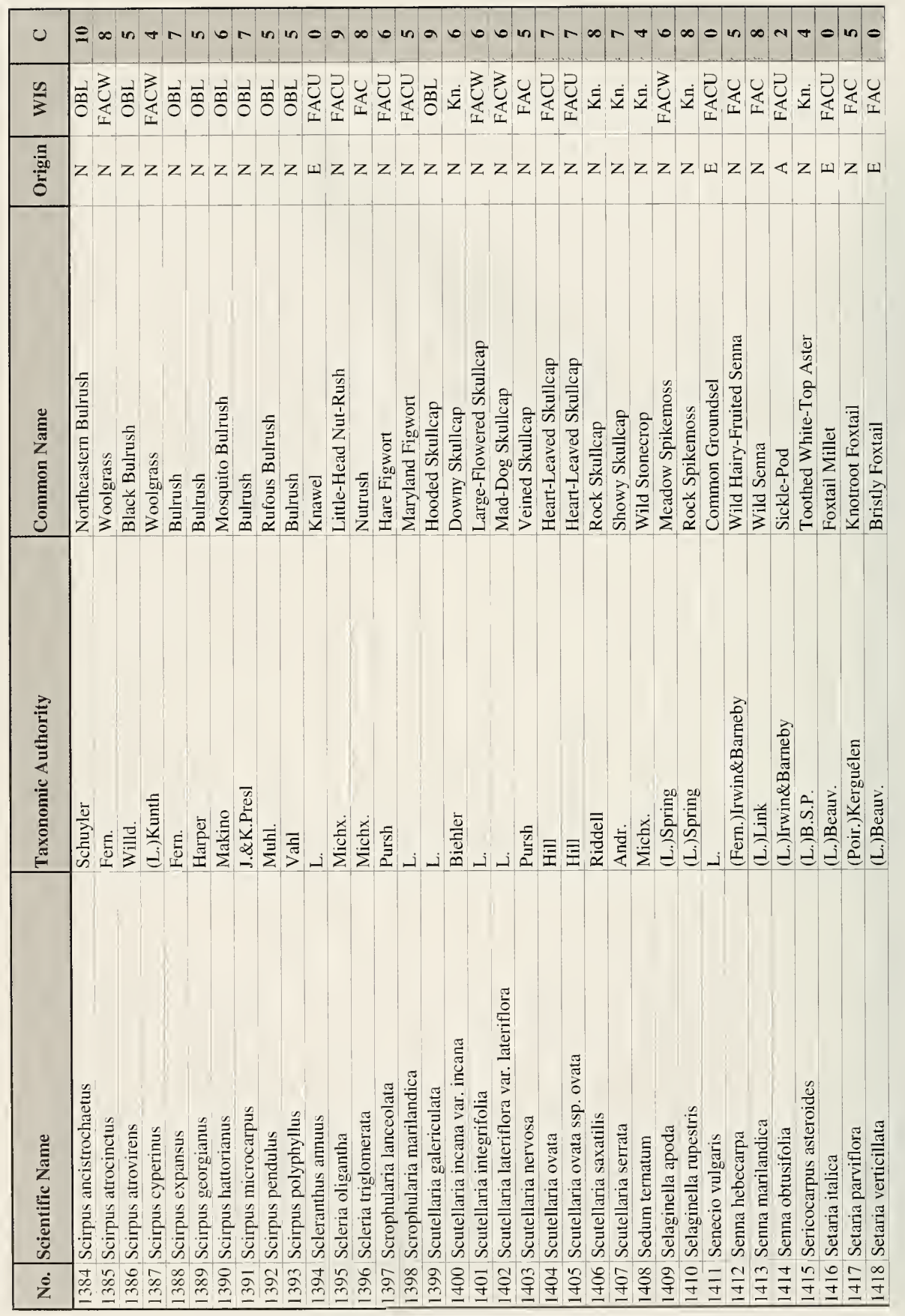




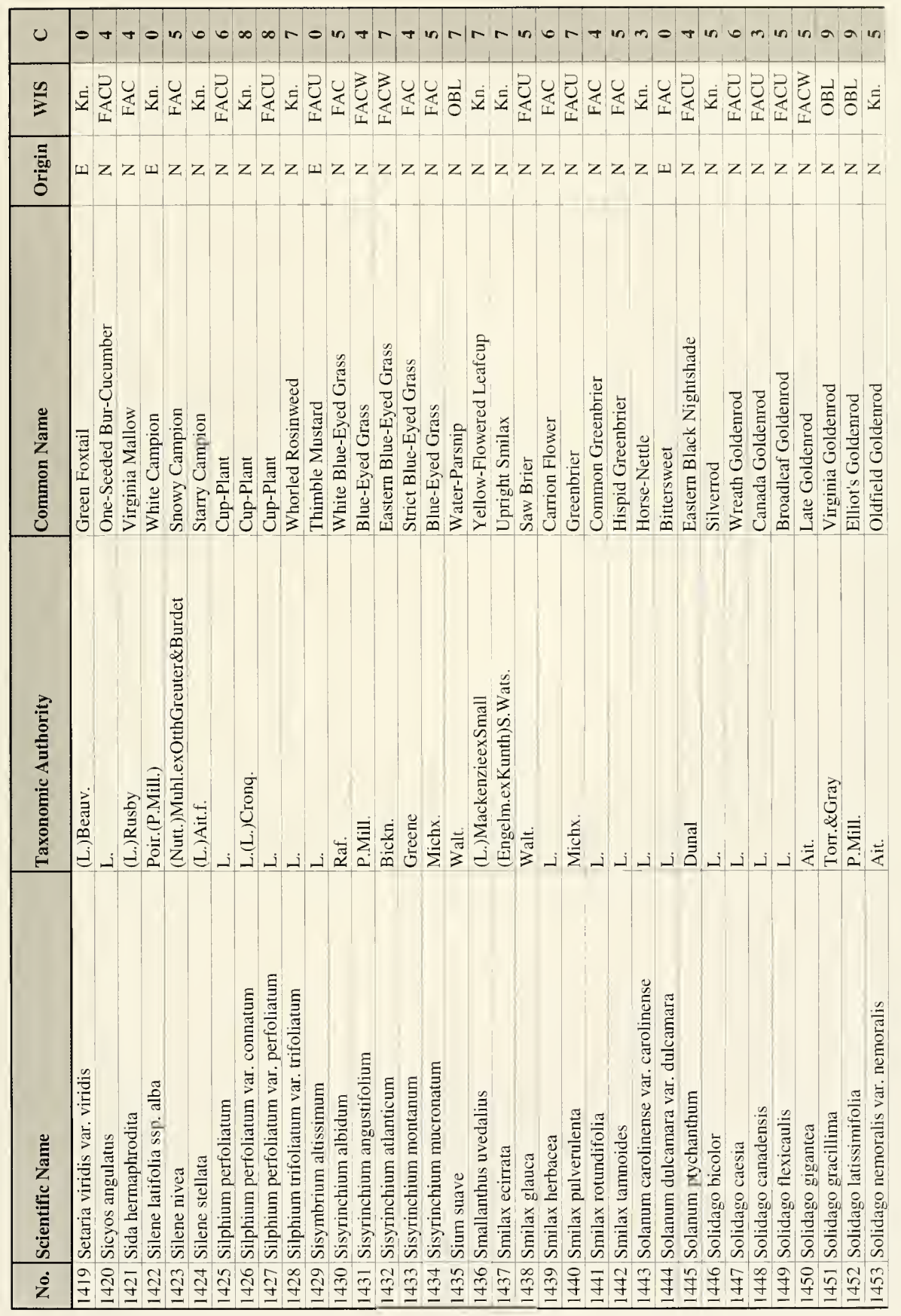




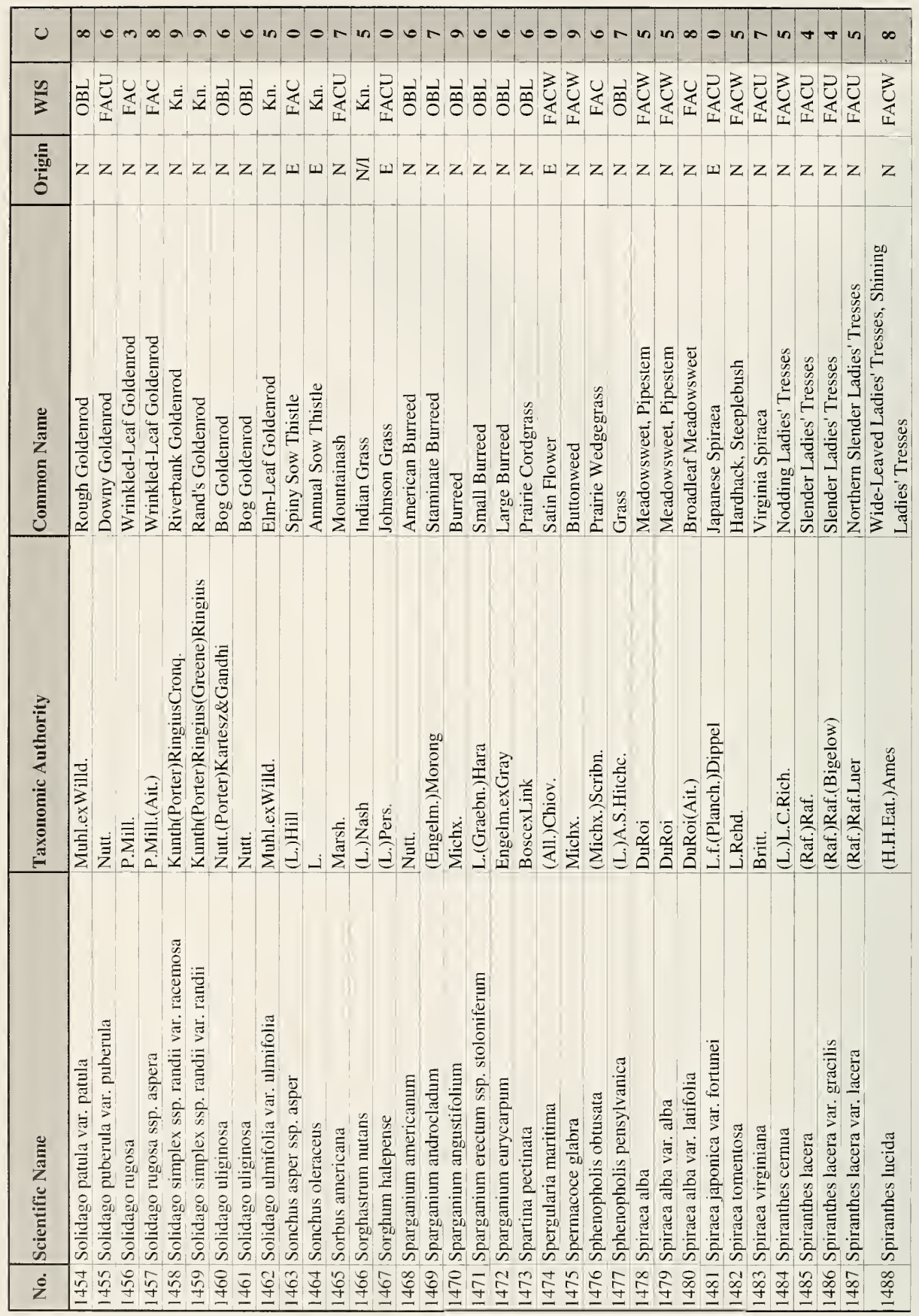




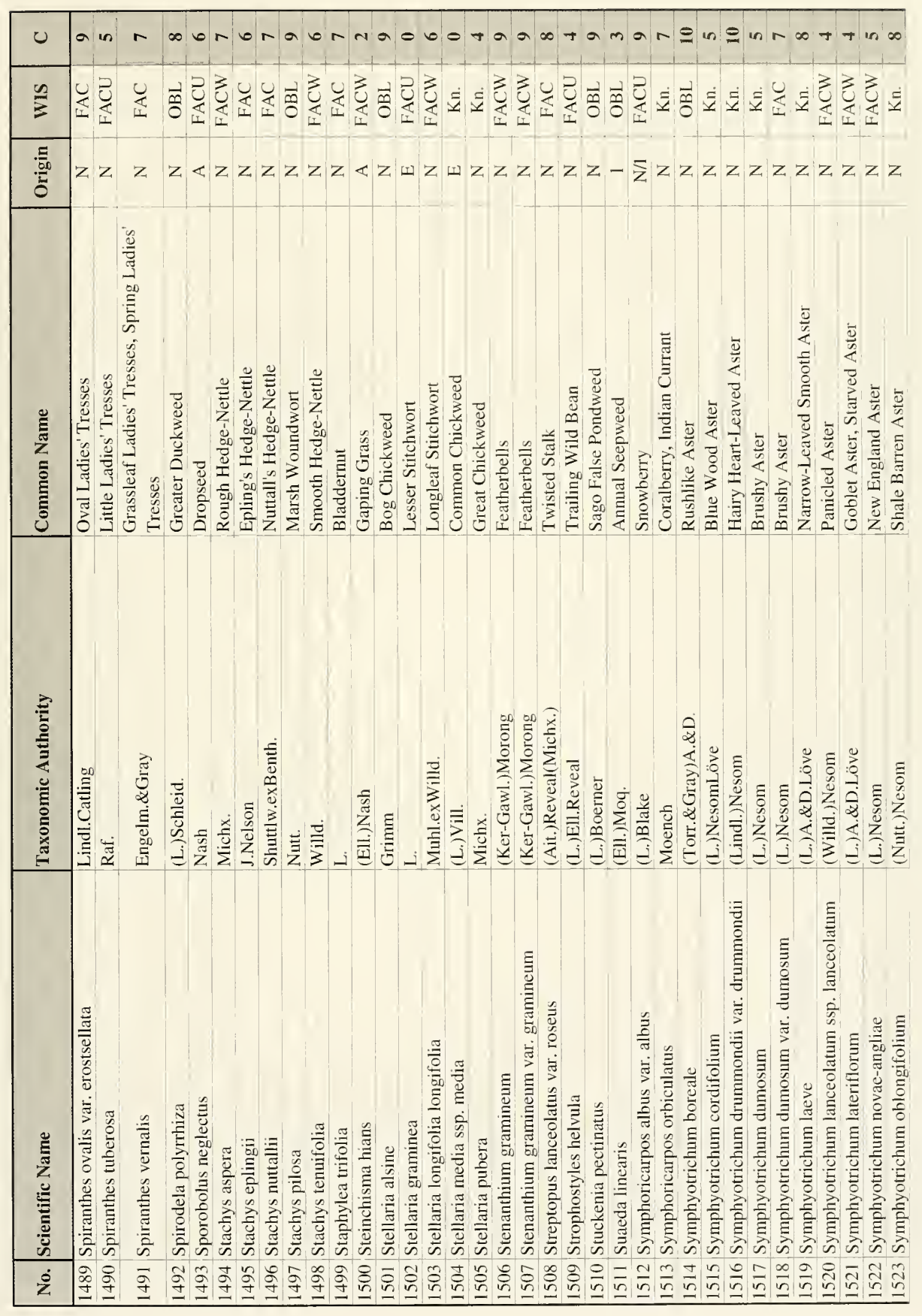




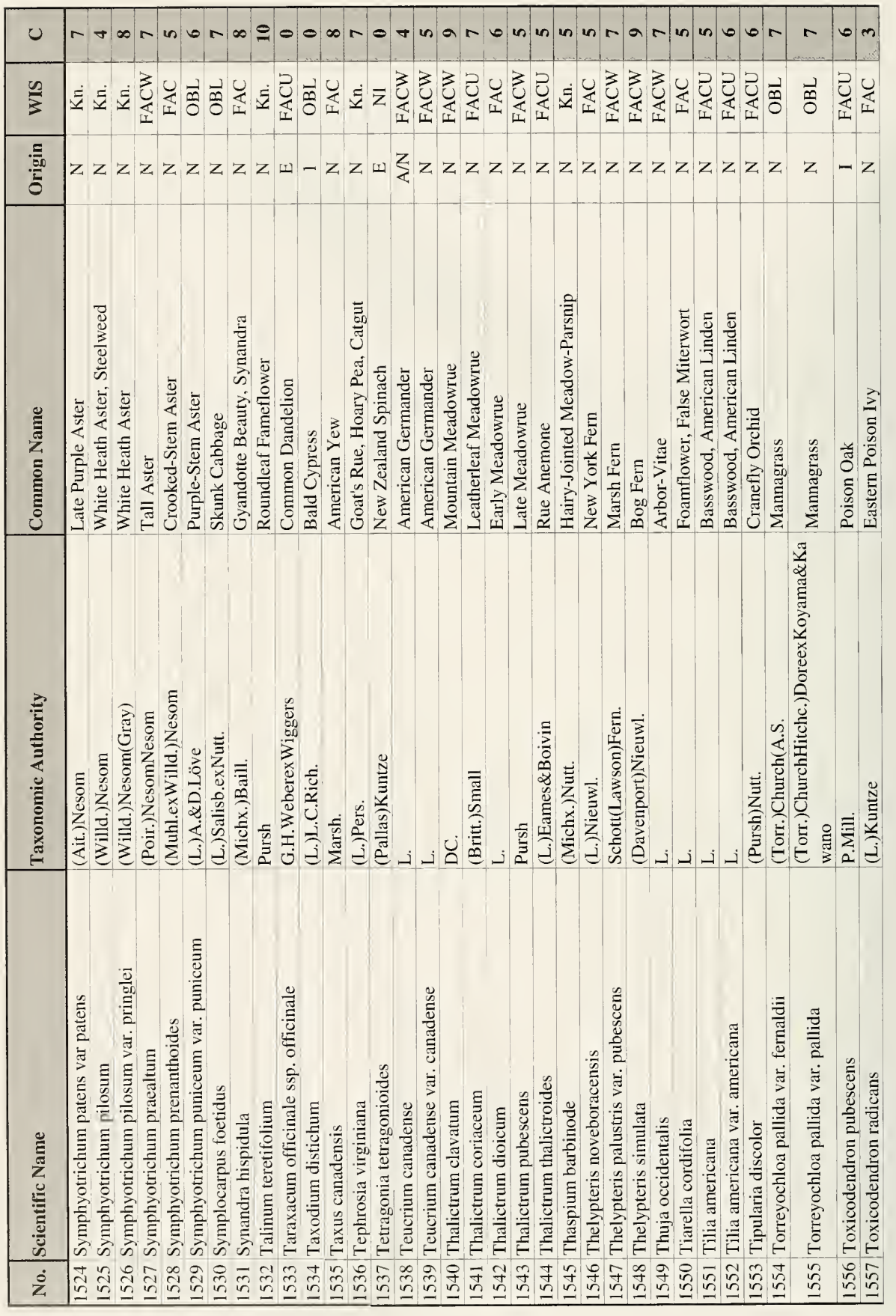




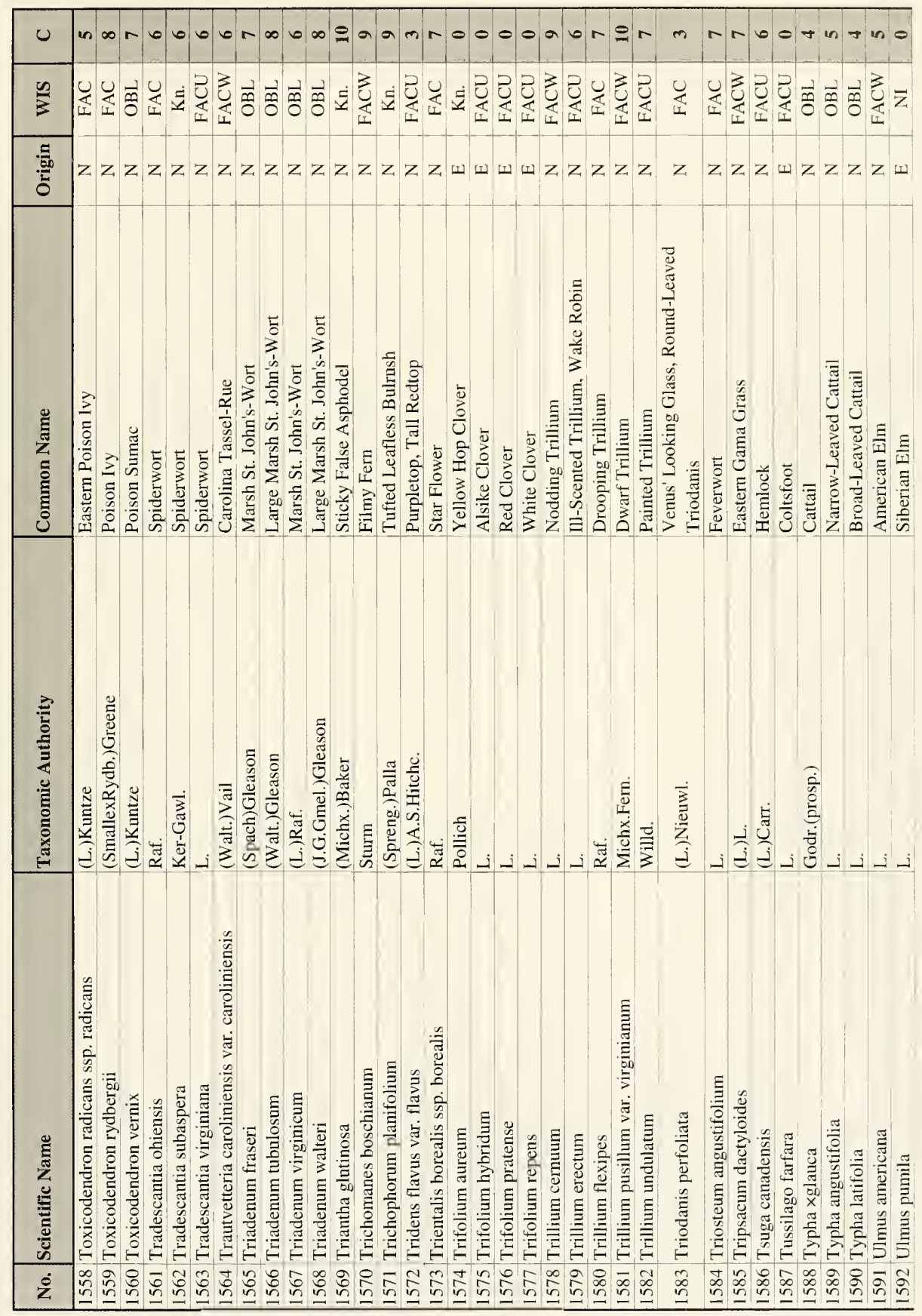




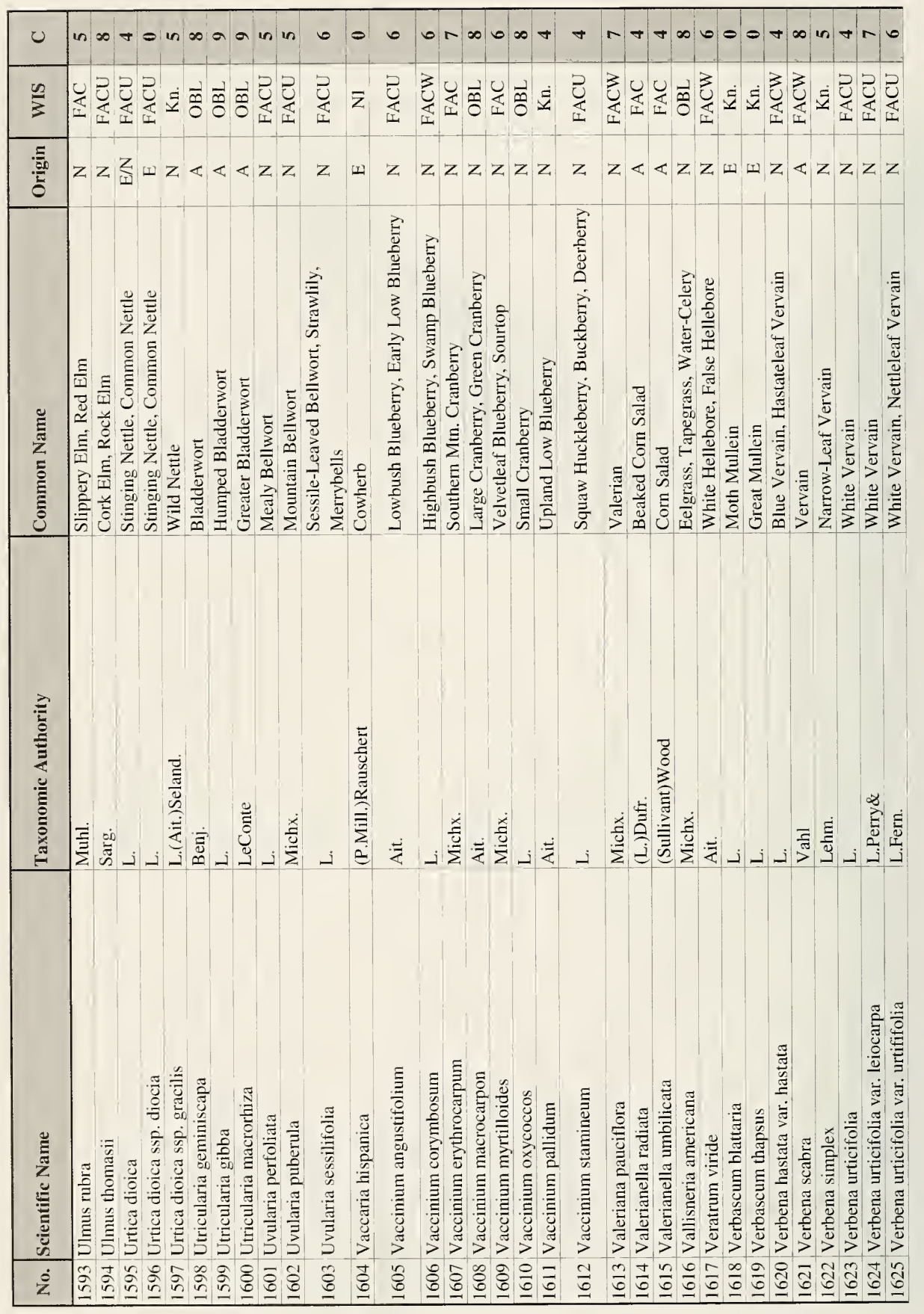




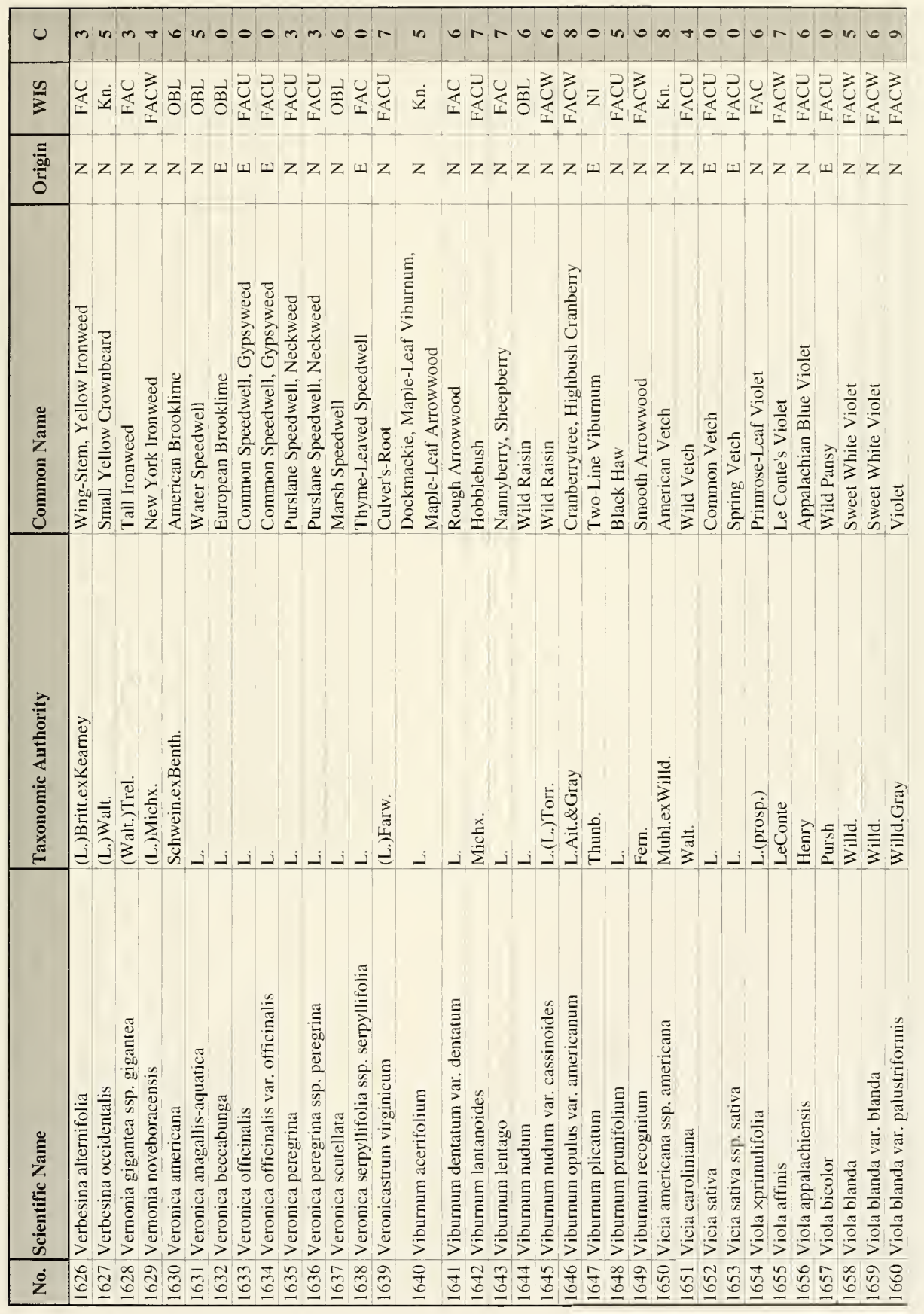




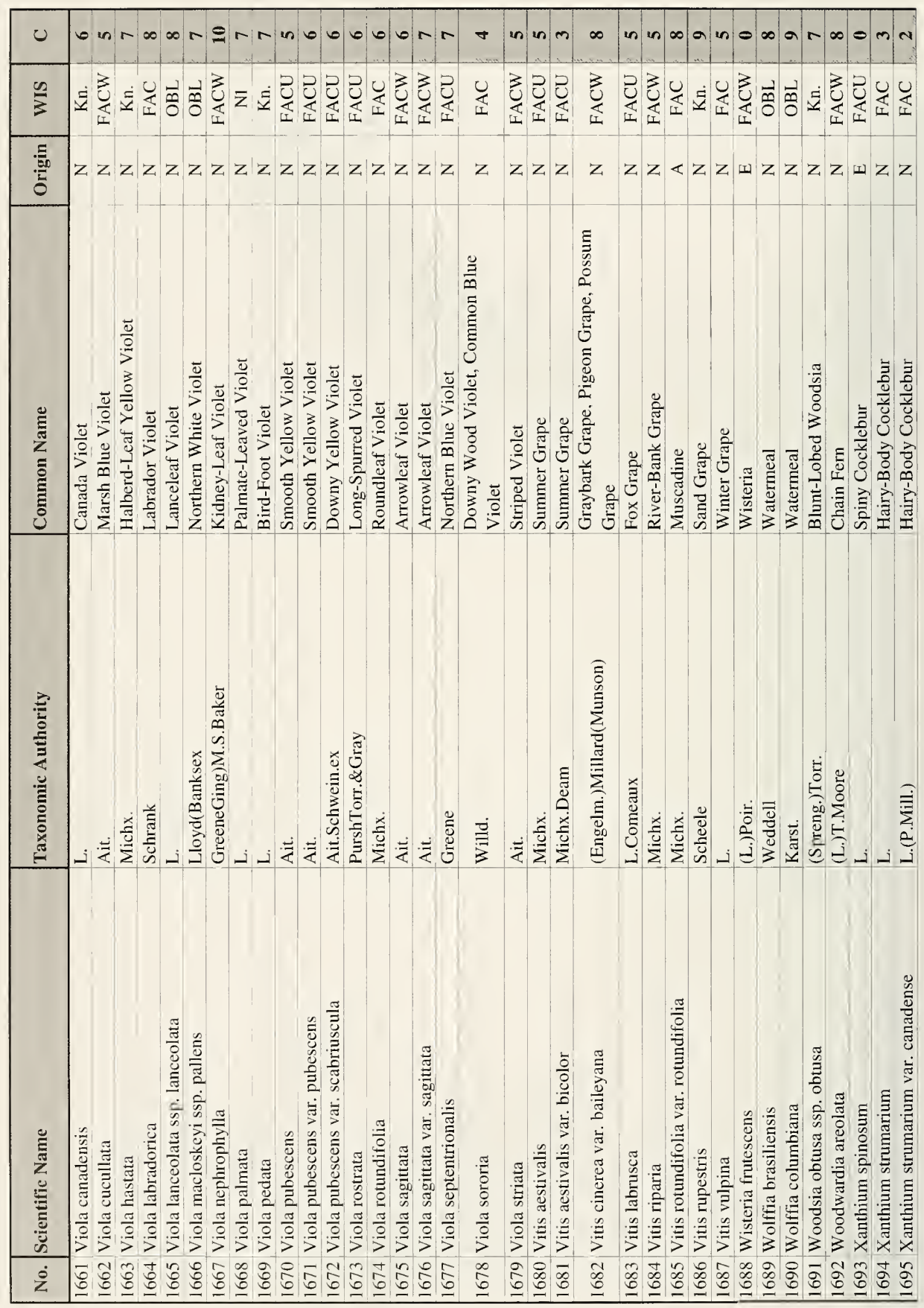




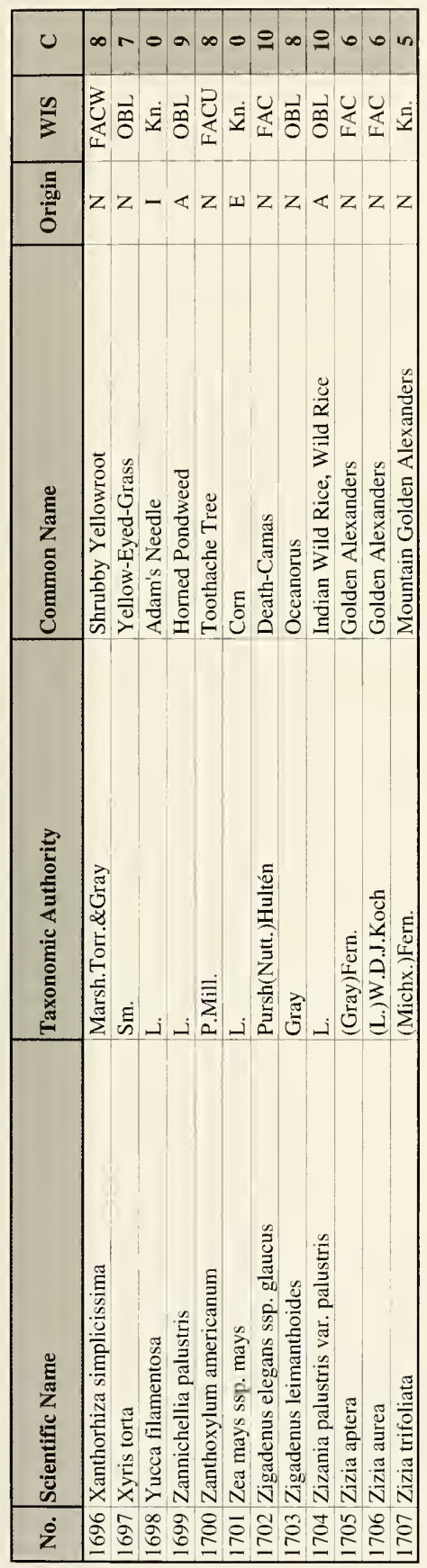





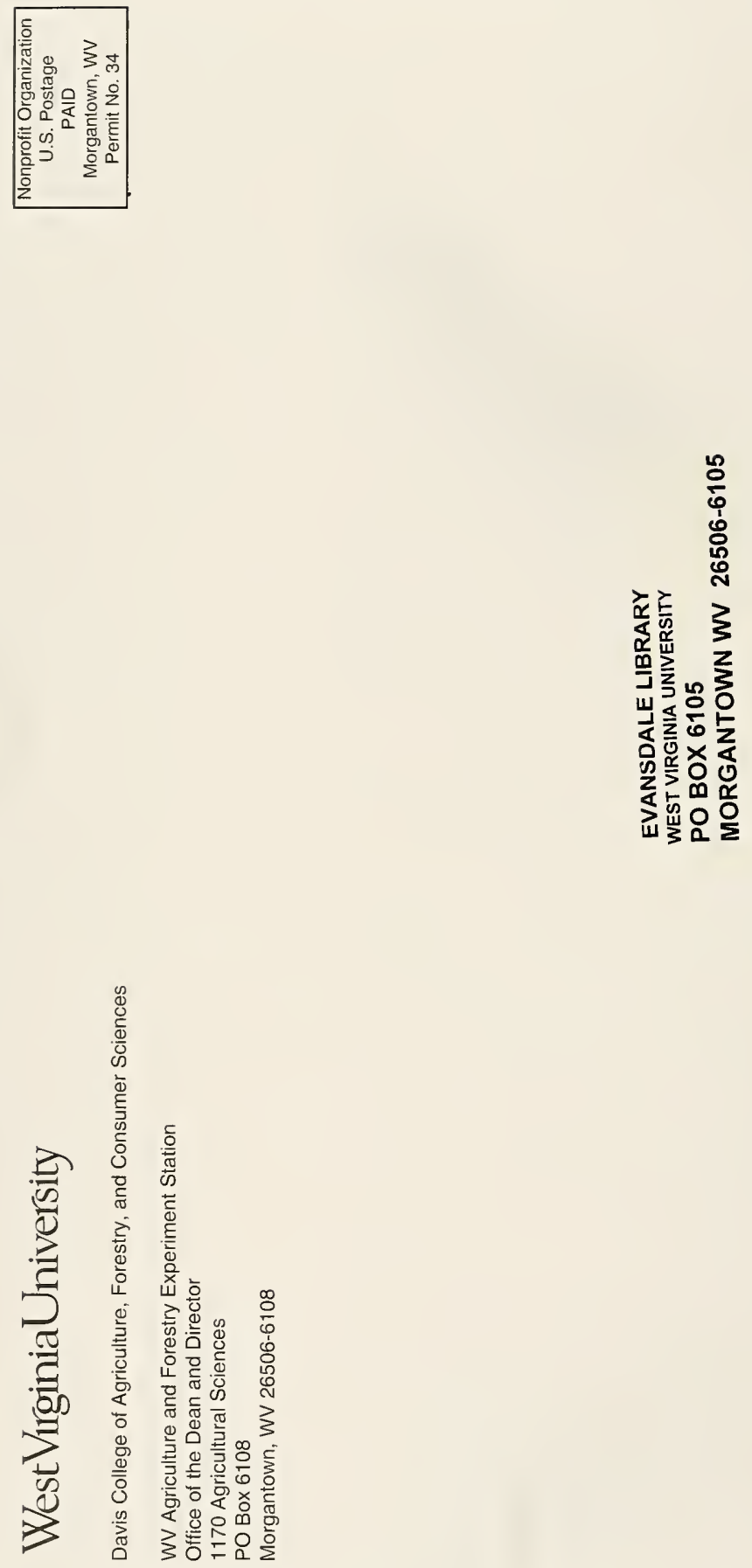